\title{
Part-time employment and human capital development
}

Citation for published version (APA):

Nelen, A. C. (2012). Part-time employment and human capital development. [Doctoral Thesis, Maastricht University]. ROA. https://doi.org/10.26481/dis.20120628an

Document status and date:

Published: 01/01/2012

DOI:

10.26481/dis.20120628an

Document Version:

Publisher's PDF, also known as Version of record

\section{Please check the document version of this publication:}

- A submitted manuscript is the version of the article upon submission and before peer-review. There can be important differences between the submitted version and the official published version of record.

People interested in the research are advised to contact the author for the final version of the publication, or visit the DOI to the publisher's website.

- The final author version and the galley proof are versions of the publication after peer review.

- The final published version features the final layout of the paper including the volume, issue and page numbers.

Link to publication

\footnotetext{
General rights rights.

- You may freely distribute the URL identifying the publication in the public portal. please follow below link for the End User Agreement:

www.umlib.nl/taverne-license

Take down policy

If you believe that this document breaches copyright please contact us at:

repository@maastrichtuniversity.nl

providing details and we will investigate your claim.
}

Copyright and moral rights for the publications made accessible in the public portal are retained by the authors and/or other copyright owners and it is a condition of accessing publications that users recognise and abide by the legal requirements associated with these

- Users may download and print one copy of any publication from the public portal for the purpose of private study or research.

- You may not further distribute the material or use it for any profit-making activity or commercial gain

If the publication is distributed under the terms of Article $25 \mathrm{fa}$ of the Dutch Copyright Act, indicated by the "Taverne" license above, 
Part-Time Employment and Human Capital Development 
(c) Annemarie Cornelia Nelen, Maastricht 2012

All rights reserved. No part of this publication may be reproduced, stored in a retrieval system, or transmitted in any form, or by any means, electronic, mechanical, photocopying, recording, or otherwise, without the prior permission in writing, from the author.

Published by ROA

Postbus 616

6200 MD Maastricht

ISBN: 978-5321-513-5

Printed in the Netherlands by Océ Business Services 


\title{
Part-Time Employment and Human Capital Development
}

\author{
Proefschrift
}

ter verkrijging van de graad van doctor aan

de Universiteit Maastricht, op gezag van de Rector Magnificus,

Prof. mr. G.P.M.F. Mols

volgens het besluit van het College van Decanen, in het openbaar te verdedigen op donderdag 28 juni 2012 om 12.00 uur

door

Annemarie Cornelia Nelen 


\section{Promotor}

Prof. dr. A. de Grip

\section{Copromotor}

Dr. D.J.A.G. Fouarge

\section{Beoordelingscommissie}

Prof. dr. L. Borghans (voorzitter)

Prof. dr. P. A. Mohnen

Prof. dr. T. A. Zwick (University of Munich) 


\section{Acknowledgements}

I am greatly indebted to my supervisors Andries de Grip and Didier Fouarge as they have provided me great guidance throughout the complete four years I have worked on my PhD. Their support and suggestions are invaluable. Moreover, I thank Lex Borghans for his enthusiastic way of selling academic research to me during my master course at Maastricht University. This was definitely of great importance for my step into the exiting world of academic research.

I have to thank a lot of people for useful discussions and comments on several papers of my dissertation. At the beginning of each chapter, I thank those who have given me comments on the underlying papers. Nevertheless, I particularly like to thank Lex Borghans, Thomas Dohmen, Arnaud Dupuy, Ben Kriechel, Raymond Montizaan, Jan Sauermann, and my roommate Olga Skriabikova. I would also like to thank the members of the assessment committee. I thank Miranda Boere for her administrative support. Moreover, I thank all my colleagues at ROA for providing me a pleasant and productive working environment.

My dissertation also benefited from comments of participants of the following conferences and seminars: the 2008 LoWER workshop in Berlin, the 2009 SOLE conference in Boston, the 2009 ESPE conference in Seville, the 2009 EALE conference in Tallinn, the 2009 IZA summer school in Buch am Ammersee, the 2010 Verein für Socialpolitik, the 2011 RGS Doctoral Conference in Dortmund, the 2011 ESPE conference in Hangzhou, the 2011 EEA in Oslo and the 2011 EALE in Cyprus, and the DUHR seminars of ROA/ Maastricht University. I thank ROA for unrestricted support to attend these conferences, and Joyce Gruijthuijsen for her assistance with administrative issues regarding these conferences. 
I like to thank Sander Dijksman and Jesper van Thor for the good conversations and laughs, about especially other things than work. I am happy that they want to be my paranymphs!

Finally, I would like to thank particularly those who are most important to me as they make my life complete and beautiful: My prospective husband Steffen, my parents, my brother Tim and his partner Stéphanie, my nephew Stijn, my sister Willemijn and her fiancé Thijs, my "opa en oma", Steffen's family, and my best friends Femke and Marieke! Special thanks go to my parents for their continues support and to Steffen for his deep love. Thanks!

Maastricht, the Netherlands

Annemarie Cornelia Nelen

April, 2012 


\section{Contents}

1 Introduction $\quad \mathbf{1}$

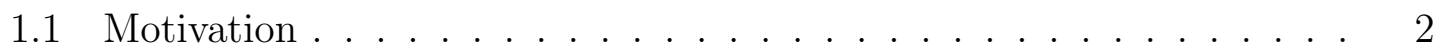

1.2 Aim ............................ 4

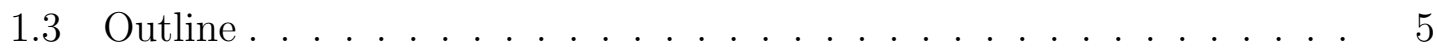

2 Human Capital Investments 9

2.1 Introduction . . . . . . . . . . . . . . . . . . . . . . 10

2.2 Related literature . . . . . . . . . . . . . . . . . . 11

2.3 Data and descriptive statistics . . . . . . . . . . . . . . 13

2.4 Empirical strategy . . . . . . . . . . . . . . . . . . 20

2.5 Results . . . . . . . . . . . . . . . . . . . . 22

2.6 Conclusion . . . . . . . . . . . . . . . . . . . . . . . . . . . . 29

3 Part-Time Pay Penalty 33

3.1 Introduction . . . . . . . . . . . . . . . . . . . . 34

3.2 Related literature . . . . . . . . . . . . . . . . . . 35

3.3 Data and descriptive statistics . . . . . . . . . . . . . . . . . 37

3.4 Empirical strategy . . . . . . . . . . . . . . . . . . . . . . . . . . . . . . . . 40

3.5 PTPP related to segregation . . . . . . . . . . . . . . . 43

3.6 Heterogeneity in the PTPP across occupations . . . . . . . . . . . . . 44

3.6.1 Results . . . . . . . . . . . . . . . . . 44

3.6.2 Why similar training participation rates? . . . . . . . . . . . 47

3.6.3 Why similar hourly wages? . . . . . . . . . . . . . . . . 49

3.7 Conclusion . . . . . . . . . . . . . . . . . . . . . 51

4 Firm Productivity $\quad \mathbf{5 5}$

4.1 Introduction . . . . . . . . . . . . . . . 56

4.2 Related literature . . . . . . . . . . . . . . . . . . 57

4.3 Empirical strategy . . . . . . . . . . . . . . . . . . 59

4.4 Data and descriptive statistics . . . . . . . . . . . . . . 61

4.5 Results . . . . . . . . . . . . . . . . . 66

4.5.1 Part-time employment and firm productivity . . . . . . . . 66

4.5.2 Robustness checks ................. 68 
Contents

4.6 Why is part-time employment beneficial for firm productivity? . . . . 71

4.7 Discussion . . . . . . . . . . . . . . . . . 76

4.8 Conclusion . . . . . . . . . . . . . . . . . . . . 77

5 Child Outcomes $\quad \mathbf{7 9}$

5.1 Introduction . . . . . . . . . . . . . . . . . . . . . 80

5.2 Related literature . . . . . . . . . . . . . . . . . . . 82

5.3 Data and descriptive statistics . . . . . . . . . . . . . . . . . . 84

5.3.1 Dutch early school system . . . . . . . . . . . . . . 84

5.3 .2 Data . . . . . . . . . . . . . . . . . . 85

5.3 .3 Descriptive evidence ....................... 91

5.4 Empirical strategy . . . . . . . . . . . . . . . . . . . 93

5.5 Results . . . . . . . . . . . . . . . . . . . . . 94

5.6 Conclusion . . . . . . . . . . . . . . . . . . . . . 97

6 Conclusions $\quad \mathbf{1 0 5}$

6.1 Summary . . . . . . . . . . . . . . . . . . 106

6.2 Part-time employment: Good or bad for human capital development? 107

Bibliography

111

$\begin{array}{ll}\text { Summary in Dutch } & 121\end{array}$

$\begin{array}{ll}\text { Biography } & 127\end{array}$

$\begin{array}{lr}\text { ROA Dissertation Series } & 129\end{array}$ 


\section{List of Figures}

1.1 Conceptual framework of the thesis . . . . . . . . . . . . . . . . 4

2.1 Training participation by employment status . . . . . . . . . . 15

2.2 Informal learning in hours of work time by employment status . . . . 16

3.1 Age-earning profiles of part-time and full-time workers . . . . . . . . 38

3.2 Age-earning profiles of part-time and full-time workers in high and low skilled occupations . . . . . . . . . . . . . . . . . . . . . 39

3.3 The relation between occupational-specific PTPPs and relative training participation .................. 46

3.4 The relation between relative training participation and occupational characteristics . . . . . . . . . . . . . . . . . 49

4.1 Distribution of work hours . . . . . . . . . . . . . . . . . . . . 64

4.2 Raw relation between firms' part-time employment share and log productivity (by quartiles of the part-time employment share) . . . . . . 66

4.3 Coefficients of firms' part-time and full-time employment shares using different definitions of part-time employment . . . . . . . . . . . 69

4.4 Allocation of part-time employees over the week . . . . . . . . . 73

4.5 Timing of labor demand - week $1 \ldots \ldots$. . . . . . . . 75

5.1 Parental work status . . . . . . . . . . . . . . . 88

5.2 Distribution of joint parent-child activities . . . . . . . . . . . 89

5.3 Distribution of language test score by maternal work status and gender 91

5.4 Distribution of sorting test score by maternal work status and gender 92

5.5 Distribution of test scores for sample and population . . . . . . . 100 



\section{List of Tables}

2.1 Construction of variables f . . . . . . . . . . . . . . . . 18

2.2 Characteristics by employment status _. . . . . . . . . . . 19

2.3 First stage of the Heckman-type selection correction Model _. . . . 22

2.4 Determinants of training participation . . . . . . . . . 24

2.5 Determinants of number of training courses attended . . . . . . 25

2.6 Determinants of informal learning (as fraction of work time) $\ldots . .27$

2.7 Probit results on training participation . . . . . . . . . . 30

2.8 Negative binomial regression results on number of training courses attended . . . . . . . . . . . . . . . 31

2.9 OLS results on informal learning (as fraction of work time) $\ldots . .32$

3.1 OLS estimation of average part-time pay penalty $\ldots \ldots \ldots \ldots$

3.2 Occupational-specific part-time pay penalties . . . . . . . . 45

3.3 OLS estimation of occupational-specific part-time pay penalties . . . 47

3.4 Training support of employer for part-time and full-time workers . . . 50

3.5 Training support of employer for part-time and full-time workers by occupations' relative training participation . . . . . . . . . 50

3.6 Occupational-specific human capital variables $\ldots \ldots \ldots \ldots$

4.1 Sample statistics of dependent and explanatory variables . . . . . . 62

4.2 Estimation results of production functions with heterogeneous labor shares based on work hours . . . . . . . . . . . . . 67

4.3 Estimation results of different shares of part-time employment on firm

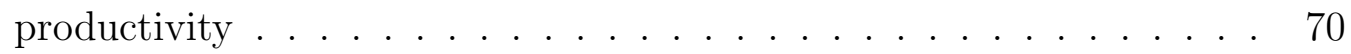

4.4 Correlations between contractual work hours and the usability of core employees . . . . . . . . . . . . . . . . . 73

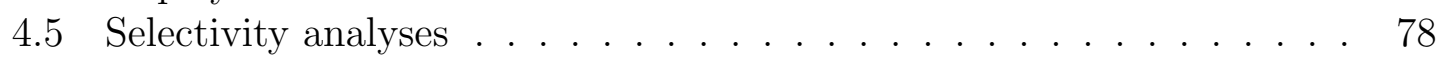

5.1 Labor force participation and average work hours of mothers by age

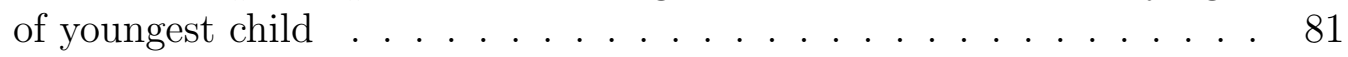

5.2 Sample size per tests and children's gender . . . . . . . 86

5.3 Summary statistics of raw test scores . . . . . . . . . . . 87

5.4 OLS results on the language test in the second school year . . . . . 95

5.5 OLS results on the sorting test in the second school year . . . . . . 95 
List of Tables

5.6 Summary statistics of control variables by gender of child . . . . . . . 101

5.7 Factor loadings on children's non-cognitive skills . . . . . . . . . . . . 102

5.8 Factor loadings on parental views . . . . . . . . . . . . . . . . . 103

5.9 Factor loadings on parenting goals . . . . . . . . . . . . . . 103 
1 Introduction 


\section{Introduction}

\subsection{Motivation}

In several European countries such as the United Kingdom, Germany, and above all the Netherlands, a significant share of the workforce is employed part-time. In particular, the percentage of women working part-time is very high in these countries. About $75 \%$ of Dutch working women is employed part-time. Several studies consider part-time employment as atypical employment in which labor market participation and care for children can be combined (Paull 2008, Yerkes and Visser 2006, Euwals 2001). Part-time employment contracts meet the preference for part-time jobs of (female) employees, although this preference might also be related to the availability of child care facilities (De Grip and Hoevenberg 1997).

However, part-time work usually has severe drawbacks for a worker's career. First, being employed part-time is often found to have negative wage effects (e.g., Ermisch and Wright 1993), although this wage penalty decreases when selectivity into part-time employment is taken into account. Aaronson and French (2004) used instrumental variables to show that male part-time workers earn substantially lower wages than full-time working men, but there is only weak evidence for such a relation for women. Hirsch (2005) controlled for both worker and job characteristics, and concluded that the wage gap between part-time and full-time workers can to a large extent be attributed to differences in these characteristics. He argued that the remaining gap is probably due to lower work experience and accumulation of human capital. Controlling for worker characteristics, labor market conditions and sample selection, Baffoe-Bonnie (2004) found that wage differentials are reduced by 10 percent, but a gap remains. Like Hirsch (2005), Baffoe-Bonnie (2004) argued that this remaining wage gap is probably due to lower human capital accumulation. Manning and Petrongolo (2008) showed that the inclusion of occupations into hourly wage analyses, reduces the part-time pay penalty to only $2.5 \%$. Their findings suggest that segregation of part-timers can explain a great part of the part-time pay penalty in Britain. However, they do not give an explicit explanation for this segregation and conclude that more research in this area is needed.

Apart from the part-time wage penalty, other negative career consequences of part-time employment have been found. Connolly and Gregory (2008) showed that there are risks of occupational downgrading when making a transition from full-time to part-time work. However, this differs across occupations: in occupations such as teaching and nursing switching to part-time jobs only rarely results in occupational downgrading. Moreover, Connolly and Gregory (2008) showed that workers who can stay with their current employer are less vulnerable to downgrading. The incidence 
of downgrading is only to a small extent affected by personal or household characteristics. Román, Fouarge, and Luijkx (2004) found similar evidence of occupational downgrading for part-timers in the Netherlands, with larger effects for women than for men.

Human capital theory offers an explanation for these negative career effects of part-time employment. Becker (1964) stated that part-time workers have lower incentives to invest in their human capital. As part-time workers have fewer work hours, workers benefit less from human capital investments in terms of wage gains. Moreover, firms benefit less from investing in part-timers compared to full-time workers in terms of productivity gains. Apart from a lower participation in formal training, part-time workers also lag behind in work experience measured in hours. Arrow (1962) was the first to introduce the importance of informal learning. Rosen (1972) introduced this in a model in which knowledge is acquired through 'production experience'. This suggests that informal learning can be seen as a by-product of market goods production. However, it can also be considered as a human capital investment. Working induces learning-by-doing which, at the cost of lower production, results in knowledge accumulation or lower human capital depreciation. Because it is difficult to measure, informal learning has often been left out in economic analyses. However, Borghans, Golsteyn, and De Grip (2007) showed that $94 \%$ of the time full-time workers learn, refers to informal learning, whereas formal training only counts for $6 \%$ of total learning time.

Several studies indeed found a lower investment in training by part-time workers compared to full-time workers. Greenhalgh and Mavrotas (1996) found that both part-time working men and women have lower training probabilities than their fulltime counterparts. Maximiano and Oosterbeek (2007) found that workers' training probability increases with the number of contractual work hours. The question remains, whether this is due to differences in workers' or firms' behavior. Maximiano and Oosterbeek (2007) concluded that part-time workers participate less often in training as a result of both workers' and firms' lower willingness to invest.

The above shows the importance of the relation between part-time work and human capital development. In this thesis, we will focus on this importance in analyses on various aspects of part-time work from the perspective of the worker, the firm and intergenerational transmission. 


\section{Introduction}

\subsection{Aim}

This thesis aims to investigate the relation between part-time employment and intraand intergenerational human capital investments, and how these relations can explain differences in workers' careers, firms' productivity, and children's human capital outcomes. More specifically, the thesis consists of four related questions articulated around the conceptual framework shown in Figure 1.1:

1. Why do part-time workers invest less in their human capital than full-timers?

2. Do differences in human capital explain the part-time pay penalty?

3. Is part-time employment beneficial for firm productivity?

4. What is the relation between maternal work status and child outcomes for school-aged children?

Figure 1.1: Conceptual framework of the thesis

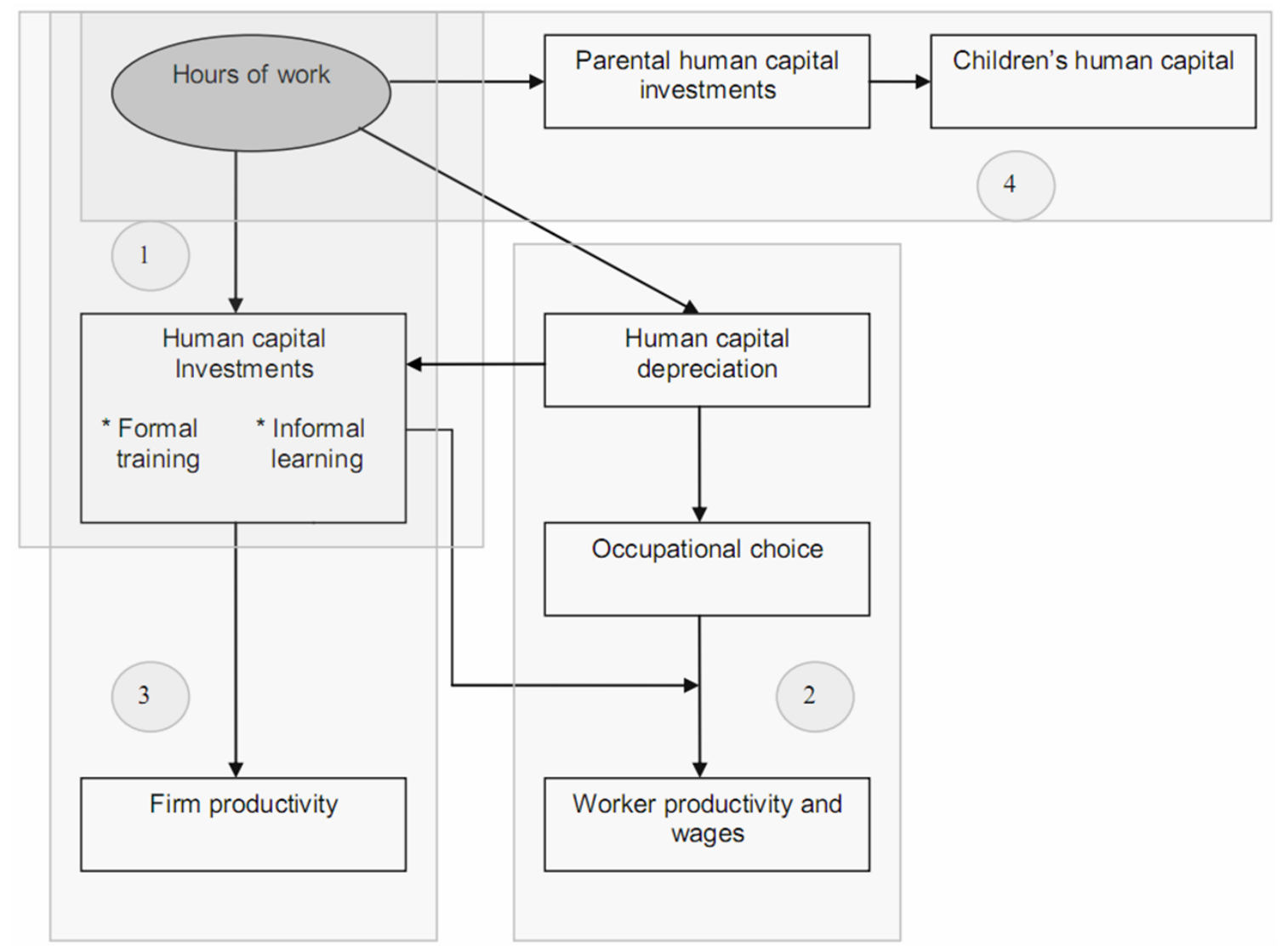


Figure 1.1 shows the conceptual framework of the thesis. The dark grey ellipse denotes workers' number of work hours. The number of work hours affects human capital investments through both formal training and informal learning: Part-time workers invest, on average, less in their human capital. The question remains, however, whether a lower human capital accumulation of part-timers compared to fulltimers is employee or employer driven (Question 1/ Chapter 2).

As being employed part-time reduces the possibility of investing in one's own human capital on the job, productivity and therefore wages of part-time workers are, ceteris paribus, expected to be lower than those of full-time workers. Additionally, the preference for a lower number of work hours is likely to affect workers' occupational choice through self-selection on human capital depreciation. This type of self-selection could result in segregation of part-timers in jobs with low average training participation and is likely to explain part of the wage gap between part-time and full-time workers (Question 2/ Chapter 3).

The prediction that part-timers invest less in their human capital than fulltimers, might not only have consequences for productivity at the individual level. Productivity at the firm level might also negatively relate to firms' part-time employment share. Conversely, part-time work might provide firms with allocation efficiencies which could increase firm productivity (Question 3/ Chapter 4).

Workers with children might face a trade off between intra- and intergenerational human capital investments, i.e. to invest in themselves or in their children. Working fewer hours provides part-timers with more time to spend with their children. Part-time employment might thereby increase parental time investments which could result in higher human capital outcomes for children (Question 4/ Chapter 5).

\subsection{Outline}

This thesis consists of four self-contained chapters which deal with four different aspects of part-time work in the context of human capital accumulation. Chapter 2, investigates determinants of two types of human capital investments for part-time and full-time workers and thereby tries to answer the question why part-time workers invest less in their human capital than full-time workers. Chapter 3, aims to explain the part-time pay penalty by differences in training participation and other human capital characteristics. Chapter 4, analyses the relation between part-time work and firm productivity in service-sector firms where opening hours exceed the full-time work week. Chapter 5, shows the relation between maternal employment status on 


\section{Introduction}

the one hand, and the diversity of parental time investments, as well as cognitive child outcomes on the other hand. Chapter 6 concludes.

\section{Chapter 2. Human capital investments}

The first study deals with the relation between part-time employment and human capital investments. It builds on human capital theory which predicts lower human capital investments for part-time workers due to lower incentives for both employers and employees to invest in a worker's human capital. Borghans, Golsteyn, and De Grip (2007) found that informal learning accounts for a very substantial part of workers' knowledge accumulation. Therefore, we distinguish between the determinants of formal training and informal learning, and analyze whether lower human capital investments by part-time workers are mainly supply or demand led. Labor supply-side factors are workers' characteristics which influence human capital investments. Borghans, Duckworth, Heckman, and Ter Weel (2008) showed that personality traits predict a variety of social and economic outcomes. We therefore not merely relate human capital investments to standard personal characteristics, but also include personality traits in our analyses. With respect to the demand side, firms' human resource practices might influence workers' human capital investments (Lynch and Black 1998). Since self-selection into part-time employment is crucial when analyzing the determinants of human capital investments, we take this possible source of endogeneity into account in a Heckman selection model.

This chapter contributes to the literature in two ways. First, we are the first to include informal learning as a human capital investment type and to investigate its determinants. Second, we analyze whether the lower human capital investments of part-time workers compared to full-timers are due to a lower employer or employee willingness to invest in part-timers. We find that full-time workers' human capital investments are positively affected by human resource practices of the firm in which they are employed. However, firms do not effectively stimulate part-time workers in a similar way. Part-time workers can only partly compensate the lack of firm support when they have a high learning motivation and a good imagination of their future development.

\section{Chapter 3. Part-time pay penalty}

In the second study, we analyze whether differences in human capital can explain the part-time pay penalty. Several studies point at a wage penalty for part-time employment (e.g., Hirsch, 2005; Baffoe-Bonnie, 2004; Aaronson and French, 2004; 
Ermisch and Wright, 1993). Manning and Petrongolo (2008) found for Britain that the part-time pay penalty is to a large extent due to occupational segregation of part-timers. In this study, we analyze to what extent human capital characteristics of occupations can explain the part-time pay penalty related to occupational segregation. Moreover, we study the heterogeneity in the part-time pay penalty across occupations. As occupations are heterogeneous in the need to continuously accumulate human capital in order to keep workers' skills up-to-date, part-time pay penalties might also differ across occupations. We estimate heterogeneous part-time pay penalties across occupations and explain differences in the part-time pay penalty by the relative human capital accumulation of part-timers compared to full-timers.

This study contributes to the literature on the part-time pay penalty by explicitly analyzing the role of human capital in explaining this penalty. First, we are the first to show that the part time pay penalty related to occupational segregation of part-timers, is to a large extent based on differences across occupations in human capital characteristics. Second, we show that the part-time pay penalty is heterogeneous across occupations. In occupations where there is a discrepancy between human capital investments of part-timers and full-timers, we do find a part-time pay penalty, whereas in occupations where human capital investments of part-timers are similar to those of full-timers, we observe no part-time pay penalty. In the latter occupations part-timers more often pay part of the training costs themselves.

\section{Chapter 4. Firm productivity}

In the third study, we analyze whether the share of part-time employment affects firm productivity in the service sector. Production function studies that include heterogeneous labor inputs, usually only distinguish between high- and low-skilled workers (e.g., Iranzo, Schivardi and Tosetti, 2008; Ilmakunnas and Maliranta, 2005), thereby implicitly assuming that part-time and full-time workers are equally productive in the hours they work. Theoretical predictions are ambiguous with respect to the expected relation between part-time employment and firm productivity. On the one hand, human capital theory predicts that part-timers are less productive than full-timers. On the other hand, literature on part-time labor demand suggest that under certain conditions there are allocation efficiencies when firms employ part-time workers (Delsen 2006). In this study, we therefore investigate whether part-time employment is beneficial for firm productivity or not. Moreover, we investigate some possible sources of allocation efficiencies provided by part-time workers.

This study contributes to the literature by analyzing the relation between pre- 


\section{Introduction}

cise measures of part-time employment and firm productivity. Due to our unique data set on the Dutch pharmacy sector, we are able to calculate firms' share of parttime employment and relate this to a "hard" physical measure of firm productivity, the number of prescription lines delivered to customers. We estimate a qualityadjusted production function with heterogeneous labor based on work hours. We find that firms with a large share of part-time employment are more productive than firms with a large share of full-time employment. Moreover, analyses on the timing of labor demand imply that it is firms' possibility to allocate labor efficiently that makes part-time employment beneficial for firm productivity in the service sector.

\section{Chapter 5. Child outcomes}

Finally, we analyze the relation between part-time work and the intergenerational human capital transfer. Since women's preference for part-time work is often related to motherhood, we investigate whether part-time working mothers contribute more to the human capital formation of their children than full-time working mothers or mothers who are not working at all. We focus on maternal work status of young school-aged children. First, we analyze whether maternal work status is related to human capital outcomes of children in their early years of primary school. We distinguish between children's language and sorting test scores around the age of 5. Second, we analyze whether the diversity of parental time investments, from now on referred to as rich home environment, can explain this relation between maternal work status and child outcomes. We quantify a rich home environment by the number of different parent-child activities. We look at both the number of joint daily activities, such as reading to a child and talking about school, and the number of planned activities, such as going to a library and a swimming pool.

Our contribution to the literature is that we analyze the role of maternal work status in human capital formation of young school-aged children. When children attend school, the potential time working mothers miss out with their children, is much smaller than when children do not yet attend school. At the same time, working might benefit children's human capital through, for example, higher family income. In contrast to what is often found for pre-school aged children (e.g., Ruhm 2004), we find no negative relation between maternal employment and child outcomes. Instead, we find that children's sorting test score is higher when their mothers work part-time (girls) or full-time (boys). We do not find, however, that a richer home environment in terms of joint parent-child activities can explain this relation. 
2 Human Capital Investments 


\subsection{Introduction}

This chapter assesses the relation between part-time employment and human capital investments. ${ }^{1}$ Several studies have found that part-time workers invest less in formal training than full-time workers (e.g., Maximiano and Oosterbeek 2007; Greenhalgh and Mavrotas 1996). This is an important finding because continuous upgrading of workers' skills is often assumed to be necessary to keep up with competitors. Human capital theory explains the lower training participation of part-time workers by lower incentives to invest in their human capital because part-timers have less work time to benefit from training investments. This holds both for the worker himself and for the employer. However, in human capital literature there is no evidence on how this is effectuated. In this chapter, we analyze the differences between part-time and full-time workers in the determinants of both formal training and informal learning. Building on human capital theory, we focus on determinants related to both the demand and the supply side of the labor market.

We contribute to the existing literature in two ways. First, there are hardly any studies that analyze to what extent it is the firms or the part-time workers themselves who are responsible for the lower investment in human capital of part-time workers. The only exception we know is the study by Maximiano and Oosterbeek (2007), which focuses on participation in formal training. We analyze to what extent the differences in both formal training and informal learning patterns of part-time workers are demand or supply lead by distinguishing between workers' psychological traits and firms' human resource practices. Second, we broaden the literature on Human Resource Management (HRM), which generally relates different packages of human resource practices to productivity or job turnover (e.g., Lynch and Black 1998, Ichniowski and Prennushi 1997). In this chapter, we relate human resource practices to investments in both formal training and informal learning.

For our analyses, we use data of the ROA Life-Long-Learning Survey 2007. This survey focuses on knowledge development and training behavior during the lifecycle. We estimate separate human capital investment equations for part-time and full-time workers. To control for selectivity into employment status we use a Heckman-type selection correction model. We find that determinants of formal training and informal learning are different for part-time and full-time workers. In contrast to Maximiano and Oosterbeek (2007), we find that lower human capital

\footnotetext{
${ }^{1}$ This chapter is a slightly revised version of Nelen and De Grip (2009). We thank Lex Borghans and Arnaud Dupuy for useful suggestions and Ben Kriechel, Thomas Dohmen, Hans Heijke, Didier Fouarge, and participants of the LoWER workshop 2008, for their comments on earlier versions of this paper.
} 
investments for part-time workers are mainly demand lead. The human capital investment behavior of part-time workers is influenced most by psychological traits such as imagination of future development, whereas full-time workers are particularly positively influenced by their firms' human resource practices such as performance interviews, personal development plans and feedback.

The structure of this chapter is as follows: The next section gives a brief review of the relevant literature. Section 2.3 describes the data and provides descriptive statistics. In Section 2.4, we describe the estimation method and in Section 2.5 we report the main results. Section 2.6 concludes.

\subsection{Related literature}

Human capital theory states that both firms and workers weigh the costs and benefits of investing in training (Becker 1964). Since training participation lowers current productivity and increases productivity after training, the work time during which workers can benefit from higher future earnings is important for the decision to invest. As part-timers work by definition fewer hours, they are expected to participate less in training and spend less time on informal learning because they have less time to benefit from such investments, whereas the investment costs of a particular training are the same for part-time and full-time workers. For the same reason, employers will benefit more from investing in full-time workers than in part-time workers. The human capital argument holds for both formal training and informal learning. Whereas investments in formal training refer to both direct and indirect costs, informal learning requires indirect investment costs in the form of foregone productivity.

Greenhalgh and Mavrotas (1996) found that both part-time working men and part-time working women have a lower training probability than their full-time counterparts. Maximiano and Oosterbeek (2007) more specifically found that workers' training probability increases when contractual work hours increase. The latter also provides a framework in which it is possible to differentiate whether training participation is caused by the employee or employer. One of their conclusions is that part-time workers participate less in training as a result of both the workers and the firms being less willing to invest. However, Maximiano and Oosterbeek (2007) did not analyze the underlying determinants of the difference in training investments.

Several streams of literature deal with determinants of workers' human capital investments. This might help to explain the willingness of employees to invest 


\section{Human Capital Investments}

in human capital. Standard determinants of workers' training participation include age, level of education, gender, marital status and number of children (e.g., Greenhalgh and Mavrotas 1996). Furthermore, the individual's time discount rate might be related participation in training (Becker 1964). Individuals with a high discount rate are expected to invest less in their human capital. However, empirical evidence for this is scarce (e.g., DellaVigna and Paserman 2005, Fersterer and Winter-Ebmer 2003, Munasinghe and Sicherman 2006). A more recent phenomenon in economic literature concerns the study of the relation between psychological traits and investments in human capital (e.g., Borghans, Duckworth, Heckman, and Ter Weel 2008). Golsteyn (2007) analyzed the effects of imagination on investments in human capital. He found that workers with more imagination invest more in their skill deficiencies. Whereas Golsteyn (2007) related imagination to the quality of human capital investments, we will relate imagination to the quantity of human capital investments. In psychological literature, the emphasis is on the relation between workers motivation for learning and training participation. Birdi, Allan, and Warr (1997) found a positive relation between learning motivation and training participation. ${ }^{2}$

The literature on HRM focuses on various human resource practices that express the willingness of firms to invest in their employees, such as performance interviews, personal development plans and career plans. However, most of the HRM literature analyzes the relation between human resource practices and outcomes such as productivity and job turnover (for an overview, see Wood 1999). Human resource practices of firms aim at maintaining and upgrading the skills of their workers. Since these human resource practices are often complementary and performance levels of firms probably do not depend on single human resource practices, most of the existing literature analyzes the role of sets of related human resource practices (e.g., Macduffie 1995, Arthur 1994). There are hardly any studies that analyze the consequences of HRM on the human capital investments of employees. The analysis of Lynch and Black (1998) on the relation between high performance workplaces (HPW) and training participation, is an exception. They found a positive correlation between HPW and the proportion of workers trained. In their paper, HPW are characterized by Total Quality Management, the use of job rotation and teams. In HPW literature, as Osterman (1994) pointed out, there seems to be no single accepted definition for describing what characterizes such workplaces. However, most studies characterize

\footnotetext{
${ }^{2}$ Another stream of literature focuses on psychological traits that influence training participation through training motivation. For an overview of psychological traits on training motivation, see Colquitt, LePine, and Noe (2000). Examples are the role of anxiety (e.g., Webster and Marrocchio 1993) locus of control (e.g., Noe and Schmitt 1986) and conscientiousness (e.g., Colquitt and Simmering 1998) on training motivation).
} 
HPW by autonomous core workers who co-operate in self-responsible teams (e.g., Youndt, Snell, Dean, and Lepak 1996). Moreover, to keep workers motivated, HPW must offer incentive payments (e.g., Becker and Huselid 1998).

Another HRM-related determinant of human capital investments of workers is feedback. Facteau, Dobbins, Russell, Ladd, and Kudisch (1995) analyzed the role of social support variables (different types of colleague feedback) on the spill-over of formal to informal training. They found a positive relation between subordinate, peer and top management support and perceived training transfer. The way in which feedback is given may also influence training behavior. Prospect theory argues that perceived losses feel much worse than gains of the same size feel good (Kahneman and Tversky 1979). An application of this theory is the analysis by McFarland and Miller (1994), which showed that recipients of feedback have more positive reactions and report higher ability levels when they focus on the positive features of feedback compared to the negative features. They separated these two forms of feedback by comparing the number of other workers in the same firm who performed better or worse than they did themselves. Thaler (1999) showed that the difference in perceived losses and gains can in turn influence decisions substantially. As far as we know, the effects of positive and negative feedback on human capital investments at the work floor have never been analyzed.

\subsection{Data and descriptive statistics}

For our analyses on the relation between part-time employment and human capital investments, we use the ROA Life-Long-Learning Survey 2007. This survey is a supplement to the basic questionnaires of the DNB Household Panel. This panel consists of 2,361 individuals who form a representative sample of the Dutch population of 16 years and older. Supplements to this panel provide information on specific topics. The ROA Life-Long-Learning Survey focuses on knowledge development and training behavior during the lifecycle. The response of this survey is equal to 1,775 respondents (which is approximately $75 \%$ ).

For our analysis, we only use information on employed persons. This leaves us with a data set of 864 respondents. We furthermore divide the sample into part-time and full-time workers based on actual work hours. ${ }^{3}$ We defined workers who work less

\footnotetext{
${ }^{3}$ When analyzing the determinants of both formal training and informal learning with contractual work hours instead of actual work hours, our findings are confirmed. Within the group of parttime workers the contractual work hours become significant for both formal training and informal learning. For full-time workers, even more HRM practices are significantly positive related to
} 


\section{Human Capital Investments}

than 33 work hours per week as part-time workers. There are different definitions of part-time work in the Netherlands (cf. De Grip and Hoevenberg 1997). The definition is in fact occupation-related. Statistics Netherlands (CBS) defines parttime workers as workers who work more than 12 and less than 35 hours per week. Since this definition qualifies full-time shift workers in some sectors of industry as part-time workers and excludes those who work less than 12 hours per week, we did not use this definition. Another difference with our definition is that Statistics Netherlands includes all pupils and students who work besides their studies. The DNB Household Survey takes 32 hours per week as the threshold. ${ }^{4}$ We decided to set the threshold at 33 hours per week so that people who work 4 days a week (32 hours) are defined as part-time workers. The sample counts 51 persons who work 32 hours per week, so we assigned 32 persons to the part-time group, who would have been defined as full-time workers by the DNB Household Survey. Those working 33 hours per week or more are defined as full-time workers.

The disadvantage of using actual work hours is that some respondents reported extreme numbers of work hours (e.g., 82). We therefore truncate the hours worked of 43 persons who reported to work more than 50 hours per week. The sample consists of 270 part-time workers ( 55 men and 215 women) and 594 full-time workers (444 men and 150 women). The percentage of part-time workers is about $31 \%$, which is 6\%-points lower than the percentage of part-time workers in the Netherlands in 2005 as measured in the Labor Force Survey.

From the ROA Life-Long-Learning Survey, we derive the following variables:

Human capital investments Human capital investments are divided into two types: formal training and informal learning. To measure formal training, we created two variables: (1) Training participation as a dummy variable which is equal to one if the respondent attended one or more trainings during the last two years, and zero otherwise; (2) the number of courses and trainings in which the respondent participated in the last two years.

Figure 2.1, shows training participation for part-time and full-time workers over the lifecycle (based on 11-year moving averages). Two features in line with human capital theory arise from the figure. First, part-time workers participate less in training than full-time workers at all ages. Second, the training gap is largest

\footnotetext{
formal training. Thus the results of the model with contractual work hours, strengthens our main conclusions.

${ }^{4}$ Using the part-time work definition used in the DNB Household Survey leads to the same results as the findings we present in this chapter.
} 
Figure 2.1: Training participation by employment status

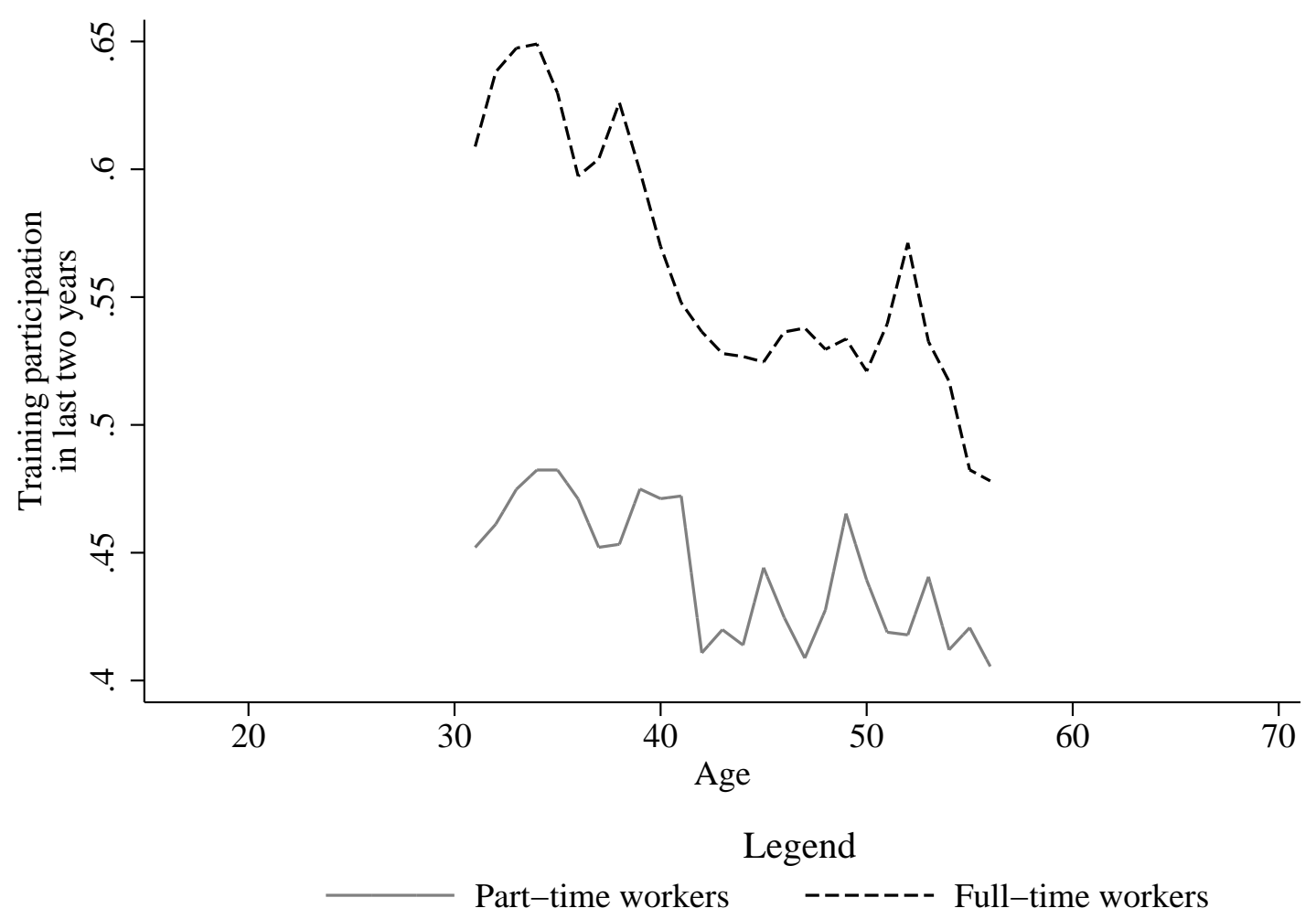

Source: ROA Life-Long-Learning Survey 2007

Note: Figure is based on 3-year moving averages (computed over the age-interval 1 year above and 1 year below a certain age).

for younger workers: While $45 \%$ of the 30 -year old part-time workers attended at least one training in the last two years, more than $60 \%$ of the full-time workers of the same age took one or more trainings. Over the lifecycle this difference declines. Table 2.2 shows that $57 \%$ of the full-time workers participated in one or more formal training courses in the last two years, compared to only $45 \%$ of the part-time workers. The table also shows that part-time workers participated on average in one course, whereas full-time workers attended 1.4 courses in the last two years.

Even though economic literature has focused mainly on formal training, recent research Borghans, Golsteyn, and De Grip (2007) found that by far the largest part of the time workers invest in their human capital development refers to informal learning. Informal learning is defined as time spend on tasks from which one can learn. The question used is: What percentage of your work time do you spend on tasks 


\section{Human Capital Investments}

from which you can learn? ${ }^{5}$ Table 2.2 shows that part-time and full-time workers spend about the same fraction of their work time on tasks from which they can learn. On average, workers report to spend about $28 \%$ of work time on informal learning. ${ }^{6}$ For our analysis we use informal learning as a fraction of work time (dividing the percentage by 100).

Figure 2.2: Informal learning in hours of work time by employment status

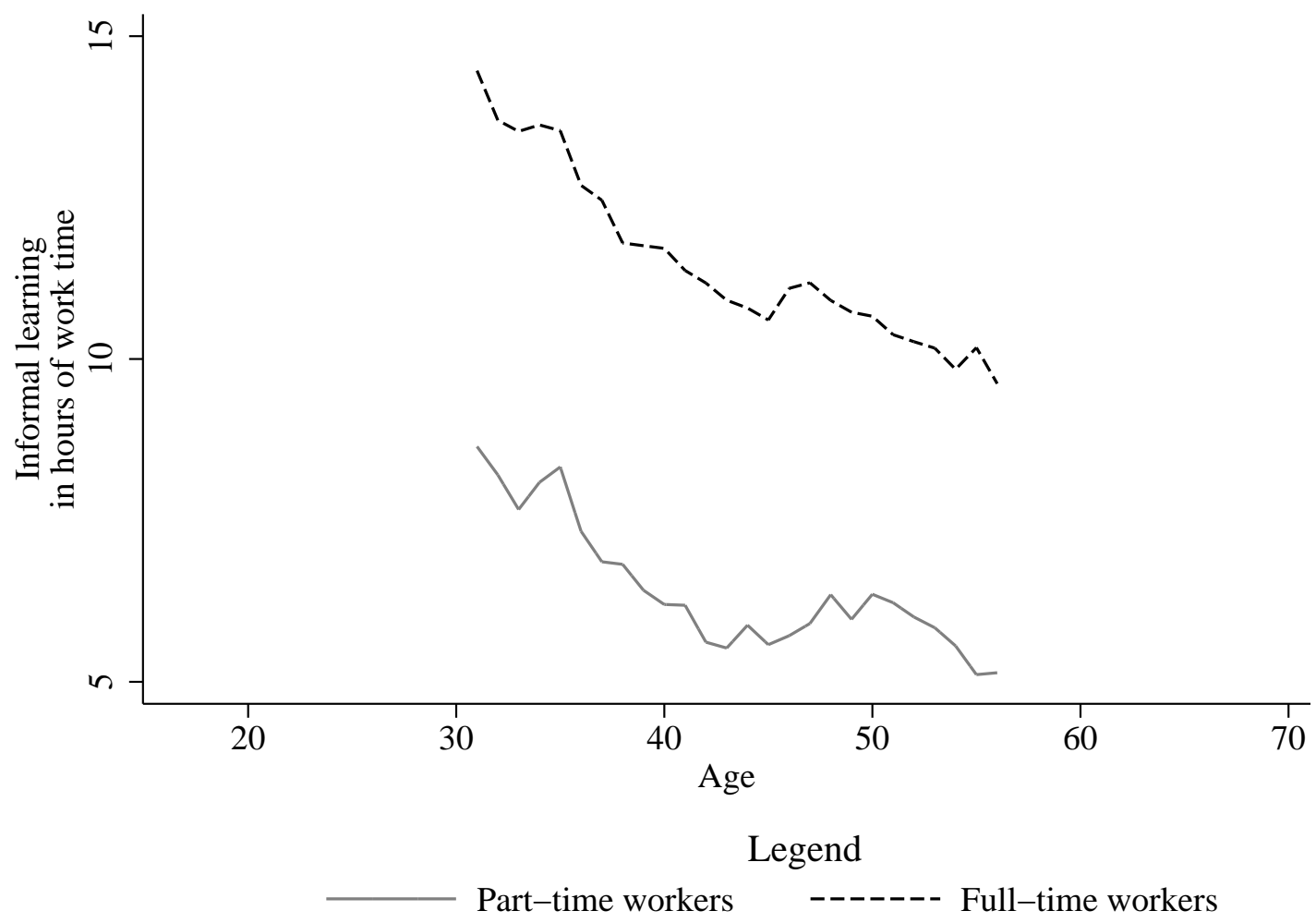

Source: ROA Life-Long-Learning Survey 2007

Note: Figure is based on 3-year moving averages (computed over the age-interval 1 year above and 1 year below a certain age).

\footnotetext{
${ }^{5}$ The fraction of working time in which workers perform tasks from which they can learn, might also include the time workers spend on formal training. However, the overlap turns out to be fairly small. For workers who participate in formal training and attend this training partly during working time (39\% of sample), in 2007 total time spent on formal training was 113 hours, of which 83.6 hours were spent during working time. For comparison, the average total time these workers spent on informal learning during 2007 was 471 hours (based on 214 working days per year and the reported 11 hours they spent on informal learning per week). Moreover, our regressions results for informal learning are similar if we only include workers who did not participate in training.

${ }^{6}$ In the first wave of the ROA Life-Long-Learning Survey in 2004, this percentage is about $30 \%$.
} 
However, because of the difference in work hours between part-time and fulltime workers, part-timers score lower on informal learning measured in hours. Figure 2.2 shows informal learning over the lifecycle. It shows the same patterns as Figure 2.1. Again, we see that part-time workers invest less in their human capital development than full-time workers. Whereas 30-year old part-time workers spend on average about 8.5 hours on tasks from which they can learn, full time workers spend almost 14 hours on informal learning per week. Furthermore, a negative relation exists between investments in informal learning and age. This is exactly what we expect, since older workers, on average, know more and therefore have less learning opportunities from tasks they perform. Furthermore, employers will not invest in allocating older workers to new tasks from which they can learn as the costs of investing might not outweigh the benefits.

Explanatory variables The explanatory variables are divided in two groups: psychological traits and HRM-related variables. Table 2.1 shows which questions are used to construct the variables. Questions that are asked on a 7-points Likert scale are standardized for the analyses (mean is equal to zero and standard deviation is equal to one). In Table 2.2, which gives the mean and standard deviations of the variables used, these variables are reported in their original 7-points Likert scale.

We include two psychological traits of workers: imagination and learning motivation. Both psychological traits are asked on a 7-points Likert scale. We measure a person's imagination by the question To what extent do you have a clear idea about how you would like to develop yourself in the next few years. Learning motivation is measured by a question in which respondents state how much they like learning new things. The two psychological traits seem to be distributed fairly equally between part-time and full-time workers, as can be seen in Table 2.2.

Since we have employee data, we do not have an exact measure for the firms' willingness to invest. However, we use HRM practices to proxy the willingness of firms to invest. These human resource practices included in the analysis are divided into three subgroups: (1) human resource development practices, (2) HPW and (3) feedback. First, we include the practices related to human resource development: performance interviews, personal development plans and career plans. The respondents were asked whether or not their employer pays attention to their performance and/or career development by means of these practices. Table 2.2 shows that the provision of human resource development practices for part-time workers is of about equal size as for full-time workers. 


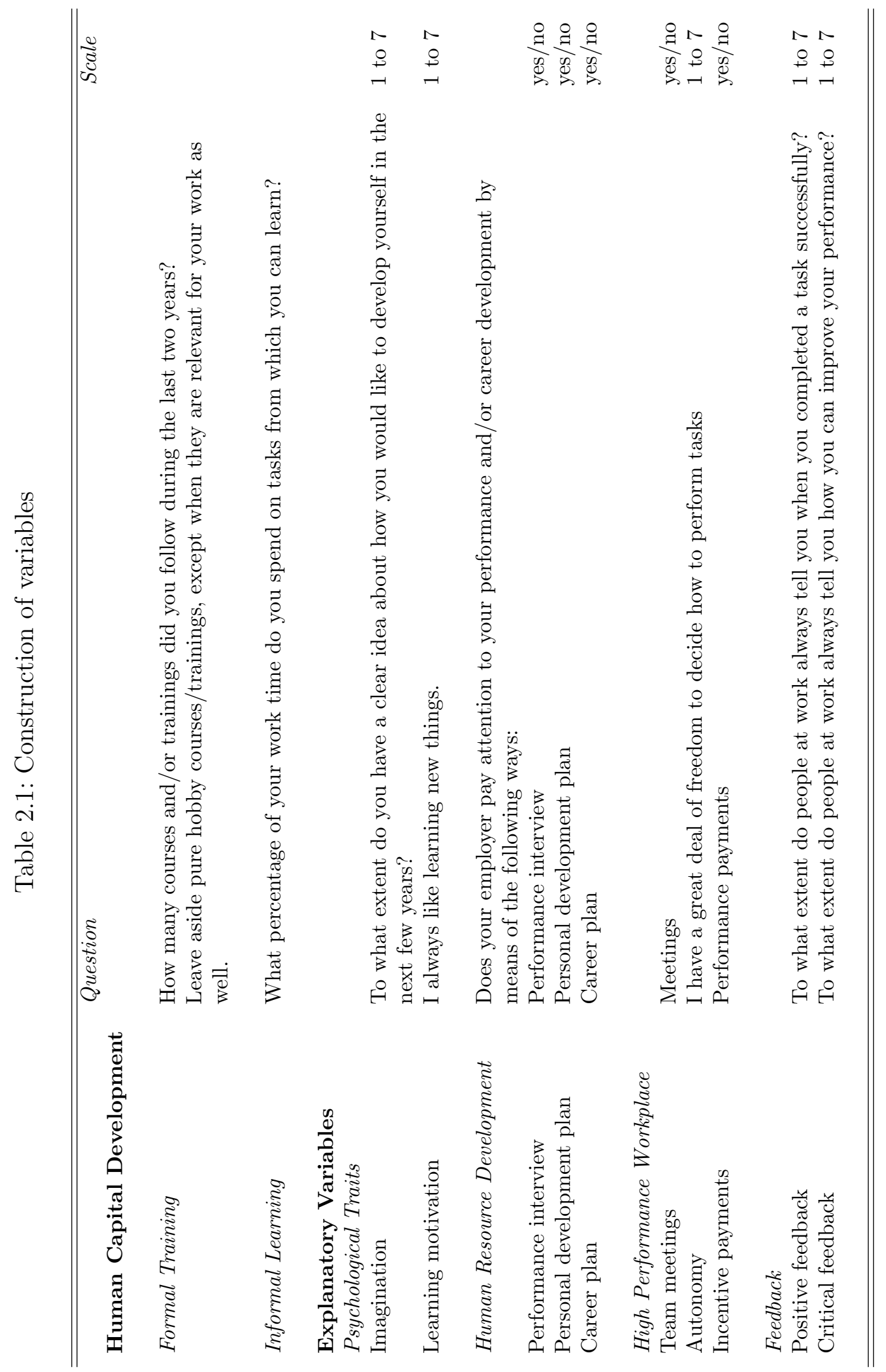


Table 2.2: Characteristics by employment status

\begin{tabular}{|c|c|c|c|c|}
\hline \multirow{3}{*}{$\begin{array}{l}\text { Human Capital Development } \\
\text { Formal Training }\end{array}$} & $\begin{array}{l}\text { Part-ti } \\
\text { mean }\end{array}$ & $\begin{array}{l}\text { ne workers } \\
\text { standard } \\
\text { deviation }\end{array}$ & $\begin{array}{l}\text { Full-tir } \\
\text { mean }\end{array}$ & $\begin{array}{l}\text { e workers } \\
\text { standard } \\
\text { deviation }\end{array}$ \\
\hline & & & & \\
\hline & & & & \\
\hline Training participation & 0.452 & 0.499 & 0.569 & 0.496 \\
\hline Number of trainings & 1.052 & 1.640 & 1.431 & 2.129 \\
\hline \multicolumn{5}{|l|}{ Informal Learning } \\
\hline in hours per week & 6.861 & 7.103 & 11.927 & 11.823 \\
\hline in $\%$ & 27.848 & 27.143 & 28.170 & 27.041 \\
\hline \multicolumn{5}{|l|}{ Explanatory Variables } \\
\hline \multicolumn{5}{|l|}{ Psychological Traits } \\
\hline Imagination $^{a}$ & 4.493 & 1.587 & 4.505 & 1.566 \\
\hline Learning motivation ${ }^{a}$ & 5.741 & 1.080 & 5.727 & 1.068 \\
\hline \multicolumn{5}{|c|}{ Human Resource Development } \\
\hline Performance interview & 0.819 & 0.386 & 0.818 & 0.386 \\
\hline Personal development plan & 0.419 & 0.494 & 0.433 & 0.496 \\
\hline Career plan & 0.204 & 0.404 & 0.215 & 0.412 \\
\hline \multicolumn{5}{|l|}{ High Performance Workplace } \\
\hline Team meetings & 0.826 & 0.380 & 0.806 & 0.395 \\
\hline Autonomy $^{a}$ & 5.056 & 1.634 & 5.458 & 1.432 \\
\hline Incentive payments & 0.144 & 0.352 & 0.335 & 0.472 \\
\hline \multicolumn{5}{|l|}{ Feedback } \\
\hline Positive feedback ${ }^{a}$ & 3.400 & 1.693 & 3.172 & 1.591 \\
\hline Critical feedback $^{a}$ & 3.207 & 1.574 & 3.042 & 1.477 \\
\hline \multicolumn{5}{|l|}{ Control Variables } \\
\hline Age & 43.448 & 10.745 & 43.428 & 10.287 \\
\hline Female & 0.796 & 0.403 & 0.253 & 0.435 \\
\hline Years of schooling & 14.598 & 2.423 & 15.180 & 2.351 \\
\hline Number of children & 1.233 & 1.101 & 0.998 & 1.171 \\
\hline
\end{tabular}

Note: ${ }^{a}$ variables are measured on a 7-points Likert scale.

Second, we include characteristics of HPW: team meetings, autonomy and performance payments. Respondents were asked to state whether or not their employer organizes team meetings and pays them according to their performance. To determine the level of autonomy, respondents could state on a 7-points Likert scale to what extent they agree with the statement $I$ have a great deal of freedom to decide how to perform tasks. Table 2.2 shows that part-time workers have slightly more team meetings than full-timers, and about 6\%-points less autonomy. The difference between part-time and full-time workers is largest with respect to performance payments. One third of the full-time workers has performance payments, compared to only $14 \%$ of the part-time workers. Third, we focus on different kinds of feedback: positive and critical feedback. Positive feedback is measured by the statement People at work always tell me when I completed a task successfully. Critical feedback is measured by At work people always tell me how I can improve my performance. On 


\section{Human Capital Investments}

a 7-points Likert scale, respondents could state to what extent they agree with these statements. It is remarkable to see that part-timers seem to get feedback of both types more often.

Finally, we include several control variables: respondent's age, gender, years of completed education, the number of children and industry. ${ }^{7}$ Gender and having a partner are included as dummy variables which equal one if the respondent is feminine and has a partner respectively, and zero otherwise. 13 industry dummies are included, based on the classification used in the DNB Household Survey. ${ }^{8}$ One can clearly see from Table 2.2 that almost $80 \%$ of the part-time workers are women, compared to $25 \%$ of the full-time employed. On average, part-time workers also have more children than full-time workers.

\subsection{Empirical strategy}

We analyze whether the factors that determine learning behavior of part-time workers are different from the factors that determine human capital investments of full-time workers. As there may be variables which determine both the choice for part-time or full-time employment and the human capital investment decisions, we use the twostep Heckman-type selection correction method. ${ }^{9}$ Two-step estimations are preferred over the more direct Maximum Likelihood (ML) estimation, because the former is less sensitive to inconsistency. ${ }^{10}$

In the first step we estimate the following selection equation:

$$
\text { EmploymentStatus }_{i}=\alpha_{0}+\beta \text { FTpartner }_{i}+\gamma \mathbf{X} \mathbf{1}_{i}+\varepsilon_{i}
$$

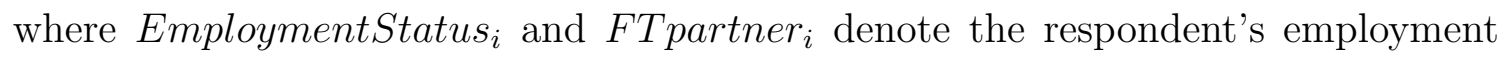
status (part-time versus full-time), and the full-time status of their partner for person i respectively. $\mathbf{X} \mathbf{1}_{i}$ is a vector with all explanatory and control variables included in the main regressions. As EmploymentStatus $i$ can only take the values zero (fulltime) or one (part-time), this model is estimated with a Probit model.

\footnotetext{
${ }^{7}$ Since the Survey does not provide information on firm size, we cannot include this in the analysis.

${ }^{8} \mathrm{We}$ combined two industries because of the small numbers of observations. It concerns industries

1 (agriculture and extracting minerals) and 3 (energy and water supply).

${ }^{9}$ We also extended our selection model to control for selection into (un)employment. However, this did not affect our results.

${ }^{10}$ As ML estimation relies on the joint normality assumption of the errors in the selection equation and the equation of interest, misspecification of one of the equations results in inconsistency. Although, the two-step estimator is less efficient if both equations are correctly specified, the estimator is less sensitive to inconsistency because it only relies on conditional moments (cf. Beblo, Beninger, Heinze, and Laisney 2003).
} 
We use the full-time employment status of the partner as our exclusion restriction. In the Netherlands, there is a strong tradition in which one partner works full-time and the other works part-time. Respondents living with a partner who does not work and those without a partner are treated as individuals without a full-time employed partner $\left(\right.$ FTpartner $\left._{i}=0\right){ }^{11}$

In the second step, the equations of interest are estimated. For part-time and full-time workers, we separately estimate the following three human capital investment equations:

$$
\begin{aligned}
T P_{i} & =a_{1}+b_{1} \text { psych }_{i}+c_{1} H R D_{i}+d_{1} H P W_{i}+e_{1} \text { feedback }_{i} \\
& +f_{1} \mathbf{X} \mathbf{2}_{i}+g_{1} I M R_{i}+u_{i 1} \\
& \\
T Q_{i} & =a_{2}+b_{2} \text { psych }_{i}+c_{2} H R D_{i}+d_{2} H P W_{i}+e_{2} \text { feedback }_{i} \\
& +f_{2} \mathbf{X} \mathbf{2}_{i}+g_{2} I M R_{i}+u_{i 2} \\
& \\
I L_{i} & =a_{3}+b_{3} \text { psych }_{i}+c_{3} H R D_{i}+d_{3} H P W_{i}+e_{3} \text { feedback }_{i} \\
& +f_{3} \mathbf{X} \mathbf{2}_{i}+g_{3} I M R_{i}+u_{i 3}
\end{aligned}
$$

where $T P_{i}, T Q_{i}, I L_{i}$ denote the three different types of human capital investments for person i: training participation, number of training courses attended and informal learning measured in fractions of work time. Psych ${ }_{i}, H R D_{i}, H P W_{i}$ and feedback denote the vectors of explanatory variables, and $\mathbf{X} \mathbf{2}_{i}$ is a vector with control variables including workers' age, gender, years of schooling, number of children and industry dummies. ${ }^{12} I M R_{i}$ denotes the Inverse Mills Ratios calculated from the estimation of Equation (2.1).

As TP is a dummy variable, Equation (2.2) is estimated with a probit model. Because $T Q$ is a count variable which only takes a small number of values, Equation (2.3) is estimated with a Negative Binominal Regression model. ${ }^{13}$ This model as-

\footnotetext{
$\overline{1185 \% \text { of the respondents has a partner. }}$.

${ }^{12}$ Ideally, we would also have included workers' occupational background and tenure as these variables are probably correlated to personality traits and HPW variables. The inclusion of industry dummies, age and education levels might pick up part of these effects. Nevertheless, measurement bias might be induced due to missing information on occupation and tenure.

${ }^{13}$ Wooldridge (2002) stated that when a count variable only takes a small number of values count data models are more appropriate than Tobit models (page 520).
} 


\section{Human Capital Investments}

sumes overdispersion (relative to the Poisson case), i.e. that the variance is greater than the mean. ${ }^{14}$ Equation (2.4) is estimated with Ordinary Least Squares (OLS). ${ }^{15}$

\subsection{Results}

Table 2.3 reports the selection equation. The table shows that the full-time status of the partner is significantly related to someone's own work status. When someone has a partner who works full-time, the chance of working part-time is $15 \%$ higher. ${ }^{16}$ Moreover, being female increases the chance of working part-time with almost $40 \%$.

Table 2.3: First stage of the Heckman-type selection correction Model

\begin{tabular}{lll}
\hline \hline Dep. Var.: Part-Time status & & \\
& coefficients & marginal effects \\
Full-time status partner & $0.447^{* * *}$ & $0.145^{* *}$ \\
& $(0.130)$ & $(0.044)$ \\
Age & $0.020^{* * *}$ & $0.006^{* * *}$ \\
& $(0.006)$ & $(0.002)$ \\
Female & $1.213^{* * *}$ & $0.382^{* * *}$ \\
& $(0.136)$ & $(0.041)$ \\
Years of schooling & $-0.101^{* * *}$ & $-0.031^{* * *}$ \\
& $(0.026)$ & $(0.008)$ \\
Number of children & $0.135^{* * *}$ & $0.041^{* *}$ \\
& $(0.050)$ & $(0.015)$ \\
Constant & $-1.484^{* * *}$ & \\
& $(0.528)$ & \\
\hline Pseudo R-squared & 0.3602 & \\
Log Likelihood & -343.354 & \\
N & 864 & \\
\hline \hline
\end{tabular}

Note: Female and full-time status partner are dummy variables equal to one when someone is female and has a partner working full-time respectively, and zero otherwise. Moreover all psychological traits, HRD, HPW and feedback variables are included in the regression. Marginal effects are evaluated at the sample means of the data. ${ }^{*}$ denotes significance at the 10 percent level, $* *$ denotes significance at the 5 percent level, $* * *$ denotes significance at the 1 percent level.

\footnotetext{
${ }^{14}$ We use the Lagrange Ratio test to test for overdispersion. With a LR statistic of 49.638 , we are sure that the Negative Binominal Regression Model is preferred above the Poisson model. See: Cameron and Trivedi (1998).

${ }^{15}$ As all equations include the same regressors, seemingly unrelated regression models are not needed (even if the three errors are correlated, OLS and Generalized Least Squares will provide identical estimators) and simultaneous models fail identification.

${ }^{16}$ The $\mathrm{F}$ statistic of FTpartner $i$ is 11.82.
} 
Formal training Table 2.4 reports the estimation results on the determinants of training participation of part-time and full-time workers. ${ }^{17}$ The table shows that learning motivation is positively related to training participation for all workers. However, the effect is larger for part-time workers than for full-time workers. Parttime workers who have a motivation to learn which is one standard deviation above the average have $13 \%$ more chance of having attended a training course during the last two years compared to an increased probability of about $5 \%$ for full-time workers. The impact of imagination on training participation is only significant for part-time workers.

Human resource development practices, on the other hand, only stimulate training participation of full-time workers, although there is a weakly significant effect of performance interviews on training participation of part-time workers. Full-time workers with performance interviews have $14 \%$ more chance of attending training. When full-time workers have a personal development plan, their chances of participating in training are $16 \%$ higher. Remarkably, having a career plan has a negative effect. However, this effect is only weakly significant. We do not find many effects of high performance workplaces on training participation of part-time or full-time workers. ${ }^{18}$ Only performance payments are stimulating training participation of full-time workers (at the $10 \%$ significance level). Feedback does not play a role in explaining training participation of both part-time and full-time workers.

As the IMRs of part-time and full-time workers are not statistically significant, selection does not seem to play a role in training participation. This suggest that the part-time / full-time status of workers is not endogenous with respect to training participation.

Furthermore, it is remarkable that control variables which are often used to explain training participation, such as workers' age, years of education and number of children, do not significantly influence workers' training participation. Gender is the only exception. Full-time working women have an increased probability of training participation. The observation that these common training determinants are not significant when the characteristics of workers and employers are included, indicates that one should be careful in relating basic characteristics such as age, gender and educational level to training behavior, without including the workers' psychological traits and the firms' human resource practices.

\footnotetext{
${ }^{17}$ Results are similar in Probit (training participation) and Negative Binomial Regression (number of training courses attended) models in which the IMR are left out. See Tables 2.7 and 2.8 in the appendix.

${ }^{18}$ The three variables that form the category high performance workplace are not jointly significant either.
} 
Table 2.4: Determinants of training participation

\begin{tabular}{|c|c|c|c|c|}
\hline \multirow[t]{2}{*}{ Dep. Var.: Training participation } & \multicolumn{2}{|c|}{ Part-time Workers } & \multicolumn{2}{|c|}{ Full-time Workers } \\
\hline & coefficients & marginal effects & coefficients & marginal effects \\
\hline \multicolumn{5}{|l|}{ Psychological Characteristics } \\
\hline \multirow[t]{2}{*}{ Imagination } & $0.238^{* *}$ & $0.094^{* *}$ & 0.087 & 0.034 \\
\hline & $(0.093)$ & $(0.037)$ & $(0.060)$ & $(0.024)$ \\
\hline \multirow[t]{2}{*}{ Learning motivation } & $0.336^{* * *}$ & $0.132^{* * *}$ & $0.134^{* *}$ & $0.053^{* *}$ \\
\hline & $(0.107)$ & $(0.042)$ & $(0.062)$ & $(0.024)$ \\
\hline \multicolumn{5}{|l|}{ Human Resource Development } \\
\hline \multirow[t]{2}{*}{ Performance interview } & $0.495^{*}$ & $0.186^{*}$ & $0.346^{* *}$ & $0.137^{* *}$ \\
\hline & $(0.285)$ & $(0.100)$ & $(0.156)$ & $(0.062)$ \\
\hline \multirow[t]{2}{*}{ Personal development plan } & 0.192 & 0.076 & $0.405^{* * *}$ & $0.157^{* * *}$ \\
\hline & $(0.213)$ & $(0.084)$ & $(0.135)$ & $(0.051)$ \\
\hline \multirow[t]{2}{*}{ Career plan } & -0.061 & -0.024 & $-0.302^{*}$ & $-0.119^{*}$ \\
\hline & $(0.258)$ & $(0.101)$ & $(0.154)$ & $(0.061)$ \\
\hline \multicolumn{5}{|l|}{ High Performance Workplace } \\
\hline \multirow[t]{2}{*}{ Team meetings } & 0.090 & 0.036 & 0.107 & 0.042 \\
\hline & $(0.274)$ & $(0.107)$ & $(0.151)$ & $(0.060)$ \\
\hline \multirow[t]{2}{*}{ Autonomy } & -0.030 & -0.012 & -0.011 & -0.004 \\
\hline & $(0.097)$ & $(0.038)$ & $(0.067)$ & $(0.026)$ \\
\hline \multirow[t]{2}{*}{ Performance payments } & -0.363 & -0.139 & 0.227 & 0.088 \\
\hline & $(0.346)$ & $(0.126)$ & $(0.145)$ & $(0.055)$ \\
\hline \multicolumn{5}{|l|}{ Feedback } \\
\hline \multirow[t]{2}{*}{ Positive feedback } & -0.064 & -0.025 & -0.047 & -0.019 \\
\hline & $(0.111)$ & $(0.044)$ & $(0.071)$ & $(0.028)$ \\
\hline \multirow[t]{2}{*}{ Critical feedback } & 0.101 & 0.040 & -0.049 & -0.019 \\
\hline & $(0.098)$ & $(0.038)$ & $(0.067)$ & $(0.026)$ \\
\hline \multicolumn{5}{|l|}{ Control variables } \\
\hline \multirow[t]{2}{*}{ Age } & 0.001 & 0.0004 & $-0.011^{*}$ & $-0.004^{*}$ \\
\hline & $(0.011)$ & $(0.004)$ & $(0.006)$ & $(0.002)$ \\
\hline \multirow[t]{2}{*}{ Female } & 0.143 & 0.056 & 0.061 & 0.024 \\
\hline & $(0.645)$ & $(0.250)$ & $(0.289)$ & $(0.113)$ \\
\hline \multirow[t]{2}{*}{ Years of schooling } & 0.003 & 0.001 & 0.033 & 0.013 \\
\hline & $(0.051)$ & $(0.020)$ & $(0.029)$ & $(0.011)$ \\
\hline \multirow[t]{2}{*}{ Number of children } & -0.092 & -0.036 & 0.043 & 0.017 \\
\hline & $(0.102)$ & $(0.040)$ & $(0.053)$ & $(0.021)$ \\
\hline \multirow[t]{2}{*}{ IMR } & -0.150 & -0.059 & -0.120 & -0.047 \\
\hline & $(0.641)$ & $(0.253)$ & $(0.467)$ & $(0.183)$ \\
\hline \multirow[t]{2}{*}{ Constant } & -0.558 & & -0.634 & \\
\hline & $(1.517)$ & & $(0.533)$ & \\
\hline Industry dummies & yes & & yes & \\
\hline Pseudo R-squared & 0.1730 & & 0.0836 & \\
\hline Log Likelihood & -151.729 & & -32.122 & \\
\hline $\mathrm{N}$ & 266 & & 594 & \\
\hline Model: Heckman-type selection c & rection mod & (two stages) & & \\
\hline
\end{tabular}

Note: Female and full-time status partner are dummy variables equal to one when someone is female and has a partner working full-time respectively, and zero otherwise. Industry dummies are included. We separate 13 industries, in the regressions, one is left out. Marginal effects are evaluated at the sample means of the data. Standard errors in parentheses; ${ }^{*} \mathrm{p}<0.1,{ }^{* *} \mathrm{p}<0.05,{ }^{* * *} \mathrm{p}<0.01$. 
Table 2.5: Determinants of number of training courses attended

\begin{tabular}{|c|c|c|c|c|}
\hline Dep. Var.: Number of trainings attended & $\begin{array}{l}\text { Part-time } \\
\text { coefficients }\end{array}$ & $\begin{array}{l}\text { workers } \\
\text { marginal } \\
\text { effects }\end{array}$ & $\begin{array}{l}\text { Full-time } \\
\text { coefficients }\end{array}$ & $\begin{array}{l}\text { workers } \\
\text { marginal } \\
\text { effects }\end{array}$ \\
\hline \multicolumn{5}{|l|}{ Psychological traits } \\
\hline Imagination & $\begin{array}{l}0.273^{* * *} \\
(0.106)\end{array}$ & $\begin{array}{l}0.218^{* * *} \\
(0.084)\end{array}$ & $\begin{array}{l}0.116^{*} \\
(0.061)\end{array}$ & $\begin{array}{l}0.147^{*} \\
(0.077)\end{array}$ \\
\hline Learning motivation & $\begin{array}{l}0.414^{* * *} \\
(0.121)\end{array}$ & $\begin{array}{l}0.331^{* * * *} \\
(0.095)\end{array}$ & $\begin{array}{l}0.203^{* * *} \\
(0.063)\end{array}$ & $\begin{array}{l}0.258^{* * *} \\
(0.079)\end{array}$ \\
\hline \multicolumn{5}{|l|}{ Human Resource Development } \\
\hline Performance interview & $\begin{array}{l}0.276 \\
(0.319)\end{array}$ & $\begin{array}{l}0.203 \\
(0.215)\end{array}$ & $\begin{array}{l}0.360^{* *} \\
(0.174)\end{array}$ & $\begin{array}{l}0.409 * * \\
(0.177)\end{array}$ \\
\hline Personal development plan & $\begin{array}{l}0.316 \\
(0.222)\end{array}$ & $\begin{array}{l}0.260 \\
(0.189)\end{array}$ & $\begin{array}{l}0.495^{* * *} \\
(0.130)\end{array}$ & $\begin{array}{l}0.656^{* * *} \\
(0.183)\end{array}$ \\
\hline Career plan & $\begin{array}{l}-0.122 \\
(0.271)\end{array}$ & $\begin{array}{l}-0.095 \\
(0.202)\end{array}$ & $\begin{array}{l}-0.224 \\
(0.145)\end{array}$ & $\begin{array}{l}-0.267 \\
(0.163)\end{array}$ \\
\hline \multicolumn{5}{|l|}{ High Performance Workplace } \\
\hline Team meetings & $\begin{array}{l}0.160 \\
(0.318)\end{array}$ & $\begin{array}{l}0.122 \\
(0.229)\end{array}$ & $\begin{array}{l}-0.037 \\
(0.156)\end{array}$ & $\begin{array}{l}-0.048 \\
(0.203)\end{array}$ \\
\hline Autonomy & $\begin{array}{l}-0.087 \\
(0.098)\end{array}$ & $\begin{array}{l}-0.070 \\
(0.079)\end{array}$ & $\begin{array}{l}-0.039 \\
(0.067)\end{array}$ & $\begin{array}{l}-0.050 \\
(0.085)\end{array}$ \\
\hline Performance payments & $\begin{array}{l}0.135 \\
(0.368)\end{array}$ & $\begin{array}{l}0.114 \\
(0.324)\end{array}$ & $\begin{array}{l}0.173 \\
(0.148)\end{array}$ & $\begin{array}{l}0.226 \\
(0.199)\end{array}$ \\
\hline \multicolumn{5}{|l|}{ Feedback } \\
\hline Positive feedback & $\begin{array}{l}-0.051 \\
(0.121)\end{array}$ & $\begin{array}{l}-0.041 \\
(0.097)\end{array}$ & $\begin{array}{l}-0.067 \\
(0.075)\end{array}$ & $\begin{array}{l}-0.085 \\
(0.095)\end{array}$ \\
\hline Critical feedback & $\begin{array}{l}-0.047 \\
(0.105)\end{array}$ & $\begin{array}{l}-0.038 \\
(0.084)\end{array}$ & $\begin{array}{l}0.007 \\
(0.068)\end{array}$ & $\begin{array}{l}0.009 \\
(0.086)\end{array}$ \\
\hline \multicolumn{5}{|l|}{ Control variables } \\
\hline Age & $\begin{array}{l}0.008 \\
(0.012)\end{array}$ & $\begin{array}{l}0.006 \\
(0.010)\end{array}$ & $\begin{array}{l}-0.009 \\
(0.006)\end{array}$ & $\begin{array}{l}-0.011 \\
(0.008)\end{array}$ \\
\hline Female & $\begin{array}{l}0.451 \\
(0.672)\end{array}$ & $\begin{array}{l}0.318 \\
(0.419)\end{array}$ & $\begin{array}{l}-0.175 \\
(0.281)\end{array}$ & $\begin{array}{l}-0.213 \\
(0.328)\end{array}$ \\
\hline Years of schooling & $\begin{array}{l}-0.005 \\
(0.048)\end{array}$ & $\begin{array}{l}-0.004 \\
(0.039)\end{array}$ & $\begin{array}{l}0.036 \\
(0.030)\end{array}$ & $\begin{array}{l}0.045 \\
(0.038)\end{array}$ \\
\hline Number of children & $\begin{array}{l}-0.074 \\
(0.106)\end{array}$ & $\begin{array}{l}-0.059 \\
(0.085)\end{array}$ & $\begin{array}{l}0.007 \\
(0.054)\end{array}$ & $\begin{array}{l}0.009 \\
(0.069)\end{array}$ \\
\hline IMR & $\begin{array}{l}-0.158 \\
(0.660)\end{array}$ & $\begin{array}{l}-0.126 \\
(0.528)\end{array}$ & $\begin{array}{l}0.211 \\
(0.480)\end{array}$ & $\begin{array}{l}0.268 \\
(0.609)\end{array}$ \\
\hline Constant & $\begin{array}{l}-1.403 \\
(1.731) \\
\end{array}$ & & $\begin{array}{l}-0.583 \\
(0.547)\end{array}$ & \\
\hline Industry dummies & yes & & yes & \\
\hline Pseudo R-squared & 0.0787 & & 0.0401 & \\
\hline Log Likelihood & -350.669 & & -937.079 & \\
\hline $\mathrm{N}$ & 270 & & 594 & \\
\hline Model: Heckman-type selection correction & model (two & ages) & & \\
\hline
\end{tabular}




\section{Human Capital Investments}

Table 2.5 shows the estimation results of the determinants of the number of training courses workers participated in. This allows us to distinguish among the workers who participated in formal training. The table shows that psychological traits are not only related to training participation, but also to the number of training courses part-time workers attend. Full-time workers who are highly motivated to learn have a stronger tendency to attend more training courses. The effect of learning motivation on the number of training courses attended is similar for part-time and full-time workers. Furthermore, the number of training courses of full-time workers is influenced by human resource development practices, whereas those of part-time workers are not: Performance interviews and personal development plans affect the number of training courses of full-time workers positively. The variables related to the high performance workplace and the feedback variables do not influence the number of training courses part-time and full-time workers attend. ${ }^{19}$

Like in Table 2.4, the coefficients on the IMRs in Table 2.5 are insignificant, indicating the absence of a selection problem.

Informal learning Table 2.6 shows the estimation results on the determinants of informal learning, as a fraction of work time. ${ }^{20}$ The only explanatory variable which has a strongly significant influence on part-time workers' informal learning behavior is imagination. Part-time workers with an imagination of their future development one standard deviation higher than the average worker spend on average almost $6 \%$ more work time on tasks from which they learn. On the contrary, full-time workers' informal learning behavior does not depend on their capacity to imagine their future development or on their learning motivation. Although human resource development and high performance workplace variables do not affect informal learning of either part-time or full-time workers ${ }^{21}$, the latter are positively influenced by the feedback they get at work. Both positive and critical feedback positively influence the fraction of work time in which full-time workers learn informally, whereas we only find a weakly significant effect of critical feedback on informal learning for part-time workers.

Since determinants of informal learning have hardly been analyzed in economic literature, we also briefly comment on the control variables. As can be seen in Table

\footnotetext{
${ }^{19}$ The variables measuring high performance workplace are not jointly significant either.

${ }^{20} \mathrm{We}$ also estimated the explanatory variables on the hours spend on tasks from which workers learn. Since the results of this estimation are comparable to the one in which informal learning is measured in fractions, we decided not to include these results explicitly in the chapter.

${ }^{21}$ The human resource development practices are not jointly significant either, nor are the variables measuring high performance workplace.
} 
Table 2.6: Determinants of informal learning (as fraction of work time)

\begin{tabular}{|c|c|c|}
\hline Dep.Var.: Informal learning & Part-time Workers & Full-time Workers \\
\hline \multicolumn{3}{|l|}{ Psychological Characteristics } \\
\hline \multirow[t]{2}{*}{ Imagination } & $0.060^{* * *}$ & 0.010 \\
\hline & $(0.017)$ & $(0.011)$ \\
\hline \multirow[t]{2}{*}{ Learning motivation } & 0.012 & $0.020^{*}$ \\
\hline & $(0.018)$ & $(0.012)$ \\
\hline \multicolumn{3}{|l|}{ Human Resource Development } \\
\hline \multirow[t]{2}{*}{ Performance interview } & 0.001 & -0.030 \\
\hline & $(0.047)$ & $(0.030)$ \\
\hline \multirow[t]{2}{*}{ Personal development plan } & 0.046 & 0.023 \\
\hline & $(0.040)$ & $(0.025)$ \\
\hline \multirow[t]{2}{*}{ Career plan } & -0.006 & 0.019 \\
\hline & $(0.048)$ & $(0.029)$ \\
\hline \multicolumn{3}{|l|}{ High Performance Workplace } \\
\hline \multirow[t]{2}{*}{ Team meetings } & 0.035 & $0.051^{*}$ \\
\hline & $(0.046)$ & $(0.028)$ \\
\hline \multirow[t]{2}{*}{ Autonomy } & -0.013 & 0.009 \\
\hline & $(0.017)$ & $(0.012)$ \\
\hline \multirow[t]{2}{*}{ Performance payments } & -0.023 & 0.003 \\
\hline & $(0.062)$ & $(0.027)$ \\
\hline \multicolumn{3}{|l|}{ Feedback } \\
\hline \multirow[t]{2}{*}{ Positive feedback } & -0.007 & $0.038 * * *$ \\
\hline & $(0.020)$ & $(0.013)$ \\
\hline \multirow[t]{2}{*}{ Critical feedback } & $0.034^{*}$ & $0.032^{* *}$ \\
\hline & $(0.018)$ & $(0.013)$ \\
\hline \multicolumn{3}{|l|}{ Control variables } \\
\hline \multirow[t]{2}{*}{ Age } & $-0.006^{* * *}$ & $-0.004^{* * *}$ \\
\hline & $(0.002)$ & $(0.001)$ \\
\hline \multirow[t]{2}{*}{ Female } & -0.092 & -0.023 \\
\hline & $(0.117)$ & $(0.054)$ \\
\hline \multirow[t]{2}{*}{ Years of schooling } & 0.013 & 0.009 \\
\hline & $(0.009)$ & $(0.006)$ \\
\hline \multirow[t]{2}{*}{ Number of children } & -0.012 & -0.006 \\
\hline & $(0.019)$ & $(0.010)$ \\
\hline \multirow[t]{2}{*}{ IMR } & -0.032 & 0.063 \\
\hline & $(0.117)$ & $(0.087)$ \\
\hline \multirow[t]{2}{*}{ Constant } & $0.514^{*}$ & $0.282^{* * *}$ \\
\hline & $(0.277)$ & $(0.101)$ \\
\hline Industry dummies & yes & yes \\
\hline Wald chi2 & 57.25 & 131.63 \\
\hline $\mathrm{N}$ & 270 & 594 \\
\hline \multicolumn{3}{|c|}{ Model: Heckman-type selection correction model (two stages) } \\
\hline
\end{tabular}

2.6, age has a negative effect on informal learning for both part-time and full-time workers. Part-time (full-time) workers who are one year older spend on average 


\section{Human Capital Investments}

around $0.6 \%$-points (0.4\%-points) less on informal learning. Other control variables do not affect the fraction of work time spend on informal learning. Since the IMRs are not significant in both the part-time and full-time informal learning equations, there seems to be no selection for both types of workers. ${ }^{22}$

Combining all forms of human capital investments, we can conclude that HRM policy is the main factor driving the human capital investments of full-time workers. Table 2.4 shows that full-time workers' chance to participate in training largely depends on the HRM practices of the firm they are working for. The role of HRM practices implies that in firms with good HRM practices, the incidence of training participation is larger. Worker characteristics do not seem to play a big role. However, this changes when we analyze the number of training courses in which full-time workers participate. Even though the two variables that identify training oriented HRM practices are still significant, learning motivation becomes important as well.

Thus, the large pool of workers that receive training is divided by motivation. Those workers with high motivation distinguish themselves from other full-time workers by attending more training courses. Table 2.6 shows that informal learning behavior of full-time workers is mainly explained by age and the feedback policy of the firm.

For part-time workers, the results are different. Table 2.4 shows that worker characteristics determine whether part-time workers participate in training or not. Even in companies that have elaborate HRM practices, only those workers who are motivated to learn and have a clear idea about their further development get trained. For part-time workers, not only training participation, but also the number of training courses attended is driven by these two variables.

The fraction of work time in which workers perform tasks from which they learn is fairly equal for part-time and full-time workers. However, while full-time workers' informal learning behavior depends most on the feedback system of the firm where they are employed, this does not hold for part-time workers. Even though part-time workers get more feedback than full-time workers, for part-time workers, the effect of critical feedback is only weakly significant. The positive feedback part-time workers get at their work, is not related to their further development. Imagination of further development is the only factor which strongly stimulates informal learning behavior of part-time workers. Again, personal drive seems to be most important in explaining human capital investments of part-time workers.

It is remarkable to note that for part-time workers the determinants of formal

\footnotetext{
${ }^{22}$ Results do not change if we estimate a simple OLS model for informal learning. See Table 2.9 in the appendix.
} 
training and informal learning are fairly similar, whereas for full-time workers there is a clear difference between formal training and informal learning determinants. Even though full-time workers are on average influenced mostly by human resource practices, human resource development such as performance interviews and personal development plans only seem to affect their formal training behavior, whereas informal learning behavior is stimulated by feedback in the workplace. All forms of human capital investments of part-time workers are driven by workers' personality traits such as imagination of further development and learning motivation.

\subsection{Conclusion}

In this chapter, we analyzed the differences in the determinants of participation in both formal training and informal learning between part-time and full-time workers. Human capital theory expects both workers themselves and firms to be less willing to invest in part-time workers. We found that human capital investments of parttime workers are mainly supply lead. Psychological traits - imagination of one's own future development being the most important one - positively influence both formal training and informal learning. Human resource practices are hardly of any influence on part-time workers' further investments in human capital development. This is in sharp contrast with the determinants of full-time workers' participation in formal training and informal learning. Whereas psychological traits only affect full-time workers' formal training incidence, human resource practices are important for both formal training and informal learning. Formal training is stimulated in particular by human resource development practices such as performance interviews and personal development plans. Informal learning is positively affected by both positive and critical feedback in the workplace. It is remarkable that although part-time workers receive more feedback than full-time workers, we do not find a strong positive effect of feedback on informal learning behavior of part-time workers. Probably, the feedback is not related to their further development.

Concluding, the differences in human capital investments between part-time and full-time workers are mainly demand lead. Full-time workers are positively affected by human resource practices of the firm in which they are employed. However, firms do not effectively stimulate part-time workers in a similar way. Part-time workers can only partly compensate the lack of firm support when they have a high learning motivation and imagination of their future development. 


\section{Appendix}

Table 2.7: Probit results on training participation

\begin{tabular}{|c|c|c|}
\hline Dep. Var.: Training participation & $\begin{array}{l}\text { Part-time Workers } \\
\text { coefficients }\end{array}$ & $\begin{array}{l}\text { Full-time Workers } \\
\text { coefficients }\end{array}$ \\
\hline \multicolumn{3}{|l|}{ Psychological Characteristics } \\
\hline Imagination & $\begin{array}{l}0.237^{* *} \\
(0.093)\end{array}$ & $\begin{array}{l}0.087 \\
(0.060)\end{array}$ \\
\hline Learning motivation & $\begin{array}{l}0.329 * * * \\
(0.103)\end{array}$ & $\begin{array}{l}0.136^{* *} \\
(0.061)\end{array}$ \\
\hline \multicolumn{3}{|l|}{ Human Resource Development } \\
\hline Performance interview & $\begin{array}{l}0.496^{*} \\
(0.285)\end{array}$ & $\begin{array}{l}0.343^{* *} \\
(0.156)\end{array}$ \\
\hline Personal development plan & $\begin{array}{l}0.196 \\
(0.212)\end{array}$ & $\begin{array}{l}0.402^{* * *} \\
(0.135)\end{array}$ \\
\hline Career plan & $\begin{array}{l}-0.064 \\
(0.258)\end{array}$ & $\begin{array}{l}-0.301^{*} \\
(0.154)\end{array}$ \\
\hline \multicolumn{3}{|l|}{ High Performance Workplace } \\
\hline Team meetings & $\begin{array}{l}0.080 \\
(0.270)\end{array}$ & $\begin{array}{l}0.111 \\
(0.150)\end{array}$ \\
\hline Autonomy & $\begin{array}{l}-0.038 \\
(0.091)\end{array}$ & $\begin{array}{l}-0.006 \\
(0.064)\end{array}$ \\
\hline Performance payments & $\begin{array}{l}-0.411 \\
(0.277)\end{array}$ & $\begin{array}{l}0.245^{*} \\
(0.128)\end{array}$ \\
\hline \multicolumn{3}{|l|}{ Feedback } \\
\hline Positive feedback & $\begin{array}{l}-0.052 \\
(0.100)\end{array}$ & $\begin{array}{l}-0.053 \\
(0.068)\end{array}$ \\
\hline Critical feedback & $\begin{array}{l}0.101 \\
(0.098)\end{array}$ & $\begin{array}{l}-0.048 \\
(0.067)\end{array}$ \\
\hline \multicolumn{3}{|l|}{ Control variables } \\
\hline Age & $\begin{array}{l}0.003 \\
(0.009)\end{array}$ & $\begin{array}{l}-0.012^{* *} \\
(0.006)\end{array}$ \\
\hline Female & $\begin{array}{l}0.282 \\
(0.248)\end{array}$ & $\begin{array}{l}-0.004 \\
(0.142)\end{array}$ \\
\hline Years of schooling & $\begin{array}{l}-0.005 \\
(0.039)\end{array}$ & $\begin{array}{l}0.037 \\
(0.026)\end{array}$ \\
\hline Number of children & $\begin{array}{l}-0.077 \\
(0.082)\end{array}$ & $\begin{array}{l}0.038 \\
(0.049)\end{array}$ \\
\hline Constant & $\begin{array}{l}-0.833 \\
(0.953)\end{array}$ & $\begin{array}{l}-0.662 \\
(0.522)\end{array}$ \\
\hline Industry dummies & yes & yes \\
\hline $\mathrm{N}$ & 266 & 594 \\
\hline Pseudo R-squared & 0.1728 & 0.0835 \\
\hline $\begin{array}{l}\text { Log Likelihood } \\
\text { Model: Probit }\end{array}$ & -155.5700 & -372.155 \\
\hline
\end{tabular}

Note: Female and full-time status partner are dummy variables equal to one when someone is female and has a partner working full-time respectively, and zero otherwise. Industry dummies are included. We separate 13 industries, in the regressions, one is left out. Beta coefficients are reported. Standard errors in parentheses; ${ }^{*} \mathrm{p}<0.1,{ }^{* *} \mathrm{p}<0.05,{ }^{* * *} \mathrm{p}<0.01$. 
Table 2.8: Negative binomial regression results on number of training courses attended

\begin{tabular}{|c|c|c|}
\hline $\begin{array}{l}\text { Dep. Var.: Number of trainings attended } \\
\text { Psychological Characteristics }\end{array}$ & Part-time Workers & Full-time Workers \\
\hline Imagination & $\begin{array}{l}0.269^{* *} \\
(0.105)\end{array}$ & $\begin{array}{l}0.115^{*} \\
(0.061)\end{array}$ \\
\hline Learning motivation & $\begin{array}{l}0.393^{* * *} \\
(0.114)\end{array}$ & $\begin{array}{l}0.200^{* * *} \\
(0.062)\end{array}$ \\
\hline Human Resource Development & & \\
\hline Performance interview & $\begin{array}{l}0.258 \\
(0.319)\end{array}$ & $\begin{array}{l}0.362^{* *} \\
(0.173)\end{array}$ \\
\hline Personal development plan & $\begin{array}{l}0.300 \\
(0.221)\end{array}$ & $\begin{array}{l}0.501^{* * *} \\
(0.130)\end{array}$ \\
\hline Career plan & $\begin{array}{l}-0.110 \\
(0.270)\end{array}$ & $\begin{array}{l}-0.225 \\
(0.145)\end{array}$ \\
\hline High Performance Workplace & & \\
\hline Team meetings & $\begin{array}{l}0.181 \\
(0.314)\end{array}$ & $\begin{array}{l}-0.046 \\
(0.155)\end{array}$ \\
\hline Autonomy & $\begin{array}{l}-0.093 \\
(0.093)\end{array}$ & $\begin{array}{l}-0.047 \\
(0.065)\end{array}$ \\
\hline Performance payments & $\begin{array}{l}0.049 \\
(0.298)\end{array}$ & $\begin{array}{l}0.141 \\
(0.128)\end{array}$ \\
\hline Feedback & & \\
\hline Positive feedback & $\begin{array}{l}-0.032 \\
(0.111)\end{array}$ & $\begin{array}{l}-0.057 \\
(0.072)\end{array}$ \\
\hline Critical feedback & $\begin{array}{l}-0.049 \\
(0.105)\end{array}$ & $\begin{array}{l}0.004 \\
(0.067)\end{array}$ \\
\hline Control variables & & \\
\hline Age & $\begin{array}{l}0.010 \\
(0.010)\end{array}$ & $\begin{array}{l}-0.008 \\
(0.006)\end{array}$ \\
\hline Female & $\begin{array}{l}0.599 * * \\
(0.286)\end{array}$ & $\begin{array}{c}-0.068 \\
(0.144)\end{array}$ \\
\hline Years of schooling & $\begin{array}{l}-0.008 \\
(0.040)\end{array}$ & $\begin{array}{l}0.029 \\
(0.026)\end{array}$ \\
\hline Number of children & $\begin{array}{l}-0.056 \\
(0.084)\end{array}$ & $\begin{array}{l}0.016 \\
(0.051)\end{array}$ \\
\hline Constant & $\begin{array}{c}-1.832^{*} \\
(1.067)\end{array}$ & $\begin{array}{l}-0.513 \\
(0.523)\end{array}$ \\
\hline Industry dummies & yes & yes \\
\hline $\mathrm{N}$ & 270 & 594 \\
\hline Pseudo R-squared & 0.0809 & 0.0400 \\
\hline $\begin{array}{l}\text { Log Likelihood } \\
\text { Model: Negative Binomial Regression }\end{array}$ & -349.828 & -937.176 \\
\hline
\end{tabular}

Note: Female and full-time status partner are dummy variables equal to one when someone is female and has a partner working full-time respectively, and zero otherwise. Industry dummies are included. We separate 13 industries, in the regressions, one is left out. Beta coefficients are reported. Standard errors in parentheses; * $\mathrm{p}<0.1,{ }^{* *} \mathrm{p}<0.05,{ }^{* * *} \mathrm{p}<0.01$. 
Table 2.9: OLS results on informal learning (as fraction of work time)

\begin{tabular}{|c|c|c|}
\hline $\begin{array}{l}\text { Dep.Var.: Informal learning } \\
\text { Psychological Characteristics }\end{array}$ & Part-time Workers & Full-time Workers \\
\hline Imagination & $\begin{array}{l}0.060^{* * *} \\
(0.017)\end{array}$ & $\begin{array}{l}0.010 \\
(0.012)\end{array}$ \\
\hline Learning motivation & $\begin{array}{l}0.011 \\
(0.018)\end{array}$ & $\begin{array}{l}0.019 \\
(0.012)\end{array}$ \\
\hline \multicolumn{3}{|c|}{ Human Resource Development } \\
\hline Performance interview & $\begin{array}{l}0.001 \\
(0.050)\end{array}$ & $\begin{array}{l}-0.029 \\
(0.030)\end{array}$ \\
\hline Personal development plan & $\begin{array}{l}0.047 \\
(0.041)\end{array}$ & $\begin{array}{l}0.025 \\
(0.026)\end{array}$ \\
\hline Career plan & $\begin{array}{l}-0.007 \\
(0.050)\end{array}$ & $\begin{array}{l}0.019 \\
(0.029)\end{array}$ \\
\hline \multicolumn{3}{|c|}{ High Performance Workplace } \\
\hline Team meetings & $\begin{array}{l}0.033 \\
(0.048)\end{array}$ & $\begin{array}{l}0.048^{*} \\
(0.029)\end{array}$ \\
\hline Autonomy & $\begin{array}{l}-0.014 \\
(0.017)\end{array}$ & $\begin{array}{l}0.006 \\
(0.012)\end{array}$ \\
\hline Performance payments & $\begin{array}{l}-0.033 \\
(0.051)\end{array}$ & $\begin{array}{l}-0.006 \\
(0.024)\end{array}$ \\
\hline \multicolumn{3}{|l|}{ Feedback } \\
\hline Positive feedback & $\begin{array}{l}-0.004 \\
(0.019)\end{array}$ & $\begin{array}{l}0.041^{* * *} \\
(0.013)\end{array}$ \\
\hline Critical feedback & $\begin{array}{l}0.034^{*} \\
(0.019)\end{array}$ & $\begin{array}{l}0.031^{* *} \\
(0.013)\end{array}$ \\
\hline \multicolumn{3}{|l|}{ Control variables } \\
\hline Age & $\begin{array}{l}-0.005^{* * *} \\
(0.002)\end{array}$ & $\begin{array}{l}-0.003^{* * *} \\
(0.001)\end{array}$ \\
\hline Female & $\begin{array}{l}-0.062 \\
(0.045)\end{array}$ & $\begin{array}{l}0.010 \\
(0.027)\end{array}$ \\
\hline Years of schooling & $\begin{array}{l}0.012 \\
(0.007)\end{array}$ & $\begin{array}{l}0.007 \\
(0.005)\end{array}$ \\
\hline Number of children & $\begin{array}{l}-0.009 \\
(0.016)\end{array}$ & $\begin{array}{l}-0.003 \\
(0.009)\end{array}$ \\
\hline Constant & $\begin{array}{l}0.453^{* *} \\
(0.175)\end{array}$ & $\begin{array}{l}0.297^{* * *} \\
(0.100)\end{array}$ \\
\hline Industry dummies & yes & yes \\
\hline $\mathrm{N}$ & 270 & 594 \\
\hline $\begin{array}{l}\text { Adjusted R Squared } \\
\text { Model: OLS }\end{array}$ & 0.088 & 0.145 \\
\hline
\end{tabular}

Note: Female and full-time status partner are dummy variables equal to one when someone is female and has a partner working full-time respectively, and zero otherwise. Industry dummies are included. We separate 13 industries, in the regressions, one is left out. Standard errors in parentheses; ${ }^{*} \mathrm{p}<0.1,{ }^{*} \mathrm{p}<0.05,{ }^{*} * * \mathrm{p}<0.01$. 
3 Part-Time Pay Penalty 


\subsection{Introduction}

This chapter focuses on the role human capital plays in the part-time pay penalty (PTPP). ${ }^{1}$ Several studies find a wage penalty for part-time employment, even after controlling for worker and job characteristics (e.g., Hirsch 2005; Baffoe-Bonnie 2004; Ermisch and Wright 1993). Manning and Petrongolo (2008) show, however, that controlling for a worker's occupation reduces the PTPP in Britain from 11.6\% to $2.5 \%$. This suggests that the occupational segregation of part-time workers explains a large part of the British PTPP.

In this chapter, we analyze whether the human capital characteristics of occupations can explain the PTPP. We distinguish between (1) the extent to which differences in human capital characteristics across occupations can explain the PTPP related to the occupational segregation of part-timers and full-timers and (2) the extent to which differences in the human capital accumulation of part-timers, compared to full-timers in the same occupation, can explain the remaining occupation-specific PTPPs. ${ }^{2}$ Our contribution is twofold. ${ }^{3}$ First, we show an underlying reason for the PTPP related to the occupational segregation of part-timers found by Manning and Petrongolo (2008). Second, we are the first to study the heterogeneity of PTPPs across occupations and explain differences in PTPPs across occupations by differences in human capital accumulation between part-timers and full-timers in the same occupation.

To investigate to what extent differences in the human capital characteristics of occupations capture the segregation effect reported by Manning and Petrongolo (2008), we include four human capital characteristics of occupations in a wage regression, namely, occupational averages with respect to training participation, education level, firm tenure, and potential labor market experience. The analyses of the remaining occupation-specific PTPPs relate occupation-specific PTPPs to the relative

\footnotetext{
${ }^{1}$ This chapter is based on joint work with Andries de Grip and Didier Fouarge. We thank participants of the 2011 ESPE conference in Hangzhou, the 2011 EALE conference in Cyprus, and of the $\mathrm{PhD}$ meeting of ROA for useful comments and suggestions.

${ }^{2}$ In contrast to Britain, where part-time jobs are concentrated in low, badly paid jobs (cf. Gregory and Connolly 2008), part-time employment in Germany is also common in high-skilled occupations. Therefore, the remaining PTPP after controlling for segregation is greater than in Britain.

${ }^{3}$ We do not take selection processes like the occupational choice of part-timers and the choice to work part-time or full-time into account in this chapter. We therefore do not report on the causal effect of part-time employment on wages, but rather document (a) to what extent the PTPP related to the occupational segregation can be explained by human capital characteristics of occupations, and (b) to what extent the PTPP differs across occupations and whether the occupational-specific PTPPs depend on relative training participation of part-timers compared to full-timers.
} 
human capital accumulation of part-timers compared to full-timers in the same occupations. The relative human capital accumulation concerns the relative training participation, education level, firm tenure, and potential labor market experience of part-timers compared to full-timers.

Using the German Socio-Economic Panel (GSOEP), we show that the segregation of part-timers can explain almost $30 \%$ of the German PTPP. This segregation effect is largely based on differences in occupational human capital characteristics. Even if the occupational segregation of part-timers is controlled for, the remaining PTPP is still about 5.1\%. This means that within occupations part-timers earn, on average, $5.1 \%$ lower hourly wages than full-timers.

However, there is great heterogeneity in the PTPP across occupations. We find that the relative human capital accumulation of part-timers relative to fulltimers in the same occupation explains this heterogeneity. In occupations in which part-timers have, for example, lower training participation rates than full-timers, we observe significant and sometimes large PTPPs. Conversely, in occupations in which the training participation of part-timers is similar to that of full-timers, we do not observe a PTPP. This similar training participation seems to be due to the need to continuously accumulate human capital to keep up with changing skill demands in these occupations. We find that part-timers in these occupations have to invest more than full-timers in their own training in terms of both direct training costs and opportunity costs.

This chapter is organized as follows: Section 3.2 presents a brief overview of the related literature. Section 3.4 presents our research framework. Section 3.3 describes the data and presents some descriptive evidence. Section 3.5 reports our findings related to the role the human capital characteristics of occupations play in explaining the PTPP related to segregation. Section 3.6 reports and discusses our findings with respect to occupation-specific PTPPs. Section 3.7 concludes this chapter.

\subsection{Related literature}

Studies related to part-time employment often find that being employed part-time has negative wage effects (e.g., Ermisch and Wright 1993), although this wage penalty decreases when selection into part-time employment is taken into account. Aaronson and French (2004) used instrumental variables to show that part-time working men earn substantially lower wages than full-time working men, but there is only weak 
evidence for such a relation for women. Baffoe-Bonnie (2004) controlled for worker characteristics, labor market conditions, and sample selection: The wage differentials between part-timers and full-timers are reduced by $10 \%$, but a gap remains. The author argued that the remaining gap is probably due to lesser work experience and the lower accumulation of human capital. Hirsch (2005) controlled for both worker and job characteristics and concluded that the wage gap between part-time and fulltime workers can largely be attributed to differences in these characteristics. As Baffoe-Bonnie (2004), Hirsch (2005) argued that the remaining wage gap is probably due to lower human capital accumulation. ${ }^{4}$

Manning and Petrongolo (2008) found that including worker and job characteristics halves the PTPP among British women; however, including occupation dummies reduced the part-time penalty from $11.6 \%$ to $2.5 \%$. The authors concluded that occupational segregation explains most of the part-time pay gap that is unexplained by worker and job characteristics. Manning and Petrongolo (2008) gave several potential reasons for this decrease in PTPP related to occupational segregation: (1) Part-time workers prefer a lower-level occupation even when working part-time is possible in high-level occupations; (2) part-time working women are restricted to jobs close to home, resulting in the underutilization of skills; and (3) employers do not allow part-time contracts in all kinds of jobs.

Employers do not offer part-time contracts in all kinds of jobs because parttime workers work too few hours to compensate for their training costs. Human capital theory predicts that part-time workers will invest less in their human capital than full-time workers. Compared to full-timers, part-timers have lower incentives to invest in their own training. Moreover, employers are expected to be more willing to invest in full-time workers than in part-time workers because the numbers of hours worked to deliver returns for the employer is higher for full-time workers than for part-time workers. In Chapter 2, we found that training participation is indeed lower among part-timers than among full-timers, and that this is especially due to the lower incentive of employers to invest in part-time workers. ${ }^{5}$

The majority of papers on the PTPP deal with the average PTPP. According to Fernández-Kranz and Rodriguez-Planas (2011), this may be due to the small sample sizes of part-time workers. There are some exceptions, however: A couple of studies analyze the PTPP separately for men and women (e.g., Booth and Wood 2008, Hirsch 2005). Fernández-Kranz and Rodriguez-Planas (2011) differentiated between women with fixed-term versus permanent contracts and found that the PTPP is

\footnotetext{
${ }^{4}$ Only the studies of Wolf $(2002,1998)$ and Schwarze (1998) deal with the German PTPP.

${ }^{5}$ Due to insufficient observations in the data, Chapter 2 did not deal with occupational differences.
} 
larger and more persistent for women with fixed-term contracts. Most closely related to our study is the work of O'Connell and Gash (2003), who distinguished between skilled and unskilled workers employed in the primary and secondary labor markets, respectively. The authors found that women working in the primary sectors of the labor market have higher hourly wages than those in the secondary labor market. ${ }^{6}$

\subsection{Data and descriptive statistics}

Our analyses use data from the GSOEP. ${ }^{7}$ We use the waves 1994-2008 and restrict the sample in several ways. First, we only include workers living in West Germany, because the East German labor market is still very different. We also exclude male workers and the self-employed, since they rarely work part-time. Workers younger than 20 or older than 55 are also excluded. For the former, part-time work is likely to relate to student jobs, whereas for the latter part-time work may involve partial retirement. Our sample contains 31,929 observations, of 6,854 individuals. A total of $43 \%$ of the women in the sample reported themselves as being employed part-time. While part-time employment is not concentrated solely in low-skilled occupations, it is not distributed equally across occupations either: Whereas in high-skilled occupations $38 \%$ of the workers are employed part-time, in low-skilled occupations $47 \%$ are.

Part-time pay penalty We are interested in the PTPP, which can be estimated from a wage regression that includes a dummy variable denoting whether or not someone works part-time. The GSOEP includes both the actual work hours as well as a subjective measure of part-time employment. As Manning and Petrongolo (2008) did, we prefer the subjective measure of part-time employment. ${ }^{8}$ Gross hourly wages are expressed in 2005 prices. As is standard in the literature on part-time em-

\footnotetext{
${ }^{6}$ There are also studies that focused on particular groups of part-timers, for example, those in the nonprofit sector (Mocan and Tekin 2003) and men (e.g. O'Dorchai, Plasman, and Rycx 2007)

${ }^{7}$ As pointed out by for example Frick and Grabka (2010), survey data is not optimal for analyzing wages. Nevertheless the GSOEP is a very rich data set which is widely used in studies on earnings (e.g., Dustmann, Ludsteck, and Schönberg 2009, Wolf 2002, Hunt 1999). Administrative data might have better quality of wage data but lacks important variables needed to analyze the question at hand. In line with the suggestion from Frick and Grabka (2010), we have included a dummy denoting whether wage data is imputed. Whereas this dummy was significant, the coefficients of interest barely changed.

${ }^{8}$ However, our results also hold when we use the objective measure of working fewer than 33 hours per week.
} 
Figure 3.1: Age-earning profiles of part-time and full-time workers

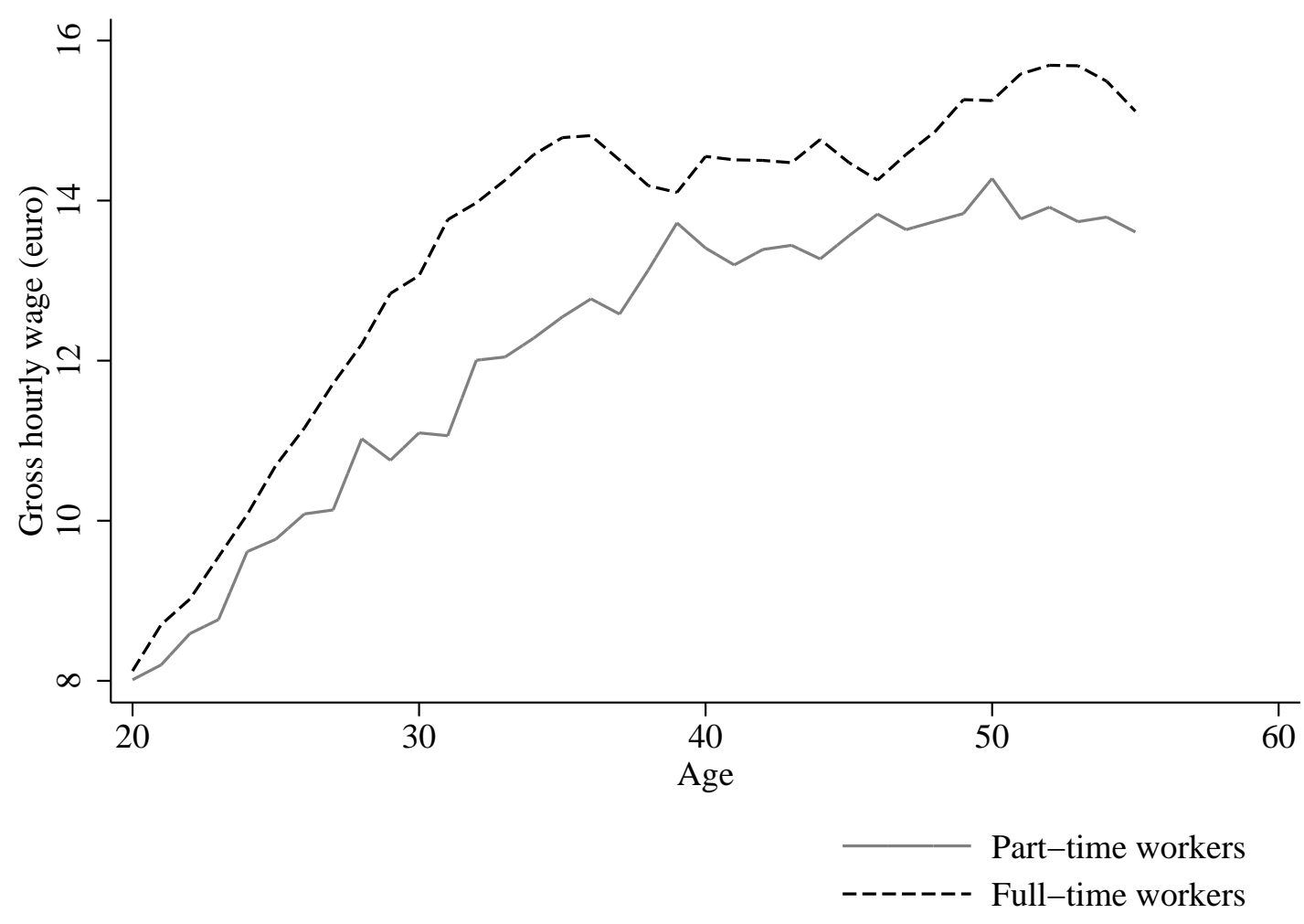

Source: GSOEP (1994-2008)

ployment, we control for age, education, job tenure, career interruption, the number of children, employer size, and industry to estimate the PTPP. ${ }^{9}$

In Figure 3.1, we plot the age-earnings profiles of part-time and full-time workers based on the raw data. At all ages, the hourly wages of part-time workers are lower than those of full-timers, and for workers aged 30-40 years the wage differential is substantial. However, this plot does not control for any differences in worker or job characteristics or for workers' occupational choices. As other studies have shown (e.g., Manning and Petrongolo 2008, Ermisch and Wright 1993), taking these differences between part-time and full-time workers into account substantially reduces the PTPP.

Figure 3.2 distinguishes between the age-earning profiles of part-timers and full-

\footnotetext{
${ }^{9}$ These variables form the vector $\mathbf{X}_{i}$ in Equations (3.1) to (3.3).
} 
Figure 3.2: Age-earning profiles of part-time and full-time workers in high and low skilled occupations
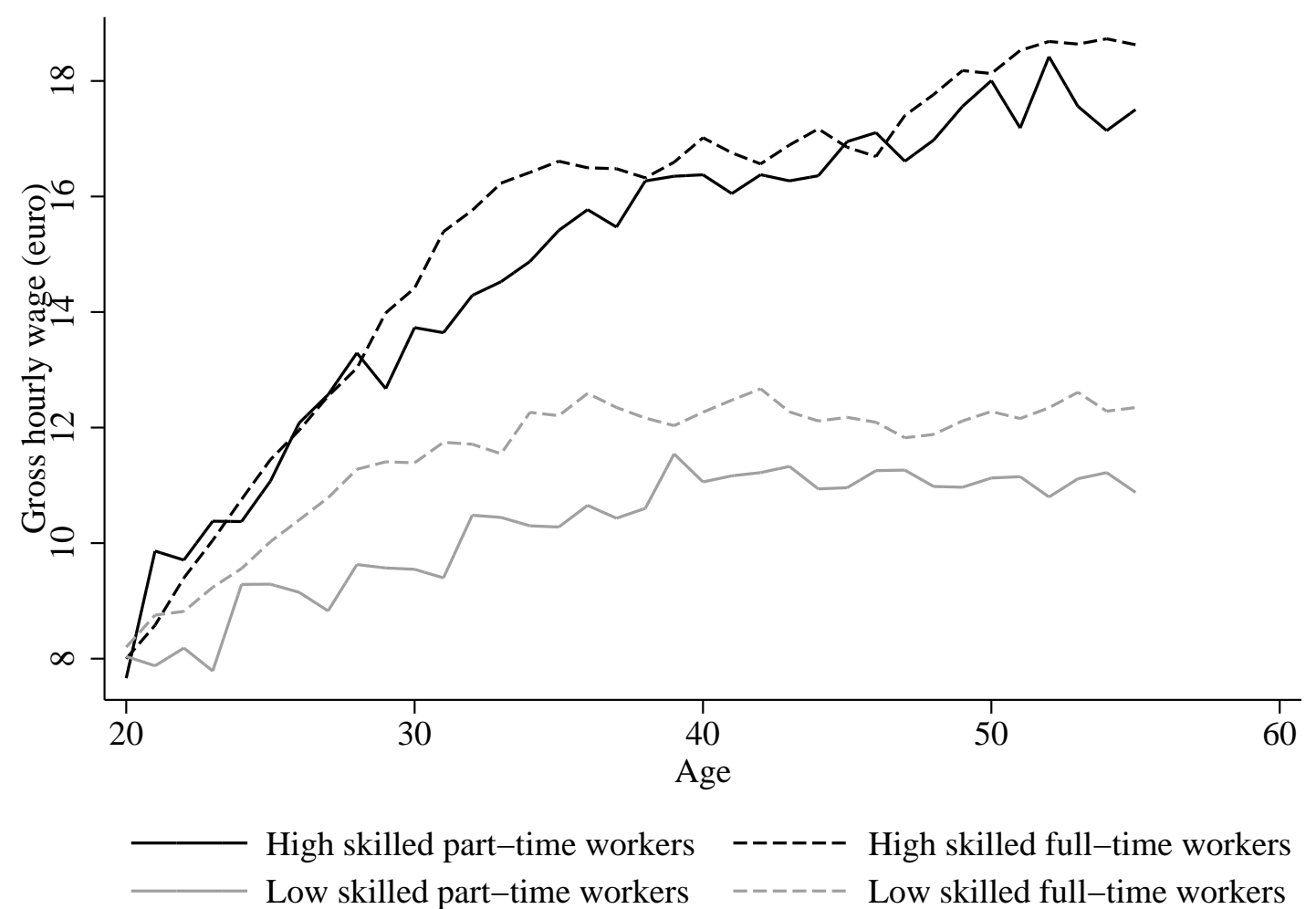

Source: GSOEP (1994-2008)

Note: High skilled occupations are defined as occupations with a one digit code of 1 , 2, or 3 . All other occupations are defined as low skilled occupations.

timers in high- and low-skilled occupations separately. ${ }^{10}$ It provides first evidence of the importance of the human capital characteristics of occupations in explaining the PTPP. While there is still a clear difference in the hourly wages of part-time and fulltime workers in low-skilled occupations, it is smaller in high-skilled occupations. ${ }^{11}$

Human capital variables Information on human capital investments is available from the GSOEP at the individual level. Every GSOEP wave provides information

\footnotetext{
${ }^{10}$ To determine occupations' skill level, occupations are categorized by their one-digit International Standard Classification of Occupations (ISCO-88) codes. Those with a one-digit ISCO-88 code of 1 to 3 are defined as high-skilled occupations; those with a one-digit code of 4 to 9 are defined as low skilled.

${ }^{11}$ Ordinary least squares (OLS) analyses show that the PTPP in high-skilled occupations is $2.5 \%$, whereas that in low-skilled occupations is $9.8 \%$.
} 
on three human capital characteristics of individuals: first, workers' education level, measured by years of education ${ }^{12}$; second, workers' firm tenure, which can be seen as a proxy for experience-related firm-specific human capital accumulation (though formal and informal learning; see Chapter 2); and, third, based on workers' age and years of education, we calculate workers' potential experience. This last variable can be seen as a proxy for experience-related general knowledge acquired by human capital accumulation. In the GSOEP waves 2000, 2004, and 2008, respondents were asked whether they participated in work-related training during the last three years. This variable is used to determine training participation at the individual level.

From the individual data on these four different types of human capital investments, we determine the (1) occupational averages and (2) relative human capital investments of part-timers compared to full-timers for each three-digit ISCO-88 occupation code. ${ }^{13}$ Relative training participation in occupations is calculated by $\frac{T P_{p t}}{T P_{f t}}$, where $T P_{p t}$ and $T P_{f t}$ denote the average training participation of part-timers and full-timers, respectively. The other human capital characteristics of occupational groups are calculated similarly. ${ }^{14}$

The analyses in which the PTPP at the occupation level is the dependent variable exclude occupations with fewer than 80 women or fewer than 50 part-time working women because of the small sample sizes. ${ }^{15}$

\subsection{Empirical strategy}

Segregation of part-timers Our starting point is the study of Manning and Petrongolo (2008), which deals with the PTPP among British women. Manning and Petrongolo (2008) found that including occupation dummies in a wage regression decreases the PTPP to only 2.5\%. Although part-time jobs in Britain are highly concentrated in low-skilled occupations, in Germany part-time jobs are more widespread and common in high-skilled occupations as well. Therefore, the role of occupational segregation in explaining the PTPP is likely to be different in Germany than in Britain. First, we analyze to what extent the German PTPP can be explained by the occupational segregation of part-time workers. For this, we estimate Equation

\footnotetext{
${ }^{12}$ This variable is constructed by the GSOEP team based on a worker's highest level of education. ${ }^{13} \mathrm{We}$ calculate the averages and relative averages of part-timers compared to full-timers over all available years. We do not compute occupational averages or relative measures per year, because we also estimate the PTPP over all years.

${ }^{14}$ See the Appendix for a table of the four human capital characteristics of occupational groups.

${ }^{15}$ When there was no three-digit ISCO-88 code occupation within a two-digit code large enough to include in our analyses, we included occupations at the two-digit level (if these included at least 50 part-time working women). The occupation codes in question were $61,71,73,74$, and 82.
} 
(3.1) by OLS, where $y_{i}$ is the gross hourly wage (in logs) and $P T_{i}$ is a dummy variable equal to one if someone works part-time, and zero otherwise. The vector $\mathbf{X}_{i}$ includes common worker and job characteristics as described in Section 3.3, and $\mathbf{O C C} \mathbf{C}_{i}$ denotes a vector of occupation dummies. The coefficient $\beta_{1}$ indicates the remaining PTPP after controlling for the segregation of part-timers. ${ }^{16}$

Second, we analyze to what extent this segregation can be captured by differences in the human capital characteristics of occupations. ${ }^{17}$ Instead of including occupation dummies, we include occupational averages with respect to training participation, education level, firm tenure, and potential experience for each individual $i$ working in a certain occupation. These human capital characteristics of occupations are represented by the vector $\mathbf{a H C}{ }_{i}$ in Equation (3.2): ${ }^{18}$

$$
\begin{gathered}
Y_{i}=\alpha_{1}+\beta_{1} P T_{i}+\gamma_{1} \mathbf{X}_{i}+\delta_{1} \mathbf{O C C}_{i}+\varepsilon_{1 i} \\
Y_{i}=\alpha_{2}+\beta_{2} P T_{i}+\gamma_{2} \mathbf{X}_{i}+\theta_{2} \mathbf{a H C}_{i}+\varepsilon_{2 i}
\end{gathered}
$$

The term $\frac{\beta_{2}-\beta_{1}}{\beta_{1}} * 100 \%$ measures the extent to which differences in the human capital characteristics of occupations explain the PTPP related to segregation (cf. Manning and Petrongolo 2008). We expect part-timers to earn, on average, lower wages than full-timers because the former are concentrated in occupations with lower human capital requirements.

Occupation-specific PTPPs Since part-time employment in Germany is common in high-skilled occupations, we do not expect the segregation of part-timers to fully explain this country's PTPP. This means that we expect a PTPP within occupations as well. This expectation results directly from human capital theory, which predicts that part-timers will invest less in their human capital than full-timers.

Because there are differences in skill demands across occupations, we expect the degree to which part-timers train less than full-timers to differ across occupations. This is due to heterogeneity in the need to train to keep skills up-to-date. For example, Görlich and De Grip (2009) showed that skills depreciation is greater in high-skilled than in low-skilled occupations. This heterogeneity in skills depreciation

\footnotetext{
${ }^{16}$ This equation is similar to the basic model of Manning and Petrongolo (2008).

${ }^{17}$ Beblo and Wolf (2002) showed that deviations from full-time employment for German women are associated with significant wage cuts. The authors argued that this is due to the depreciation of human capital during periods of part-time employment.

${ }^{18}$ We compute robust standard errors by clustering at the occupation level.
} 
is expected to cause heterogeneity in the relative training participation of part-timers compared to full-timers. This, in turn, may result in heterogeneity in the PTPP across occupations.

Therefore, we calculate occupation-specific PTPPs and analyze to what extent occupation-specific PTPPs are due to differences in the relative training participation of part-timers compared to full-timers. Therefore, we first estimate Equation (3.3) in which we estimate the part-time pay penalty of each occupation based on individual data.

$$
Y_{i j}=\alpha_{3 j}+\beta_{3 j} P T_{i j}+\gamma_{3 j} \mathbf{X}_{i j}+\varepsilon_{3 i j}
$$

for each occupation $j$. This provides us with $J$ estimates of occupationalspecific PTPPs $\left(\hat{\beta_{3 j}}\right)$. Then, we estimate Equation $(3.4)$ in which the estimated occupational-specific PTPPs are the dependent variable. We explain the estimated occupational-specific PTPPs by the relative difference of human capital characteristics of part-timers compared to full-timers employed in occupation $j$. The human capital characteristics we include are the relative training participation, number of years of schooling, firm tenure, and potential experience of part-timers compared to full-timers. ${ }^{19}$

$$
\hat{\beta_{3 j}}=\eta+\zeta \mathbf{r H C}{ }_{j}+\epsilon_{j}
$$

We expect the PTPP to be lower in occupations in which part-timers and full-timers have similar human capital accumulation than in occupations in which full-timers accumulate more human capital than part-timers. We especially expect the relative training participation of part-timers compared to full-timers to play a role, since human capital theory predicts part-timers will invest less in human capital than full-timers. Such a theoretical foundation is absent for the other relative human capital accumulation variables (education level, firm tenure, and potential experience). ${ }^{20}$

\footnotetext{
${ }^{19}$ As defined by $r H C=\frac{H C_{P T}}{H C_{F T}}$.

${ }^{20}$ These variables are nevertheless included, since they may be correlated to the relative training participation of part-timers compared to full-timers.
} 


\subsection{PTPP related to segregation}

Table 3.1 estimates the average PTPP in Germany over the years 1994-2008. In Column (1), we control for standard worker and job characteristics. ${ }^{21}$ The PTPP is 7.2\%. In Column (2), we follow Manning and Petrongolo (2008) by including threedigit occupation codes. This reduces the PTPP by 2.1\%-points to $5.1 \%$. This means that the segregation of part-time workers explains $30 \%$ of the PTPP when controlled for worker and job characteristics. In Column (3), we report to what extent the PTPP related to segregation is based on the human capital characteristics of occupations. Instead of using occupation codes, we use the average training participation rate, education level, tenure, and potential experience among workers within occupations.

Table 3.1: OLS estimation of average part-time pay penalty

\begin{tabular}{|c|c|c|c|}
\hline Dep. Var.: Gross hourly wage & (1) & $(2)$ & $(3)$ \\
\hline Part-time $(=1)$ & $\begin{array}{l}-0.072^{* * *} \\
(0.015)\end{array}$ & $\begin{array}{l}-0.051^{* * *} \\
(0.009)\end{array}$ & $\begin{array}{l}-0.055^{* * *} \\
(0.010)\end{array}$ \\
\hline Average training participation & & & $\begin{array}{l}0.471^{* * *} \\
(0.072)\end{array}$ \\
\hline Average education level & & & $\begin{array}{l}0.038^{* * *} \\
(0.006)\end{array}$ \\
\hline Average tenure & & & $\begin{array}{l}0.004 \\
(0.004)\end{array}$ \\
\hline Average potential experience & & & $\begin{array}{l}0.002 \\
(0.003)\end{array}$ \\
\hline Constant & $\begin{array}{l}0.463^{* * *} \\
(0.089)\end{array}$ & $\begin{array}{l}1.175^{* * *} \\
(0.123)\end{array}$ & $\begin{array}{l}0.213^{*} \\
(0.121)\end{array}$ \\
\hline Worker and job characteristics & yes & yes & yes \\
\hline Occupation dummies & no & yes & no \\
\hline Adjusted R-squared & 0.440 & 0.503 & 0.488 \\
\hline $\mathrm{N}$ & 31929 & 31929 & 31929 \\
\hline \multicolumn{4}{|c|}{$\begin{array}{l}\text { Source: GSOEP (1994-2008) } \\
\text { Note: Worker and job characteristics are age (and age squared), number of } \\
\text { children, years of schooling, job tenure, career interruption, firm size, and in- } \\
\text { dustry. Year dummies are included as well. Average training participation } \\
\text { rates, education level, tenure and age are calculated as occupational averages } \\
\text { over the years } 2000,2004 \text { and } 2008 \text {. Standard errors are clustered by occupa- } \\
\text { tions. }{ }^{*} \mathrm{p}<0.1 ;{ }^{* *} \mathrm{p}<0.05 ;{ }^{* *}<0.01 \text {. }\end{array}$} \\
\hline
\end{tabular}

Column (3) of Table 3.1 shows that both the average training participation and average education level of workers within occupations are significantly related to gross hourly wages. This finding shows that wages are higher in occupations in which the average level of education and training participation are relatively high. ${ }^{22}$

${ }^{21}$ Without controlling for worker and job characteristics, the PTPP is $8.2 \%$.

${ }^{22}$ Apart from this effect of a worker's own education level, we also find that the average education 
Including these human capital variables in the wage regression reduces the PTPP to $5.5 \% .^{23}$ This implies that about $80 \%$ of the PTPP related to segregation can be attributed to differences in human capital characteristics across occupations. The average training participation rate and average education level within occupations are especially important in explaining the PTPP related to the segregation of part-timers. As expected, part-time workers appear to be concentrated in occupations that require less training participation to keep their skills up-to-date and that require a lower education level.

\subsection{Heterogeneity in the PTPP across occupations}

\subsubsection{Results}

Even after controlling for occupational segregation, the PTPP in Germany is still about 5.1\%. As Table 3.2 shows, these occupation-specific PTPPs differ considerably across occupations. Part-time workers in low-skilled occupations have a large probability of facing a PTPP: In 10 out of 19 low-skilled occupations, the PTPP is significant, ranging from $6 \%$ to $28 \%$. The observation that part-timers in low-skilled occupations earn lower wages than full-timers within the same occupation may be due to lower investments in the human capital accumulation of part-timers compared to full-timers.

We only observe a PTPP in about a quarter of all high-skilled occupations. Of the 22 high-skilled occupations, six have a PTPP, from $6 \%$ to $23 \%$. The other 16 high-skilled occupations have no significant PTPP. ${ }^{24}$ Since part-time professionals as well as associate professionals receive similar wages as full-timers in the same occupation, we expect to find similar training participation rates as well.

Figure 3.3 plots the occupation-specific part-time coefficients against the relative training participation of part-timers compared to full-timers. It shows that the relative training participation of part-timers compared to full-timers varies across occupations: On average, it is 0.82 , which is, as predicted by human capital theory, below one. However, there are also occupations for which we observe a ratio of about

level of workers within the same occupation is positively related to wages. Such an effect has been reported in the literature on overeducation (e.g., Hartog and Oosterbeek 1988).

${ }^{23}$ If we only include the average training participation rate and leave out the other three human capital characteristics of occupations, the PTPP equals 5.7.

${ }^{24}$ We even observe a part-time pay premium for primary and pre-primary education teaching professionals. This is most likely due to a fixed salary component teaching professionals with children receive in the public sector/teaching sector. 
Table 3.2: Occupational-specific part-time pay penalties

\begin{tabular}{|c|c|c|c|c|c|}
\hline \multicolumn{2}{|c|}{ Occupation } & \multicolumn{2}{|c|}{$\begin{array}{l}\text { Part-time } \\
\text { Coefficient }\end{array}$} & \multirow{2}{*}{$\begin{array}{l}\text { Part-time } \\
\text { Share } \\
0.17\end{array}$} & \multirow{2}{*}{$\begin{array}{l}\text { Size } \\
(=\mathrm{N}) \\
329\end{array}$} \\
\hline 123 & Other Department Managers & -0.11 & $* *$ & & \\
\hline 214 & Architects, Engineers And Related Professionals & -0.17 & $* * *$ & 0.22 & 384 \\
\hline 222 & Health Professionals (Except Nursing) & 0.11 & & 0.47 & 231 \\
\hline 232 & Secondary Education Teaching Professionals & 0.05 & * & 0.63 & 773 \\
\hline 233 & Primary And Pre-Primary Education Teaching Professionals & 0.11 & $* * *$ & 0.65 & 242 \\
\hline 234 & Special Education Teaching Professionals & 0.09 & & 0.60 & 119 \\
\hline 235 & Other Teaching Professionals & 0.01 & & 0.55 & 148 \\
\hline 241 & Business Professionals & -0.04 & & 0.20 & 329 \\
\hline 244 & Social Science And Related Professionals & 0.05 & * & 0.36 & 590 \\
\hline 247 & Public Service Administrative Professionals & -0.08 & $* * *$ & 0.42 & 661 \\
\hline 311 & Physical And Engineering Science Technicians & -0.06 & $* *$ & 0.30 & 586 \\
\hline 312 & Computer Associate Professionals & 0.09 & & 0.41 & 210 \\
\hline 313 & Optical And Electronic Equipment Operators & 0.03 & & 0.66 & 84 \\
\hline 321 & Life Science Technicians And Related Associate Professionals & 0.04 & & 0.39 & 238 \\
\hline 322 & Modern Health Associate Professionals (Except Nursing) & -0.01 & & 0.40 & 387 \\
\hline 323 & Nursing And Midwifery Associate Professionals & -0.01 & & 0.45 & 1490 \\
\hline 332 & Pre-Primary Education Teaching Associate Professionals & 0.01 & & 0.41 & 937 \\
\hline 334 & Other Teaching Associate Professionals & -0.23 & $* * *$ & 0.63 & 99 \\
\hline 341 & Finance And Sales Associate Professionals & -0.15 & $* * *$ & 0.30 & 1303 \\
\hline 343 & Administrative Associate Professionals & -0.01 & & 0.38 & 2514 \\
\hline 344 & Customs Tax And Related Government Associate Professionals & 0.00 & & 0.41 & 1055 \\
\hline 346 & Social Work Associate Professionals & -0.01 & & 0.43 & 667 \\
\hline 411 & Secretaries And Keyboard-Operating Clerks & -0.07 & $* * *$ & 0.45 & 1082 \\
\hline 412 & Numerical Clerks & -0.12 & $* * *$ & 0.32 & 1429 \\
\hline 413 & Material-Recording And Transport Clerks & -0.05 & & 0.25 & 657 \\
\hline 414 & Library, Mail And Related Clerks & 0.04 & & 0.55 & 271 \\
\hline 419 & Other Office Clerks & -0.06 & $* * *$ & 0.45 & 2133 \\
\hline 421 & Cashiers, Tellers And Related Clerks & -0.04 & & 0.63 & 628 \\
\hline 422 & Client Information Clerks & -0.04 & & 0.43 & 438 \\
\hline 512 & Housekeeping And Restaurant Services Workers & -0.08 & $* * *$ & 0.40 & 1000 \\
\hline 513 & Personal Care And Related Workers & -0.01 & & 0.46 & 1891 \\
\hline 514 & Other Personal Services Workers & -0.02 & & 0.34 & 286 \\
\hline 522 & Shop Salespersons And Demonstrators & -0.07 & $* * *$ & 0.58 & 2066 \\
\hline 913 & Domestic And Related Helpers, Cleaners And Launderers & -0.07 & $* * *$ & 0.73 & 1381 \\
\hline 914 & Building Caretakers, Window And Related Cleaners & -0.28 & $* * *$ & 0.52 & 103 \\
\hline 932 & Manufacturing Laborers & -0.05 & & 0.30 & 725 \\
\hline 61 & Skilled Agricultural And Fishery Workers & -0.07 & & 0.36 & 176 \\
\hline 71 & Extraction And Building Trades Workers & -0.15 & $* * *$ & 0.33 & 259 \\
\hline 73 & Precision Handicraft Craft Printing And Related Trades Workers & -0.18 & $* * *$ & 0.28 & 324 \\
\hline 74 & Other Craft And Related Trades Workers & -0.07 & $*$ & 0.22 & 325 \\
\hline 82 & Machine Operators And Assemblers & -0.07 & $* * *$ & 0.22 & 950 \\
\hline
\end{tabular}

Source: GSOEP (1994-2008)

Note: In case there was no three digit occupation within a two digit code large enough (number of workers at least 80 and number of part-time workers at least 50) to include in our analyses, we included occupations on two-digit level (if the two-digit occupation counted at least 50 part-time working women). It concerns occupations: $61,71,73,74$ and 82 .

one. For 15 occupations, of which nine belong to high-skilled occupations, we observe a relative training participation of at least 0.9 (see Table 3.6 in the Appendix).

Moreover, Figure 3.3 shows that there is a positive and significant relation between the relative training participation of part-timers compared to full-timers within occupations and the occupation-specific part-time coefficients. ${ }^{25}$ This means

\footnotetext{
${ }^{25}$ For the relative education level of part-timers compared to full-timers, we find a positive and
} 
Figure 3.3: The relation between occupational-specific PTPPs and relative training participation

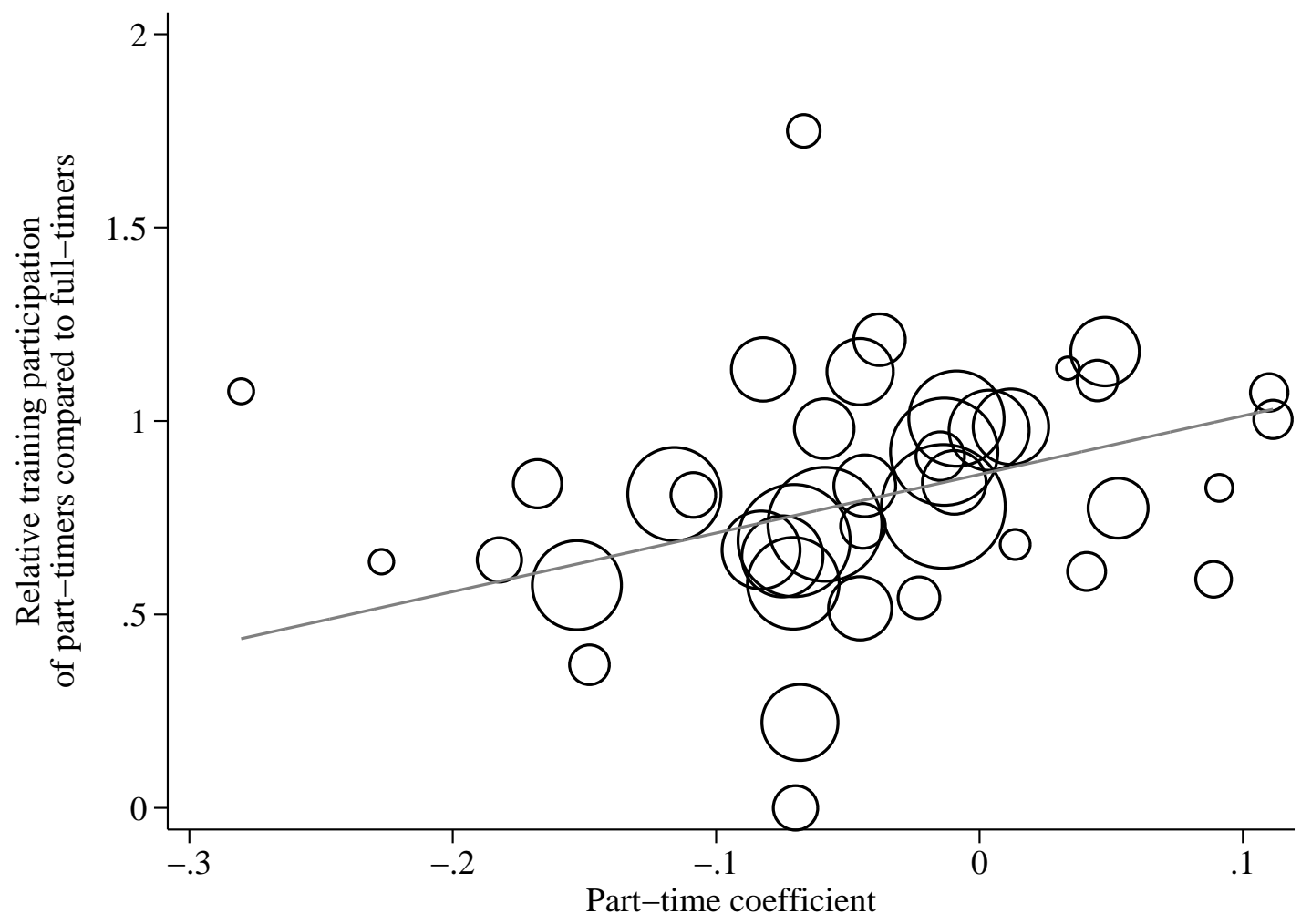

Source: GSOEP (1994-2008)

Note: Every dot refers to a three or two digit occupation. On the Y-axis, the relative human capital accumulation of part-timers compared to full-timers in occupations is plotted. On the X-axis, occupational-specific part-time coefficients are plotted. The correlation is: $0.3782(0.0148)$. Both in the figure as well as in the correlation, we weight the occupational-specific characteristics based on the size of occupations.

that in occupations where the relative training participation is large, the PTPP is low or even absent.

Since the relative training participation of part-timers compared to full-timers may be highly related to other relative human capital investments, we regress the occupation-specific part-time coefficient on the four human capital investment variables that reflect the relative investments of part-timers compared to full-timers. The results are reported in Table 3.3. Again, we find a significant relation between the occupation-specific part-time coefficients and the relative training participation

significant relation as well. For both tenure and potential experience, a significant relation with occupations' PTPP does not exist. 
Table 3.3: OLS estimation of occupational-specific parttime pay penalties

\begin{tabular}{ll}
\hline \hline Dep. Var.: Occupational-specific part-time coefficient & $(1)$ \\
Relative training participation & $0.090^{* *}$ \\
& $(0.037)$ \\
Relative tenure & 0.025 \\
& $(0.037)$ \\
Relative education level & $0.749^{* *}$ \\
& $(0.315)$ \\
Relative potential experience & 0.070 \\
& $(0.094)$ \\
Constant & $-0.979^{* *}$ \\
& $(0.370)$ \\
\hline Adjusted-R-squared & 0.191 \\
N & 41 \\
\hline \hline & Source: GSOEP $(1994-2008)$ \\
Note: Occupational-specific PTPPs are estimated by separate wage equa- \\
tions for each occupation including next to a part-time dummy the follow- \\
ing control variables: age (and age squared), number of children, education, \\
job tenure, career interruption, employer size, and industry. Year dummies \\
are included as well. ${ }^{*}$ p $<0.1 ; * *$ p $<0.05 ; * * *<0.01$.
\end{tabular}

of part-timers compared to full-timers. The adjusted R-squared shows that about $20 \%$ of the difference in occupation-specific part-time coefficients can be explained by the differences in the relative human capital investments of part-timers compared to full-timers. This means that about $20 \%$ of the heterogeneity in occupation-specific PTPPs can be explained by the difference in the human capital accumulation of part-timers compared to full-timers in the same occupation.

\subsubsection{Why similar training participation rates?}

The observation that in most high-skilled occupations part-timers and full-timers have similar training participation rates seems at odds with the predictions of human capital theory. However, human capital theory does not focus on occupational differences. That there are indeed occupational differences in the need to train to keep skills up-to-date is shown by, for example, Görlich and De Grip (2009). These authors showed that skills depreciation is greater in high-skilled occupations than in low-skilled ones.

We expect that, in occupations in which continuous human capital accumulation is necessary to keep up with changing skill demands, part-timers cannot lag behind full-timers, since this would have negative consequences for firm productivity. Therefore, employers probably prefer employing full-timers. However, certain service 
occupations, such as occupations in the health and education sectors, are dominated by female workers. Since many women want to work part-time, a lack of full-time labor supply may force employers to employ part-time workers. ${ }^{26}$ Continuous skill requirements in high-skilled and female-dominated occupations may explain why we observe similar training participation rates among part-time and full-time workers in most (associate) professions.

Another reason for similar training participation rates between part-timers and full-timers is the degree to which those employed in high-skilled professions work autonomously. If workers work closely together, it may not be necessary to train all employees. Employers will then only invest in the workers who provide the highest net returns, leaving the tasks that do not require further training for the untrained workers. Alternatively, employers may expect spill-over effects to partly transfer the acquired human capital to the untrained part-time workers. However, if workers work autonomously, as, for example, teachers, then employers must train all employees to make sure that they all deliver high-quality services. Moreover, autonomy in one's job also implies that workers are able to fulfill a broad range of job tasks. This indicates a high responsibility for keeping their skills up-to-date (cf. Lindbeck and Snower 2000).

Figure 3.4 relates the relative training participation of part-timers compared to full-timers to the training participation of full-timers ${ }^{27}$ in Panel (a) and to the average degree of autonomy within occupations in Panel (b). ${ }^{28}$ Panel (a) of Figure 3.4 shows a positive and significant relation between the relative training participation of parttimers compared to full-timers in the same occupation and the training participation of full-timers. This confirms our expectation that in occupations in which continuous human capital accumulation is required for adequate performance in the job, parttimers have training participation rates similar to those of full-timers.

Panel (b) of Figure 3.4 confirms the expected relation between the relative training participation and the degree of autonomy: In occupations in which workers work more autonomously, part-timers and full-timers have similar training participation rates.

\footnotetext{
${ }^{26}$ This is suggested by the large percentage of part-time working women (83\%) who report being satisfied with their work hours or even wanting to work fewer hours per week.

${ }^{27}$ Since we do not have information on occupations' skills depreciation, we proxy the degree to which training is required to keep up with changing skill demands by the training participation of full-timers.

${ }^{28}$ Autonomy in occupational actions is a variable generated by the GSOEP team.
} 
Figure 3.4: The relation between relative training participation and occupational characteristics

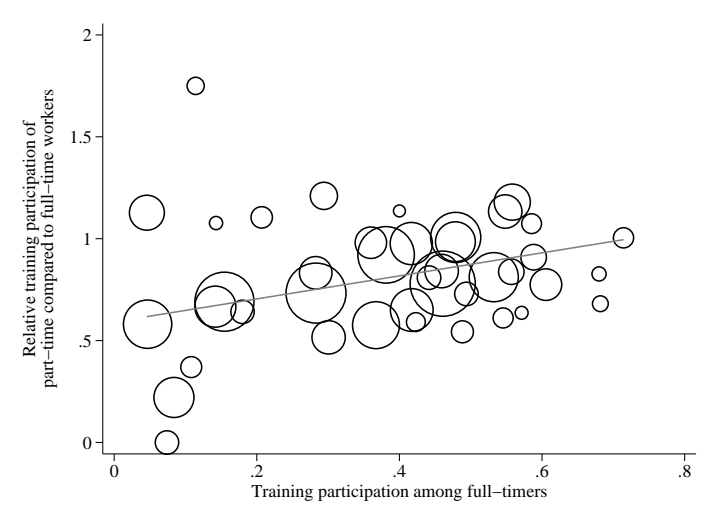

(a) Training participation of full-timers Source: GSOEP (1994-2008)

Note: Every dot refers to a three or two digit occupation. On the Y-axis, the relative training participation of part-timers compared to full-timers in occupations is plotted. On the X-axis, in Panel (a), the training participation rate of full-timers is plotted. The correlation is: 0.4206(0.0086). On the X-axis, in Panel (b), the average degree of autonomy is plotted. The correlation is: 0.4604(0.0036). Both in the figures as well as in the correlations, we weight the occupational-specific characteristics based on the size of occupations.

\subsubsection{Why similar hourly wages?}

Due to the equal training participation rates of part-timers and full-timers, parttimers are expected to be as productive as full-timers. However, the question remains as to why employers pay part-timers similarly to full-timers when the net returns of investing in them are less than those of investing in full-timers.

Instead of paying part-timers a lower hourly wage than full-timers, employers may require part-timers to pay part of the training themselves and/or to lower opportunity costs by training partly outside work hours. Since the GSOEP provides information about training financial support and timing (during or outside work hours), we investigate this possibility.

Table 3.4 shows the percentage of part-time and full-time workers who stated they had received training support from their employer. Whereas almost $70 \%$ of the full-timers received financial support for their training, only $62 \%$ of the part-timers did. A t-test shows that this difference is significant. The degree to which workers are allowed to train during work hours also appears to differ between part-timers and full-timers: $65 \%$ of the full-timers were able to attend their training entirely during work hours, whereas this only holds for $51 \%$ of the part-timers. A t-test shows that 
part-timers are more often able to attend only part of their training during work hours.

Table 3.4: Training support of employer for part-time and full-time workers

\begin{tabular}{lll}
\hline \hline & PT & FT \\
& $\%$ & $\%$ \\
& 62 & 69 \\
Employer provided financial support & 51 & 65 \\
Training completely during work time & 57 & 10 \\
Training partly during work time & 17 & \\
\hline \hline
\end{tabular}

Table 3.5 divides workers into two groups with respect to the training participation of part-timers relative to full-timers in the same occupation. In occupations where the relative training participation is below average (and there is a PTPP), part-timers and full-timers receive equal financial support: The 5\%-points difference is not significant (based on a t-test). For occupations in which the relative training participation is high and no PTPP is found, we find that part-timers receive employer-provided training less often than full-timers. This difference is significant and suggests that instead of a penalty in pay, part-timers face a penalty in training support in the sense that they have to pay for their own human capital investments more often than full-timers in the same occupation. Furthermore, Table 3.5 shows that in both occupation groups, part-timers have to train significantly more often outside work hours than full-timers. However, this difference is greater in occupations in which the relative training participation is higher than average.

Table 3.5: Training support of employer for part-time and full-time workers by occupations' relative training participation

\begin{tabular}{llllll}
\hline \hline & \multicolumn{3}{l}{ relative TP $>=$ mean } & \multicolumn{2}{l}{ relative TP $<$ mean } \\
& PT & FT & PT & FT \\
& $\%$ & $\%$ & $\%$ & $\%$ \\
Employer provided financial support & 62 & 71 & 62 & 67 \\
Training completely during work time & 49 & 64 & 53 & 67 \\
Training partly during work time & 19 & 13 & 14 & 7 \\
\hline \hline
\end{tabular}

Source: GSOEP (2000, 2004, 2008)

Note: Cells denote percentage of workers within sub group who agree with the support statements. Occupations are split by the relative training participation of part-timers and full-timers.

This descriptive evidence supports the idea that part-timers who work in occu- 
pations in which they train as much as full-timers, have to invest significantly more in their own training in terms of both direct training costs and opportunity costs than full-timers in the same occupation. Rather than pay lower hourly wages, employers use this cost-sharing rule to compensate for their lower net returns from investing in part-timers compared to full-timers. The finding that firms support their full-time workers more to invest in their human capital development than part-timers is also reported in Chapter 2.

There may be three other reasons for our finding that employers pay similar wages to similarly trained part-time and full-time workers. First, similar wages may be related to the public nature of these occupations: Most workers in health care and education occupations are employed in non-profit firms. Second, due to the lack of a full-time labor supply in these occupational fields, part-timers may have great bargaining power in asking for similar wages as full-timers. Third, it may be beneficial for firms to employ part-time workers. In Chapter 4, we show, for example, that firm productivity in the pharmacy sector is higher in firms with a large share of part-timers than in firms with a large share of full-timers. Service-sector firms especially provide good conditions for exploiting the allocation efficiencies provided by part-time workers when operating hours are larger than the full-time work week and customer demand fluctuates during the day or work week.

\subsection{Conclusion}

In this chapter, we analyze whether the human capital characteristics of occupations explain the PTPP. We distinguish between (1) the extent to which differences in human capital characteristics across occupations can explain the PTPP related to the occupational segregation of part-timers and full-timers and (2) the extent to which differences in the human capital accumulation of part-timers compared to full-timers can explain the remaining occupation-specific PTPPs. We show that human capital investments across and within occupations explain the PTPP to a large extent.

The occupational segregation of part-time employees explains about $30 \%$ of the German PTPP. After controlling for segregation, a PTPP of about $5.1 \%$ remains. Our results indicate that about $80 \%$ of the PTPP related to segregation can be attributed to differences in training participation and other human capital characteristics of those employed in a particular occupation. Furthermore, we find that occupations differ greatly in their PTPPs. Descriptive evidence shows that the 
PTPP is related to the skill level of occupations, being more prevalent in low-skilled than in high-skilled occupations.

Analyses of occupation-specific PTPPs show that the relative training participation of part-timers compared to full-timers is important in explaining PTPPs across occupations. In occupations where the relative training participation of parttimers compared to full-timers is low, we observe large PTPPs. In occupations in which the relative training participation of part-timers is high and comparable to that of full-timers, we find no PTPP. The relative human capital accumulation of part-timers compared to full-timers explains $20 \%$ of the heterogeneity of the PTPP across occupations.

We find that relative training participation rates are related to the need to continuously accumulate human capital to keep skills up-to-date in an occupation. Moreover, the greater the degree of employee autonomy in occupations, the greater the degree of relative training participation.

Since employers receive higher net returns from training full-time workers than from part-time workers, a lack of full-time labor supply in certain occupations may explain our finding that part-timers are similarly trained as full-timers in some occupations. We show, however, that part-timers must invest significantly more often in their training than full-timers in the same occupation. Part-timers receive less financial support from their employers and have fewer opportunities to train during work hours. These differences can be seen as a levy for part-time employment in professions that require workers to continuously keep their skills up-to-date. 


\section{Appendix}

Table 3.6: Occupational-specific human capital variables

\begin{tabular}{|c|c|c|c|c|c|c|c|c|}
\hline \multirow[t]{2}{*}{ Occupation } & \multicolumn{2}{|c|}{ Training participation } & \multicolumn{2}{|c|}{ Education levels } & \multicolumn{2}{|c|}{ Tenure } & \multicolumn{2}{|c|}{ Potential experience } \\
\hline & average & relative & average & relative & average & tenure & average & relative \\
\hline 123 & 0.43 & 0.81 & 12.79 & 0.93 & 7.89 & 1.22 & 25.38 & 1.17 \\
\hline 214 & 0.53 & 0.84 & 16.01 & 0.97 & 6.53 & 1.20 & 21.12 & 1.25 \\
\hline 222 & 0.58 & 1.07 & 16.81 & 1.02 & 5.55 & 2.20 & 22.06 & 1.49 \\
\hline 232 & 0.59 & 1.18 & 17.45 & 1.01 & 13.51 & 1.15 & 26.27 & 1.15 \\
\hline 233 & 0.72 & 1.00 & 17.57 & 1.03 & 14.18 & 1.32 & 24.88 & 1.18 \\
\hline 234 & 0.62 & 0.83 & 16.72 & 1.02 & 11.32 & 1.70 & 26.58 & 1.16 \\
\hline 235 & 0.58 & 0.68 & 15.47 & 0.95 & 8.07 & 0.69 & 25.41 & 1.00 \\
\hline 241 & 0.45 & 0.73 & 15.20 & 0.95 & 7.67 & 1.03 & 23.42 & 1.08 \\
\hline 244 & 0.53 & 0.77 & 15.25 & 1.04 & 7.31 & 1.35 & 22.95 & 1.19 \\
\hline 247 & 0.58 & 1.13 & 14.97 & 1.00 & 14.49 & 1.15 & 24.78 & 1.12 \\
\hline 311 & 0.33 & 0.98 & 12.09 & 0.99 & 9.44 & 1.17 & 24.10 & 1.20 \\
\hline 312 & 0.34 & 0.59 & 13.82 & 1.04 & 7.55 & 0.82 & 24.81 & 1.14 \\
\hline 313 & 0.45 & 1.14 & 12.03 & 1.01 & 11.76 & 4.37 & 27.94 & 1.42 \\
\hline 321 & 0.43 & 0.61 & 12.65 & 0.97 & 8.34 & 1.32 & 26.57 & 1.40 \\
\hline 322 & 0.56 & 0.91 & 13.41 & 1.00 & 5.18 & 1.18 & 21.62 & 1.39 \\
\hline 323 & 0.45 & 1.01 & 12.16 & 1.02 & 8.83 & 1.37 & 24.94 & 1.18 \\
\hline 332 & 0.45 & 0.99 & 12.72 & 1.01 & 7.49 & 0.88 & 25.01 & 1.17 \\
\hline 334 & 0.50 & 0.64 & 13.87 & 0.92 & 13.93 & 1.01 & 29.09 & 1.04 \\
\hline 341 & 0.32 & 0.58 & 12.23 & 0.98 & 7.40 & 1.22 & 23.50 & 1.32 \\
\hline 343 & 0.40 & 0.78 & 12.03 & 1.00 & 9.01 & 0.98 & 27.08 & 1.14 \\
\hline 344 & 0.41 & 0.98 & 11.82 & 0.98 & 12.67 & 1.09 & 28.05 & 1.16 \\
\hline 346 & 0.42 & 0.84 & 11.29 & 1.01 & 5.72 & 0.91 & 29.79 & 1.08 \\
\hline 411 & 0.33 & 0.65 & 12.01 & 1.00 & 8.86 & 0.84 & 28.74 & 1.12 \\
\hline 412 & 0.49 & 0.81 & 12.29 & 1.00 & 10.64 & 1.20 & 24.12 & 1.24 \\
\hline 413 & 0.24 & 0.52 & 11.84 & 0.95 & 9.11 & 1.05 & 22.94 & 1.38 \\
\hline 414 & 0.20 & 1.10 & 11.47 & 1.01 & 7.24 & 0.71 & 27.15 & 1.17 \\
\hline 419 & 0.22 & 0.73 & 11.59 & 1.00 & 7.81 & 1.00 & 27.21 & 1.21 \\
\hline 421 & 0.22 & 0.83 & 11.25 & 1.02 & 8.81 & 0.73 & 28.10 & 1.03 \\
\hline 422 & 0.30 & 1.21 & 12.13 & 0.98 & 5.40 & 0.94 & 24.13 & 1.21 \\
\hline 512 & 0.11 & 0.67 & 10.54 & 1.00 & 4.77 & 0.81 & 27.32 & 1.07 \\
\hline 513 & 0.36 & 0.92 & 11.35 & 1.03 & 7.03 & 1.08 & 24.63 & 1.36 \\
\hline 514 & 0.31 & 0.54 & 10.69 & 1.00 & 4.79 & 1.04 & 22.50 & 1.30 \\
\hline 522 & 0.11 & 0.69 & 10.85 & 1.00 & 5.58 & 0.98 & 27.83 & 1.23 \\
\hline 913 & 0.03 & 0.58 & 9.80 & 1.07 & 5.30 & 0.85 & 32.51 & 0.97 \\
\hline 914 & 0.12 & 1.08 & 11.09 & 1.00 & 5.72 & 1.05 & 28.77 & 1.03 \\
\hline 932 & 0.04 & 1.13 & 9.99 & 1.08 & 7.72 & 0.57 & 28.96 & 0.91 \\
\hline 61 & 0.11 & 1.75 & 11.05 & 0.96 & 4.68 & 1.02 & 22.44 & 1.30 \\
\hline 71 & 0.05 & 0.37 & 9.93 & 1.02 & 10.11 & 0.76 & 28.66 & 1.03 \\
\hline 73 & 0.00 & 0.64 & 10.71 & 0.97 & 4.56 & 0.86 & 26.66 & 1.11 \\
\hline 74 & 0.23 & 0.00 & 10.68 & 1.05 & 2.94 & 1.00 & 27.92 & 1.08 \\
\hline 82 & 0.05 & 0.22 & 9.91 & 1.06 & 6.98 & 0.74 & 31.14 & 1.01 \\
\hline
\end{tabular}

Source: SOEP (1994-2008; women only).

Note: The relative human capital variables are constructed by $\frac{H C_{p t}}{H C_{f t}}$. 

4 Firm Productivity 


\section{Firm Productivity}

\subsection{Introduction}

This chapter investigates whether the share of part-time employment affects firm productivity. ${ }^{1}$ In many countries, the fraction of the workforce working part-time is large, especially among females. In the European Union, almost one third of the prime aged women work part-time (Eurostat 2010), while in the United States about $27 \%$ of the workforce in non-agricultural related industries has a part-time job (Bureau of Labor Statistics 2011). In the United States, about $80 \%$ of the working population is employed in a service-sector job (Bureau of Labor Statistics 2011) compared to $70 \%$ of the working population in Europe (OECD Stat Extracts 2010). Moreover, it is expected that the service sector will add even more jobs in the future (Woods 2009). This makes it highly relevant to know how part-time employment affects firm productivity in the service sector.

From a theoretical point of view, it is not clear whether part-time employment is positively or negatively related to firm productivity. The human capital theory predicts part-time workers to be less productive than full-time workers. Research on the part-time pay penalty confirms this prediction (e.g., Baffoe-Bonnie 2004; Aaronson and French 2004). Nevertheless, some studies on part-time labor demand suggested that part-time employment might be beneficial at the firm level if, for example, operating hours exceed the full-time work week or when firms face fluctuations in customer demand (e.g., Delsen 2006, Owen 1978).

The aim of this chapter is to analyze and explain the relation between parttime employment and firm productivity in service-sector firms. For this purpose, we estimate a production function including heterogeneous employment shares (cf. Dearden, Reed, and Van Reenen 2006; Ilmakunnas and Maliranta 2005; Hellerstein, Neumark, and Troske 1999) based on employees' work hours.

The empirical identification of the relation between part-time employment and firm productivity requires at least three specific features of the data: (1) a homogeneous sector in terms of capital use and a homogeneous workforce in terms of education level, (2) information on the work hours of all employees within firms, and (3) a "hard" physical or monetary measure of productivity. We use a unique matched employer-employee data set on Dutch pharmacies that fulfills all three requirements and that can be considered characteristic of service-sector firms whose openings hours

\footnotetext{
${ }^{1}$ We are grateful to Daniëlle Bertrand-Cloodt, Arnaud Dupuy, Dan Hamermesh, Ben Kriechel, and seminar and conference participants at Maastricht University, SOLE 2009 in Boston, ESPE 2009 in Sevilla, LOPSI 2009 in Milan, EALE 2009 in Tallinn, and the IZA Summer School 2010 in Buch am Ammersee for useful discussions and comments on earlier versions of this paper. We thank Sander Dijksman for collecting parts of the data.
} 
exceed the full-time work week. Our analyses focus on the core workers (Osterman 2000, 1994), that is, pharmacy assistants, who account for $70 \%$ of total employment, measured in full-time equivalents (FTEs). All pharmacy assistants are females and share the same educational background (both in level and in field) required by law to be employed in their profession. Administrative data on the work hours of all employees in the sector enable us to construct firms' part-time and full-time labor shares based on work hours. Moreover, the number of prescription lines delivered to customers serves as a "hard" firm-level productivity measure. ${ }^{2}$

Other studies dealing with the relation between part-time employment and firm productivity have merely included a dummy variable to indicate the existence or importance of part-time employment (Arvanitis 2005) or were restricted to subjective productivity measures (Pérotin and Robinson 2000). Our data set enables us to more precisely estimate the relation between part-time employment and firm productivity. We find that firms with a large part-time employment share are more productive than firms with a large share of full-time workers. Additional data on the timing of labor demand enable us to explain this relation by thoroughly examining possible allocation efficiencies provided by the use of part-time employment. We show that firms with high shares of part-time workers can bridge the gap between opening hours and a full-time work week. Moreover, we show that part-time workers are allocated differently than full-time workers. In particular, we find that part-time workers enable their full-time colleagues to take lunch breaks so that the firm can remain open during these times.

This chapter is organized as follows: The next section briefly reviews related literature. Section 4.3 presents the empirical strategy. Section 4.4 describes the data and presents some sample statistics. Section 4.5 reports the results and presents robustness checks. Section 4.6 uses data on the timing of part-time labor demand to determine why part-time employment could be beneficial for firm productivity. Section 4.7 discusses the results in the context of quasi-fixed costs. Section 4.8 concludes this chapter.

\subsection{Related literature}

Although production function studies have included heterogeneous employment shares based on skill level, training participation, age, and/or gender (e.g., Iranzo, Schivardi, and Tosetti 2008; Zwick 2006; Ilmakunnas and Maliranta 2005), they implicitly as-

\footnotetext{
${ }^{2}$ Section 4.4 explains how registered medicines can be acquired in the Netherlands.
} 


\section{Firm Productivity}

sumed that part-time and full-time workers are equally productive in the hours they work. This is in sharp contrast to studies dealing with the effect of part-time employment on hourly wages. Relying on the assumption that wages reflect productivity, most studies found part-time workers to be less productive than full-timers in the hours they work (e.g., Hirsch 2005, Baffoe-Bonnie 2004, Aaronson and French 2004, Ermisch and Wright 1993). One exception is Manning and Petrongolo (2008), who found that including information on workers' occupations almost fully closes the gap between the hourly wages of part-time and full-time workers.

Apart from these individual productivity effects, part-time employment can also affect firm productivity through allocation efficiencies. Explanations for such firm-level productivity advantages in employing part-time workers can be found in the literature on part-time labor demand. This stream of literature describes several scenarios in which the demand for part-time employment is relatively high. Owen (1978) argued that firms employ part-time labor to avoid hiring overlapping shifts of full-time workers in industries where operating hours exceed the full-time 40-hour work week. Furthermore, Owen hypothesized that employers will use part-timers when there are fluctuations in demand. The author's results indeed show that the relative demand for part-time labor is higher in industries with an uneven distribution of temporal service demands, than in other industries. Mabert and Showalter (1990) also argued that the introduction of part-time employment implies efficiency gains in service-sector firms that face fluctuations in customer demand because of the accompanying reduction in the number of hours during which workers are inactive due to lack of demand. These scenarios suggest allocation efficiency due to part-time employment.

However, research on the effect of part-time work on firm productivity is scarce and has mainly been limited to the inclusion of a part-time dummy for the presence or importance of part-time employment in firms. ${ }^{3}$ Arvanitis (2005) constructed a dummy variable to indicate whether part-time work is important within a firm. The author found a negative relation between the importance of part-time work and sales per FTE. Whereas Pérotin and Robinson (2000) included a variable measuring the fraction of part-time employment in their analyses, their data set is restricted to subjective productivity measures. The authors did not find a significant relation

\footnotetext{
${ }^{3}$ One exception is a French study by Roux (2007) that examined the relation between part-time labor shares and firms' value added. However, it did not focus on a homogeneous workforce, which complicates identification of the part-time employment effect. Moreover, the reliability of value added as a productivity measure is questionable in labor-intensive sectors.
} 
between the proportion of part-time employment and managers' self-assessed labor productivity. ${ }^{4}$

\subsection{Empirical strategy}

Our approach is inspired by three papers that modeled the productivity effects of different employment shares (Dearden, Reed, and Van Reenen 2006; Ilmakunnas and Maliranta 2005; Hellerstein, Neumark, and Troske 1999). ${ }^{5}$ The approach assumes that different types of employees are perfect substitutes but can have different marginal productivities. The sector under scrutiny, the Dutch pharmacy sector (see Section 4.4), employs a homogeneous core workforce with respect to education and gender, which allows us to divide the workforce into three employment shares: parttime $(P T)$ and full-time $(F T)$ core workers and other employees $(O E)$. With the latter as our reference group, and its productivity normalized to unity, the relative productivity of the part-time employment share equals $\gamma_{p t}$ and the relative productivity of the full-time employment share equals $\gamma_{f t}$. If the $\gamma^{\prime} s$ are larger than unity, the relevant employment share is more productive than the reference group of other employees. The quality-adjusted labor input is therefore:

$$
L^{*}=L\left[1+\left(\gamma_{p t}-1\right) \frac{P T}{L}+\left(\gamma_{f t}-1\right) \frac{F T}{L}\right]
$$

Under the assumption that $\left(\gamma_{p t}-1\right) \frac{P T}{L}$ and $\left(\gamma_{f t}-1\right) \frac{F T}{L}$ are 'small,' we can simplify Equation (4.1) by the following approximation ${ }^{6}$ :

$$
\ln \left[1+\left(\gamma_{p t}-1\right) \frac{P T}{L}+\left(\gamma_{f t}-1\right) \frac{F T}{L}\right] \approx\left(\gamma_{p t}-1\right) \frac{P T}{L}+\left(\gamma_{f t}-1\right) \frac{F T}{L}
$$

\footnotetext{
${ }^{4}$ Whereas our study is the first to examine possible productivity differences between part-time and full-time work hours, there exists literature on the differences between standard and overtime hours. Most of these studies used data at the industry level (e.g., Craine 1973, Feldstein 1967). As criticized by Leslie and Wise (1980), it is difficult to interpret these results, since the coefficient for the average work week can reflect other differences between industries.

${ }^{5}$ Dearden, Reed, and Van Reenen (2006) allowed for productivity differentials by training participation, education, occupation, age, tenure, and gender. Ilmakunnas and Maliranta (2005) included employment shares based on age, level and field of education, and gender. Hellerstein, Neumark, and Troske (1999) distinguished employment shares by gender, race, marital status, age, education, and occupation.

${ }^{6}$ Following Dearden, Reed, and Van Reenen (2006) and Ilmakunnas and Maliranta (2005), we make this assumption to simplify the estimation. Then ordinary least squares (OLS) estimation is possible. However, the assumption can be relaxed without affecting our main findings. Following Hellerstein, Neumark, and Troske (1999), we also estimate a nonlinear least squares model. The results are similar, with the productivity differential between firms' shares of part-time and fulltime employment being statistically significant.
} 


\section{Firm Productivity}

The part-time and full-time employment shares are thereby directly included in a log-form production function. Using the quality-adjusted labor input $\left(L^{*}\right)$, we write the Cobb-Douglas production function as follows ${ }^{7}$ :

$$
Y=A K^{\alpha} L^{* \beta}
$$

where output $(Y)$ is a function of capital $K$ and quality-adjusted labor $L^{*}$. Taking the logs of terms and using the approximation in Equation (4.2), we have

$$
\ln (Y)=\ln (A)+\alpha \ln (K)+\beta \ln (L)+\beta\left(\gamma_{p t}-1\right) \frac{P T}{L}+\beta\left(\gamma_{f t}-1\right) \frac{F T}{L}
$$

We follow Ilmakunnas and Maliranta (2005) in allowing for deviations from constant returns to scale. When FTEs are used instead of the number of workers $L$, the production function becomes:

$$
\begin{aligned}
\ln (Y) & =\ln A+\alpha^{\prime} \ln (K)+\left(\alpha^{\prime}+\beta^{\prime}-1\right) \ln (F T E)+\beta^{\prime}\left(\gamma_{p t}^{\prime}-1\right) \frac{P T_{F T E}}{F T E} \\
& +\beta^{\prime}\left(\gamma_{f t}^{\prime}-1\right) \frac{F T_{F T E}}{F T E}
\end{aligned}
$$

where $P T_{F T E}$ and $F T_{F T E}$ denote the number of part-time and full-time FTEs per firm, respectively.

Contrary to the three studies mentioned above, our focus on firms in a specific sector allows us to assume that the capital/labor ratio is homogeneous across firms. Therefore, the following production function is estimated:

$$
\ln (Y)=\theta+\delta \ln \left(F T E_{i}\right)+\phi_{p t} p t_{i}+\phi_{f t} f t_{i}+\varepsilon_{i}
$$

where $p t_{i}$ and $f t_{i}$ denote firms' part-time and full-time employment shares as defined as $\frac{P T_{F T E}}{F T E}$ and $\frac{F T_{F T E}}{F T E}$, respectively. Moreover, $\theta$ is a constant term and includes $\ln A$ and $\alpha^{\prime}, \delta$ equals $\left(\alpha^{\prime}+\beta^{\prime}-1\right)$, and $\phi_{p t}$ and $\phi_{f t}$ denote $\beta^{\prime}\left(\gamma_{p t}^{\prime}-1\right)$ and $\beta^{\prime}\left(\gamma_{f t}^{\prime}-1\right)$, respectively. If $\phi_{p t}$ and $\phi_{f t}$ are larger than zero, results imply that firms' shares of core employees are more productive than their shares of other employees. If $\phi_{p t}$ is significantly larger than $\phi_{f t}$, firms with a large share of part-time workers will be, on average, more productive than firms with a large share of full-time workers. We do not interpret a significant difference between $\phi_{p t}$ and $\phi_{f t}$ as a marginal productivity difference between part-time and full-time workers due to skill differences between

\footnotetext{
${ }^{7}$ Since we assume capital use to be homogeneous across firms and workers, we only have one production input, quality-adjusted labor, and cannot estimate a translog production function as Hellerstein, Neumark, and Troske (1999) did.
} 
part-time and full-time workers. Instead, we interpret the difference $\phi_{p t}-\phi_{f t}$ as an establishment-wide productivity shift due to the use of part-time work within firms. ${ }^{8}$ Such an establishment-wide productivity shift could reflect allocation efficiencies due to part-time work. In Section 4.6 we analyze whether allocation efficiencies indeed might play a role in establishment-wide productivity shifts due to part-time work.

In alternative specifications, the model also controls for worker, pharmacist, firm, and market characteristics (see Section 4.4). ${ }^{9}$

\subsection{Data and descriptive statistics}

We use a unique matched employer-employee data set of Dutch pharmacies that fulfills all requirements to identify the relation between part-time employment and firm productivity. This data set includes two sources of information: (1) employee administrative data ${ }^{10}$ and (2) an employer survey. The data sets are merged on the basis of a unique firm identifier. The employers from all 1,890 Dutch pharmacies were invited to participate in an employer survey in January 2008, with two reminders sent in February and March 2008. Our final sample consists of 236 firms. ${ }^{11}$ Analyses related to the non-response show that our sample is selective with respect to a pharmacy's geographical location, but not with respect to the firm's other characteristics. ${ }^{12}$ Therefore, we include regional dummies in all analyses.

Firm productivity Our dependent variable is firm productivity. This is measured in the employer survey by firms' numbers of prescription lines delivered to customers

\footnotetext{
${ }^{8}$ The distinction in interpreting productivity functions either in terms of marginal productivity effects of two groups of workers, or in terms of a establishment-wide productivity shift due to employing one type of workers, is also common in the literature on union effects on productivity (e.g., Brown and Medoff 1978).

${ }^{9}$ Our data set does not allow for Internal Instrumental Variable analyses (IIV) to take possible endogeneity problems into account (e.g., Black and Lynch 2001) as we do not have panel data on firms' productivity. However, a more restricted form of IIV in which we do not include lagged productivity levels, but instrument firms' employment shares by their lagged shares does yield similar results as the analyses in Table 4.2, i.e. the productivity differential between firms' shares of part-time and full-time employment is statistically significant.

${ }^{10}$ This data set is provided by the pharmacy sector's pension fund (PMA) and contains information on all employed workers within the sector. The data are from January 2006 and 2008.

${ }^{11}$ The data set consists of 260 firms; data cleaning eliminated 24 firms.

${ }^{12}$ Our sample is representative with respect to key variables in our analysis, namely, the number of prescription lines delivered in 2007 and the hours distribution within firms. Whereas in our sample the average pharmacy delivered 78,291 prescription lines, the average number of prescription lines over the 1,890 pharmacies equals 78,000 (data from SFK, an independent foundation that publishes key indicators for the pharmacy sector). Moreover, our sample is representative with respect to the distribution of work hours among pharmacy assistants and other employees. See for the selectivity analysis, Table 4.5 in the appendix.
} 


\section{Firm Productivity}

in $2007 .{ }^{13}$ Every prescription line refers to a particular medicine that has been prescribed by a family doctor. In the Netherlands, this is the only possible way to obtain registered medicines. There is a close link between the number of prescription lines and firm sales due to the fixed amount of 6.10 Euros that pharmacies receive for each prescription line, and pharmacies only have a small market share in the sale of nonregistered medicines. ${ }^{14}$ The physical character of this productivity measure ensures a relatively "hard" measure of firm productivity (Ichniowski, Kochan, Levine, Olson, and Strauss 1996). Table 4.1 reports sample statistics of our employer-employee sample. On average, firms delivered 78,291 (exp(11.21)) prescription lines in 2007.

Table 4.1: Sample statistics of dependent and explanatory variables

\begin{tabular}{lllll}
\hline \hline & Mean & Std. Dev. & Min & Max \\
Dependent variable & & & & \\
Number of prescription lines (log) & 11.21 & 0.38 & 8.89 & 11.98 \\
Explanatory variables & & & & \\
Firms' part-time employment share in FTEs * & 0.19 & 0.11 & 0 & 0.51 \\
Firms' full-time employment share in FTEs * & 0.50 & 0.14 & 0.08 & 1.00 \\
Control variables & & & & \\
Firms' total number of FTEs (log) & 2.22 & 0.40 & 0.73 & 3.09 \\
Assistants' average age in years & 38.03 & 4.36 & 22.50 & 50 \\
Assistants' average firm tenure in years & 8.31 & 3.10 & 0.81 & 17.93 \\
Pharmacist tenure in years & 15.84 & 8.47 & 0 & 39 \\
Independent pharmacy (yes/no) & 0.42 & 0.50 & 0 & 1 \\
Number of opening hours per week & 49.87 & 12.25 & 6 & 168 \\
Excess labor (yes/no) & 0.13 & 0.33 & 0 & 1 \\
Absentee ratio & 0.04 & 0.04 & 0 & 0.30 \\
Newly founded firm & 0.04 & 0.19 & 0 & 1 \\
Percentage of elderly within postal code area & 0.22 & 0.07 & 0 & 0.60 \\
Number of competitors within a 5-km radius & 9.61 & 12.25 & 0 & 77 \\
\hline \hline
\end{tabular}

Employment shares Our main variables of interest are firms' heterogeneous employment shares in terms of FTEs. Therefore, we need to know the number of work hours of all the workers within all the firms. Information on contractual work hours for pharmacy assistants and other support staff is available in the administrative

\footnotetext{
${ }^{13}$ De Grip and Sieben (2005) used the same measure of productivity in their analyses on firm productivity in the pharmacy sector.

${ }^{14}$ In the Netherlands, most non-registered medicines are bought in firms other than pharmacies: Commercial drugstores and supermarkets have a market share of $85 \%$ for non-registered medicines (data from IMS Health, http ://www.hbd.nl/view.cfm?page $e_{i} d=4288$ ).
} 
data set. Information about the work hours of pharmacists is available from the employer survey. With these data, we can distinguish between firms' shares of parttime core employees, full-time core employees, and other employees. We focus on the core workers, that is, pharmacy assistants, ${ }^{15}$ because of their homogeneity with respect to several characteristics. Pharmacy assistants all have the same educational background required by law (in terms of both level and field). Moreover, the population of pharmacy assistants is homogeneous with respect to gender, $99 \%$ being female. We compute firms' part-time and full-time (core) employment shares as follows: $p t_{i}=\frac{F T E_{i, p t}}{F T E_{i, \text { total }}}$ and $f t_{i}=\frac{F T E_{i, f t}}{F T E_{i, \text { total }}} \cdot 16$

The standard full-time work week in the pharmacy sector being 36 hours, we define part-time workers as pharmacy assistants with fewer than 24 contractual work hours, that is, fewer than three work days. This definition differs from the definitions of part-time work usually used in the literature on part-time employment. Although there is no generally agreed upon standard, definitions ranging from 30 to 35 hours a week are most common (e.g., Connolly and Gregory 2008; Manning and Petrongolo 2008). However, our definition is well suited within our context. The Netherlands is known for its large share of part-time employment. Moreover, the pharmacy sector employs almost exclusively female pharmacy assistants with less than full-time work hours. Within the Netherlands as a whole, around $50 \%$ of all working women work fewer than 24 hours. In the pharmacy sector, $42 \%$ work fewer than 24 hours a week. ${ }^{17}$ Figure 4.1 shows the distribution of the work hours of all core workers within the sample. Whereas working fewer than two days (16 hours) is uncommon in the sector, working part-time is not. The largest group of core workers works between 16 and 24 hours per week. Work weeks of 24 to 32 hours and 32 to 36 hours per week are also quite common in the pharmacy sector. A total of $20 \%$ of all pharmacy assistants work exactly 36 hours per week (not shown in Figure 4.1). Section 4.5.2 checks the robustness of our findings by using other definitions of part-time employment and by dividing the core workers into more employment shares.

Table 4.1 reports the average sizes of firms' employment shares and shows that firms' part-time employment share is, on average, equal to 0.19, and their full-time employment share is, on average, equal to 0.50. This large difference between firms'

\footnotetext{
$\overline{{ }^{15} \text { Osterman }(2000,1994) \text { defined these }}$ core workers as the largest group of non-supervisory, nonmanagerial workers in a firm who are directly involved in making the product or providing the service.

${ }^{16}$ Firms' share of other employees is constructed the same way: oe $e_{i}=\frac{F T E_{i, o e}}{F T E_{i, \text { total }}}$.

${ }^{17}$ The difference in the percentage of part-timers working is due to a larger percentage of Dutch women (compared to Dutch pharmacy assistants) working in jobs with fewer than 16 hours a week (data from OSA-Labor Supply Panel 2006).
} 
Figure 4.1: Distribution of work hours

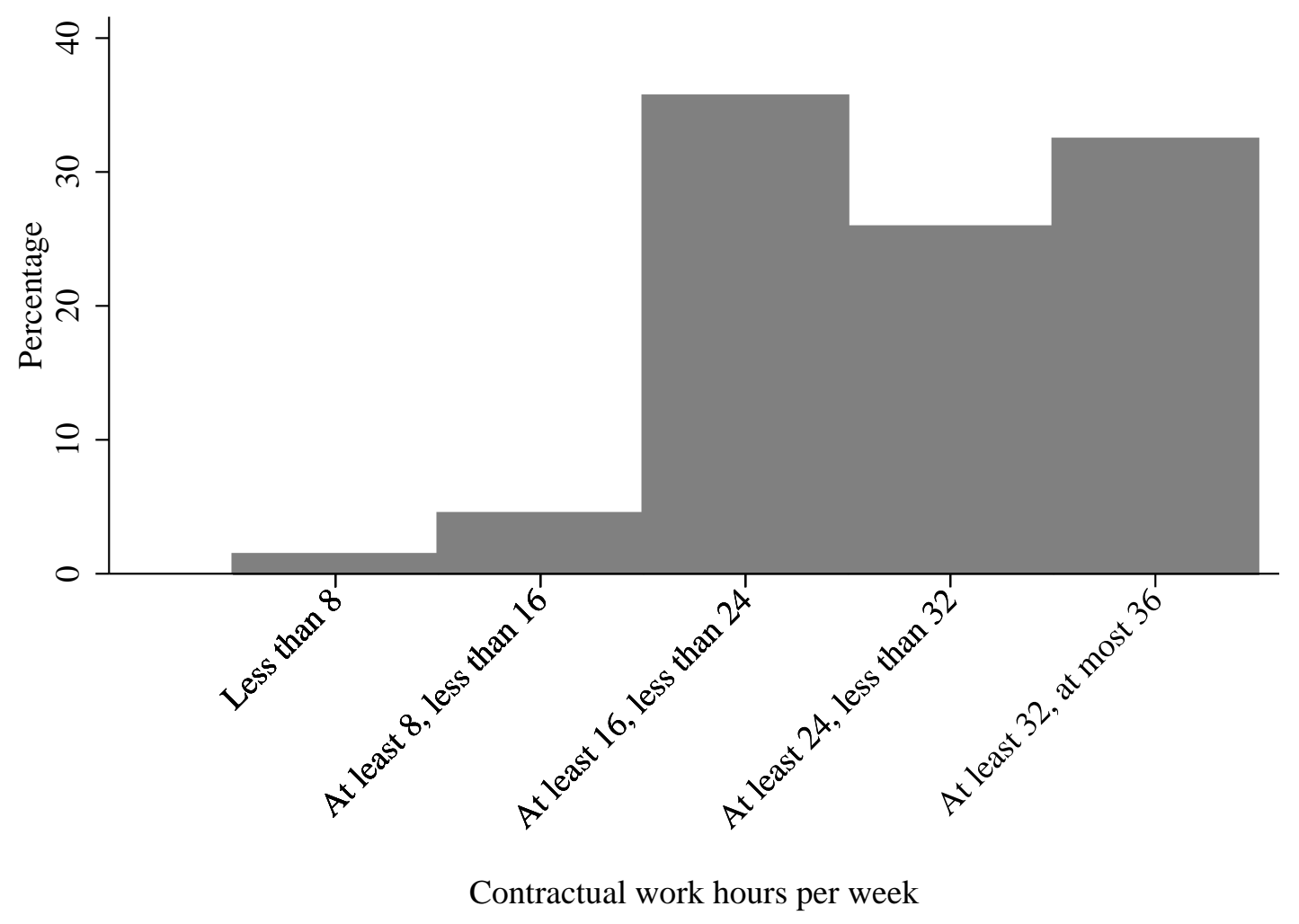

part-time and full-time employment shares is due to measurement in FTEs. Together, core workers account for almost $70 \%$ of firms' total employment.

Apart from these core workers, pharmacies employ pharmacists and other support staff. Most important among the latter are assistants' support staff and student pharmacy assistants. Assistants' support staff help pharmacy assistants in activities related to the production process. Student pharmacy assistants are involved in a dual training track combining work and classroom education. ${ }^{18}$ As can be seen in Table 4.1, the other employees altogether account for $31 \%$ of firms' total employment.

Control variables Since firm productivity can also be influenced by worker, pharmacist, firm, and market characteristics, we control for such confounders. We include the total number of firms' employees, in FTEs, to take into account deviations from constant returns to scale. On average, firms' total number of FTEs equals 9.9. ${ }^{19}$

\footnotetext{
${ }^{18}$ Due to the involvement of all employment types in the primary production process, all employees in the sector are substitutes.

${ }^{19}$ Table 4.1 reports the logarithmic form because we use the log form in the analyses as well.
} 
Regarding worker characteristics, we include the average age and tenure of the core workers. This information is available from the administrative data covering all employees. Table 4.1 shows that assistants are on average 38 years old and have a firm tenure of slightly more than eight years. ${ }^{20}$ We include pharmacist tenure to control for productivity differences due to employers. On average, pharmacists have a tenure of almost 16 years. The firm characteristics we include in our analyses are pharmacy type (independent or not), newly founded firm (yes/no), number of opening hours, and variables related to possible inefficiencies in the firm's allocation of labor: a dummy variable equal to one when employers report excess labor, and zero otherwise, and a variable measuring absenteeism due to sickness leave from the fraction of workers calling in sick during the last calendar year. Moreover, two factors related to management styles are included. One factor can be characterized by the degree of availability of several human resource schemes (e.g., life-course savings scheme, child care schemes) and the other to the extent in which human resource development practices are used in the firm (e.g., performance interviews, personal development plan). These variables are constructed from the employer survey. Table 4.1 shows that $42 \%$ of pharmacies are characterized as independent firms. The rest cooperates with other pharmacies, either in terms of chains or franchises or as part of legalized partnerships. A total of $4 \%$ of the firms are newly founded. On average, pharmacies are open for around 50 hours a week, while the full-time work week for pharmacy assistants equals 36 hours. A total of $13 \%$ of the firms report excess labor. The average annual absentee rate is $4 \%$.

Finally, we account for two market characteristics that can affect productivity: the demand for medicines in the neighborhood where the pharmacy is located and the local degree of competition. We measure demand for medicines by the percentage of elderly (60+ years old) living within the pharmacy's postal code (four digits) area. Table 4.1 shows that, on average, the percentage of elderly within a postal code equals $22 \%{ }^{21}$ The degree of competition is measured by the number of competitors within a radius of five kilometers. This is calculated as the distances between all the pharmacies in the sample and all the other pharmacies located in the same region on the basis of postal codes. ${ }^{22}$ Table 4.1 shows that the number of competitors differs considerably across firms. Although, on average, firms have

\footnotetext{
${ }^{20}$ Since the majority of assistants are female and career breaks are common, we include both age and tenure in the analyses. Since the correlation between age and tenure is $35 \%$, including both variables will not cause any problems in the estimations.

${ }^{21}$ These data are from the online statistical database of Statistics Netherlands (CBS Statline).

${ }^{22}$ We use a standard Dutch regional classification (COROP). The Netherlands counts 40 COROP regions, and every COROP region has a central point (city) with a surrounding service area.
} 


\section{Firm Productivity}

around 10 competitors, some have no competitors. The pharmacy facing the most competition has 77 competitors within a radius of five kilometers.

\subsection{Results}

\subsubsection{Part-time employment and firm productivity}

Figure 4.2 provides first evidence for the relation between firms' part-time employment share and their log productivity. Average log productivity is shown for the four quartiles of firms' part-time employment share. This figure indicates that there is a

Figure 4.2: Raw relation between firms' part-time employment share and log productivity (by quartiles of the part-time employment share)

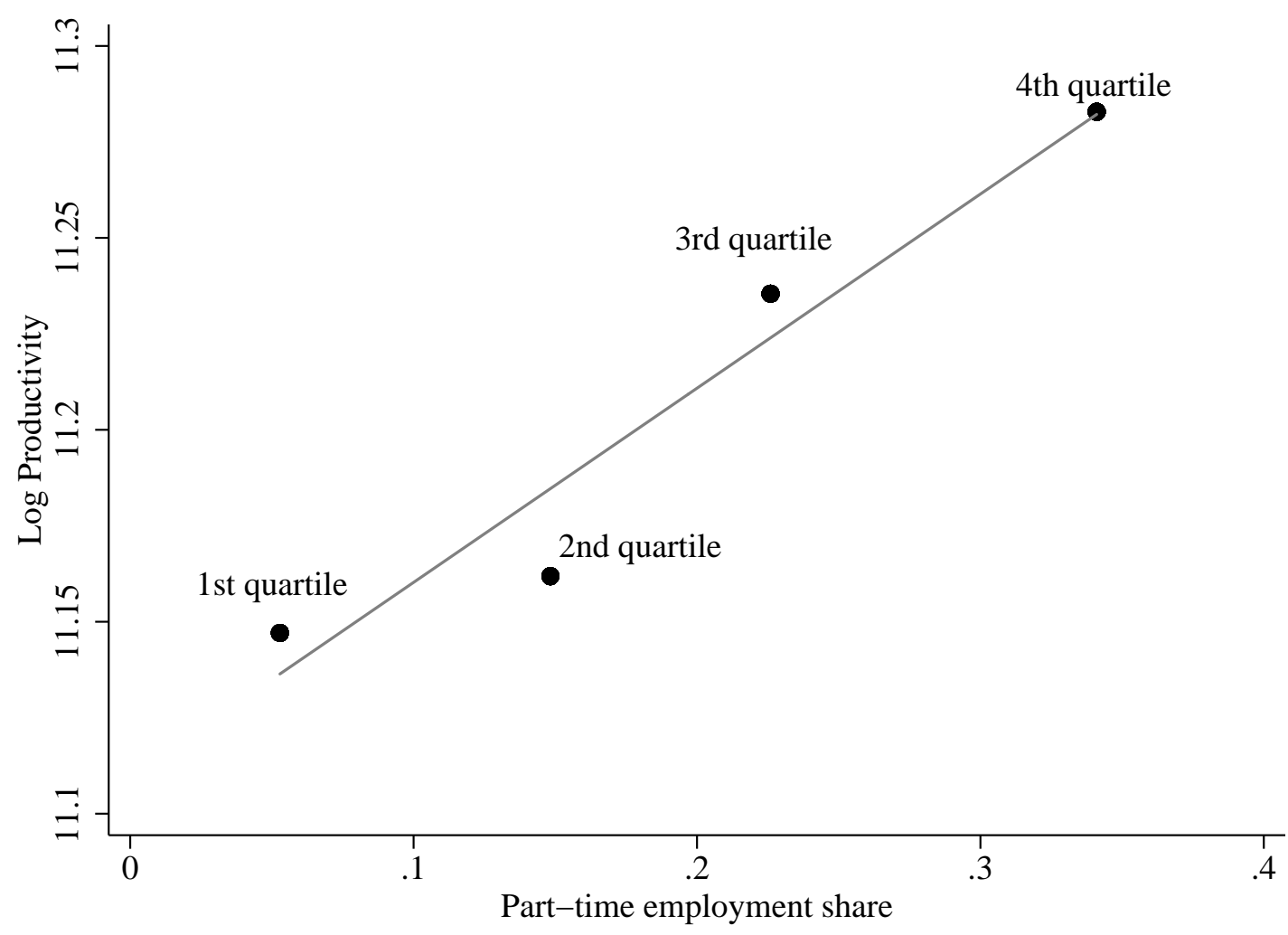

positive correlation between firms' part-time employment share and their productivity. For each subsequent quartile of firms' share of part-time employment, we find a higher average log productivity. While log productivity is 11.15 , on average, for firms with a part-time employment share of 0.05 or less, average log productivity is 11.28 for firms in the top fourth quartile (with a part-time employment share of at 
least 0.34 ). This means a difference in log productivity of 0.13 corresponding with a 0.29 difference in part-time employment share. In other words, a $10 \%$ increase in part-time employment share is associated with $4.5 \%$ larger productivity.

Table 4.2 shows the estimation results of several specifications of our production function. Column (1) takes into account only the scale effect and the two employment shares. The difference between the coefficients of firms' shares of part-time and fulltime employees $\left(\phi_{p t}-\phi_{f t}\right)$ equals 0.562 and is significant at the $1 \%$ level. The 0.56 log point difference in coefficients between firms' part-time and full-time employment shares, implies that a $10 \%$ increase in the part-time share (which is roughly one standard deviation) is associated with $5.6 \%$ higher productivity.

Table 4.2: Estimation results of production functions with heterogeneous labor shares based on work hours

\begin{tabular}{llll}
\hline \hline Dep. Variable.: Productivity (log) & $(1)$ & $(2)$ & $(3)$ \\
Total amount of labor in FTEs (logs) & $0.738^{* * *}$ & $0.694^{* * *}$ & $0.703^{* * *}$ \\
& $(0.044)$ & $(0.047)$ & $(0.048)$ \\
Firms' employment shares (other employees & are reference & group) & \\
Firms' part-time employment share in FTEs & $0.947^{* * *}$ & $0.831^{* * *}$ & $0.888^{* * *}$ \\
& $(0.182)$ & $(0.186)$ & $(0.194)$ \\
Firms' full-time employment share in FTEs & $0.385^{* * *}$ & $0.416^{* * *}$ & $0.403^{* * *}$ \\
& $(0.143)$ & $(0.142)$ & $(0.143)$ \\
Constant & $9.175^{* * *}$ & $9.422^{* * *}$ & $9.388^{* * *}$ \\
& $(0.157)$ & $(0.223)$ & $(0.232)$ \\
\hline Worker, pharmacist and firm characteristics & no & yes & yes \\
External factors & no & no & yes \\
\hline Adjusted R-squared & 0.556 & 0.589 & 0.588 \\
N & 235 & 235 & 235 \\
Model & OLS & OLS & OLS \\
\hline Wald Tests: PT share = FT share & 13.05 & 6.36 & 7.42 \\
Prob $>$ F = & 0.0004 & 0.0124 & 0.0070 \\
\hline \hline
\end{tabular}

Note: Standard errors in parentheses; ${ }^{*} \mathrm{p}<0.1,{ }^{* *} \mathrm{p}<0.05,{ }^{* * *} \mathrm{p}<0.01$. Specification (1) includes region dummies. Specification (2) additionally includes assistants' average age and tenure, pharmacist tenure, the firm's number of opening hours per week, two standardized factors related to management style, size dummies, the firm's sick leave percentage, two factors denoting management styles and dummy variables to indicate independent firms, excess labor, and newly founded firms. Specification (3), moreover, includes the percentage of elderly living in the firm's postal code area and the number of competitors within a radius of $5 \mathrm{~km}$.

Column (2) reports the regression results when including worker, pharmacist, and firm characteristics. The main results remain the same; however, the productivity differential is slightly smaller when including control variables. The finding that firms with a large share of part-time employees are more productive than firms with a large share of full-time employees still holds at the $2 \%$ level. We do not report the control variables, as most of them are not significant. One exception is 


\section{Firm Productivity}

a dummy variable denoting whether the firm is newly founded. We find that newly founded firms are significantly less productive than older firms, which is in line with the literature on the impact of vintage on productivity (e.g., Jensen, McGuckin, and Stiroh 2001). Moreover, we find that firms with an employee surplus are less productive than firms without such a surplus. The two standardized factors denoting management style are significantly related to productivity as well. The results given in Column (3) include a set of variables that indicate the demand and competition the pharmacy faces, as specified in Section 4.4. ${ }^{23}$ Again, the finding that firms with a large share of part-time employment are more productive than firms with a large share of full-time employment is unaffected by the inclusion of these market characteristics. The $0.50 \mathrm{log}$ point difference shows that a $10 \%$ increase in the part-time share is associated with $5.0 \%$ higher productivity. Due to inclusion of control variables this establishment-wide effect of part-time employment has decreased slightly. Nevertheless, it is close to the raw productivity difference we have seen in Figure 4.2.

\subsubsection{Robustness checks}

This section presents a series of robustness checks that address two particularly important decisions made in the estimation of Equation (4.6): the definition of parttime employment and the division of core workers into two groups.

The definition of part-time employment A first robustness analysis tests whether our estimation results change when using different thresholds for part-time employment. Figure 4.3 reports the coefficients of firms' part-time and full-time employment shares, as well as their confidence intervals, using definitions of part-time employment ranging from working fewer than 16 hours to fewer than 33 hours per week. ${ }^{24}$ Figure 4.3 shows several interesting findings: When a part-time work week is defined as less than 16 hours, the coefficients of firms' shares of part-time and full-time core workers are not significantly different from each other. This is due to the large confidence interval of the coefficient for firms' part-time employment share, which, in turn, may be due to the small variation in this variable across firms. On average, when part-time employment is defined as a work week of less than 16 hours, firms' part-time employment share equals $0.017 \%$ (with a standard deviation equal

\footnotetext{
${ }^{23}$ These controls are not significant. We tried several alternative specifications for the measures for demand and competition, such as the number of inhabitants within a postal code area, the number of competitors within a radius of 10 kilometers, and the degree of urbanization. However, these did not change the estimation results.

${ }^{24}$ The analyses are comparable to those reported in Table 4.2, Column (3).
} 
to 0.032 ). When part-time employment is defined as a work week of less than $h$ hours with $h=[16, \ldots, 20]$, the same line of reasoning holds: Despite a larger coefficient for firms' share of part-time employees compared to their share of full-time employees, the imprecision of the estimated coefficients results in an insignificant difference between the firms' part-time and full-time employment shares.

Figure 4.3: Coefficients of firms' part-time and full-time employment shares using different definitions of part-time employment

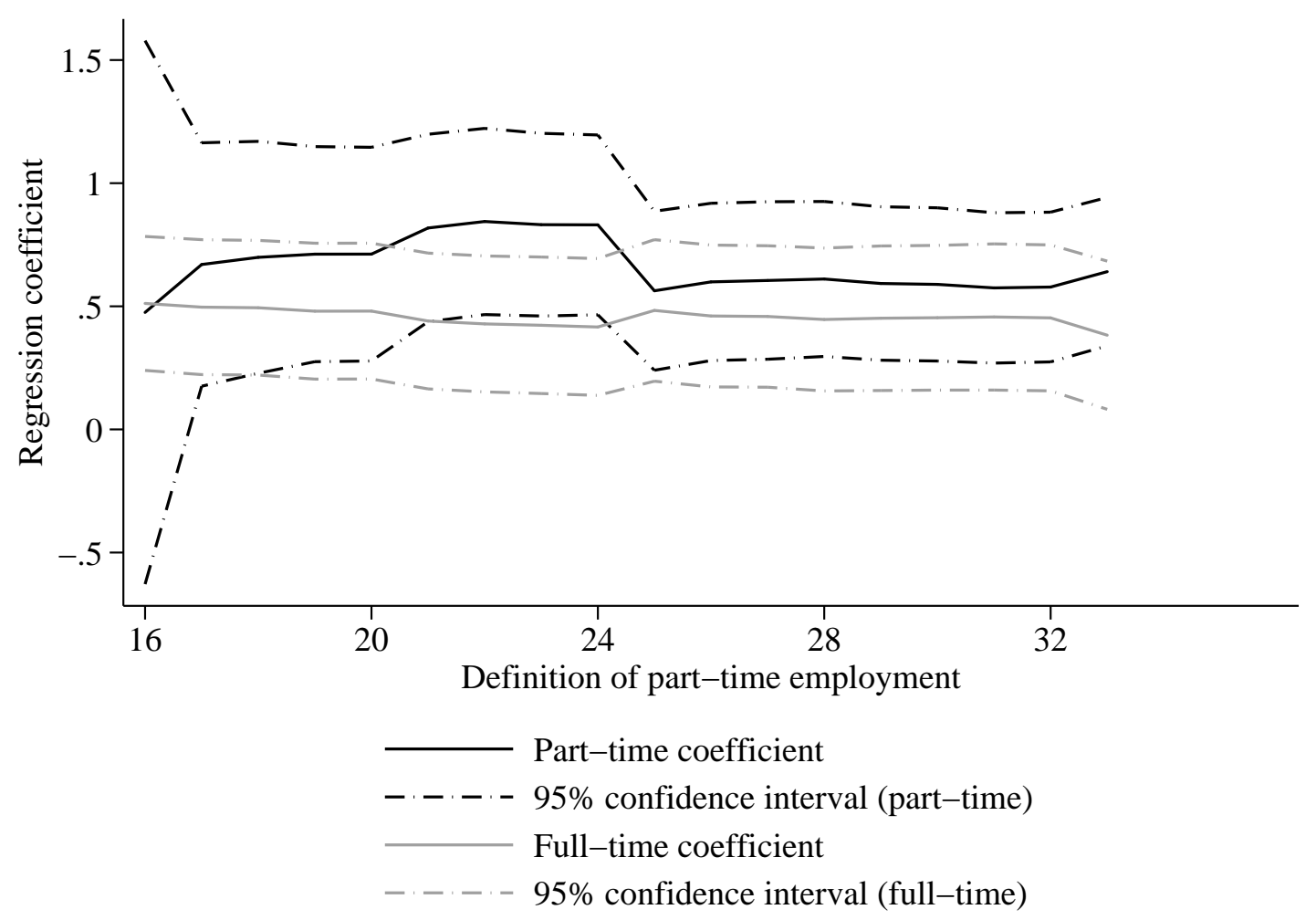

Note: This figure reports the coefficients of firms' part-time and full-time employment shares, as well as their confidence intervals, using definitions of part-time employment ranging from working fewer than 16 hours to fewer than 33 hours per week. The analyses are comparable to those reported in Column (2) of Table 4.2.

Figure 4.3 shows that when part-time work is defined as a work week of less than 21 hours, the coefficient of the part-time employment share is significantly higher than that of the full-time employment share. This also holds when part-time work is defined as a work week shorter than 22, 23, or 24 hours. However, when we define part-time employment as a work week of less than $h$ hours with $h=[25, \ldots, 33]$, the coefficients of firms' part-time and full-time employment shares are not significantly different. 


\section{Firm Productivity}

This robustness check shows that our finding is robust to a particular range of hours for defining part-time employment. When we use definitions of part-time employment that reflect larger jobs, our results suggest that firms that employ large shares of part-time employees are as productive as firms that employ large shares of full-time employees. This suggests that firms are not able to benefit from allocation efficiencies when a relatively large share of workers works at least 24 hours a week.

More shares of core employees We also check the robustness of our results by distinguishing core workers in small, medium, and large part-time jobs and full-time jobs. We define the four groups as follows: Employees in small part-time jobs work fewer than 16 hours. Employees in medium-sized part-time jobs work between 16 and 24 hours per week. Large part-time jobs are jobs of 24 hours or more per week but fewer than 32 hours. Employees working 32 hours per week or more are defined as full-time workers. We compute the employment shares for these four groups of core workers and use, as previously, other employees as the reference group. Except for including two extra shares of employees, the estimation strategy remains the same. Table 4.3 reports the results.

Table 4.3: Estimation results of different shares of parttime employment on firm productivity

\begin{tabular}{ll}
\hline \hline Dep. Variable: Productivity (log) & \\
Total amount of labour in FTEs (log) & $\begin{array}{l}0.690^{* * *} \\
(0.047)\end{array}$ \\
& 0.425 \\
Firms' small part-time employment share in FTEs & $(0.557)$ \\
& $0.863^{* * *}$ \\
Firms' medium part-time employment share in FTEs & $(0.192)$ \\
& $0.364^{* *}$ \\
Firms' large part-time employment share in FTEs & $(0.178)$ \\
& $0.434^{* * *}$ \\
Firms' full-time employment share in FTEs & $(0.150)$ \\
\hline Worker, pharmacist and firm characteristics & yes \\
\hline Adjusted R-squared & 0.5869 \\
N & 235 \\
\hline Wald Tests: & Prob $>\mathrm{F}$ \\
Medium PT share $=$ FT share 5.78 & 0.017 \\
\hline \hline
\end{tabular}

As before, we compare the relative productivity of the different employment 
shares of core employees. Table 4.3 shows no significant coefficient for the share of firms' small part-time employment. ${ }^{25}$ The share of firms' medium part-time employment has the largest coefficient. Table 4.3 shows that the coefficient for the share of firms' large part-time employment is only weakly significant, and the size of the coefficient is much smaller than the size of the coefficient for firms' medium part-time employment share. Most important is the finding that the share of firms' medium part-time employment is significantly more productive than the share of firms' full-time employment (at the $2 \%$ level). The finding that the coefficient of the share of firms' large part-time employment is only weakly significant supports the idea mentioned before, that the number of work hours of these part-time workers is too large to be allocated as efficiently as for part-time workers with fewer work hours per week. From this robustness check, we conclude that firms especially benefit from a large share of part-time employees working between 16 and 24 hours per week.

In conclusion, our robustness analyses show that firms with a large part-time employment share are more productive than firms with a large full-time employment share. This appears to be due to the fraction of part-time employees working between 16 and 24 hours per week, suggesting that these part-time workers are allocated most efficiently.

\subsection{Why is part-time employment beneficial for firm productivity?}

Our finding that firms with a large share of part-time employment are more productive than firms with a large share of full-time employment is not likely to be due to a larger productivity of part-timers compared to full-timers. First, part-time and full-time pharmacy assistants all have the same educational background as described in Section 4.4. Moreover, additional analyses on a representative employee survey among pharmacy assistants did not show any difference in training participation or training intensity between part-time and full-time employees.

Therefore, our finding is most likely due to allocation efficiencies offered by parttime employment. Especially in service-sector firms, part-time employment can, for example, be used to bridge the gap between opening hours and contractual work hours. Such a gap is also observed in our data. On average, firms are open around 50 hours a week, whereas the full-time work week counts 36 hours (see Table 4.1).

A second argument for the beneficial allocation effects of part-time employment

\footnotetext{
${ }^{25}$ Again, this is probably due to this variable's small value and small standard deviation, as explained in Section 4.5.2.
} 


\section{Firm Productivity}

is related to fluctuations in customer demand during opening hours. Due to these fluctuations, part-time employment enables firms to cushion peak hours by deploying more workers during that time than during opening hours with lower customer demand. Whether part-time or full-time workers are deployed during peak hours can depend on their relative productivity. A third way in which part-time employees can provide allocation efficiencies is by bridging the lunch breaks of their full-time colleagues.

To gain more insight into the allocation efficiency of part-time employment, we use additional data on the timing of labor demand within the Dutch pharmacy sector. These data are provided by the administrator of a scheduling program that is used by almost half of all Dutch pharmacies. ${ }^{26}$ Therefore, we know the work schedules of all the employees of 900 pharmacies in January 2010. From this data set, we construct for each week the firms' number of core employees working and the fraction of part-time core workers in each half-hour time slot. Based on this information, we examine possible weekly and daily allocation efficiencies. At the individual level, we also look at the correlations between the number of contractual work hours, on the one hand, and the number of work hours per day and the work days per week, on the other hand.

Table 4.4 shows the correlation between, on the one hand, workers' contractual work hours and, on the other hand, the number of hours worked per work day, as well as the number of work days per week and per month. The correlation coefficients in Table 4.4 show that the greater the number of contractual work hours, the more hours employees work per work day. Nevertheless, Table 4.4 also shows that it is not the case that part-time workers work one or two hours per day solely to cover the lunch break of a full-time colleague. The table also shows that longer contractual work hours significantly relate to more work days per week and per month. Parttime workers therefore work not only fewer hours per work day, but also fewer days per week (month). This implies that part-time workers are allocated differently than full-time employees. The following analyses whether the different allocations of part-time and full-time employees result in weekly or daily allocation efficiencies or both.

Figure 4.4 shows the allocation of total labor and part-time employment over the days of the week. Total labor is measured by the number of half-hour time slots worked by all employees per day. We sum the number of half-hour time slots of all

\footnotetext{
${ }^{26}$ This scheduling program is freely available online to Dutch pharmacies. It allows them to plan the work time of their employees and contains details on the positions of employees, their contractual work hours, and the time slots they are scheduled to work.
} 
4.6 Why is part-time employment beneficial for firm productivity?

Table 4.4: Correlations between contractual work hours and the usability of core employees

\begin{tabular}{lll}
\hline \hline & $\begin{array}{l}\text { Contractual } \\
\text { work hours }\end{array}$ & $\begin{array}{l}\text { Part-time } \\
\text { worker }\end{array}$ \\
\hline Number of hours & 0.2180 & -0.3679 \\
per work day & $(0.000)$ & $(0.000)$ \\
Number of days & 0.7293 & -0.6605 \\
worked in week 1 & $(0.000)$ & $(0.000)$ \\
Number of days & 0.8294 & -0.5832 \\
worked in January & $(0.000)$ & $(0.000)$ \\
\hline \hline
\end{tabular}

Note: Based on the data of 8,257 core employees.

Figure 4.4: Allocation of part-time employees over the week

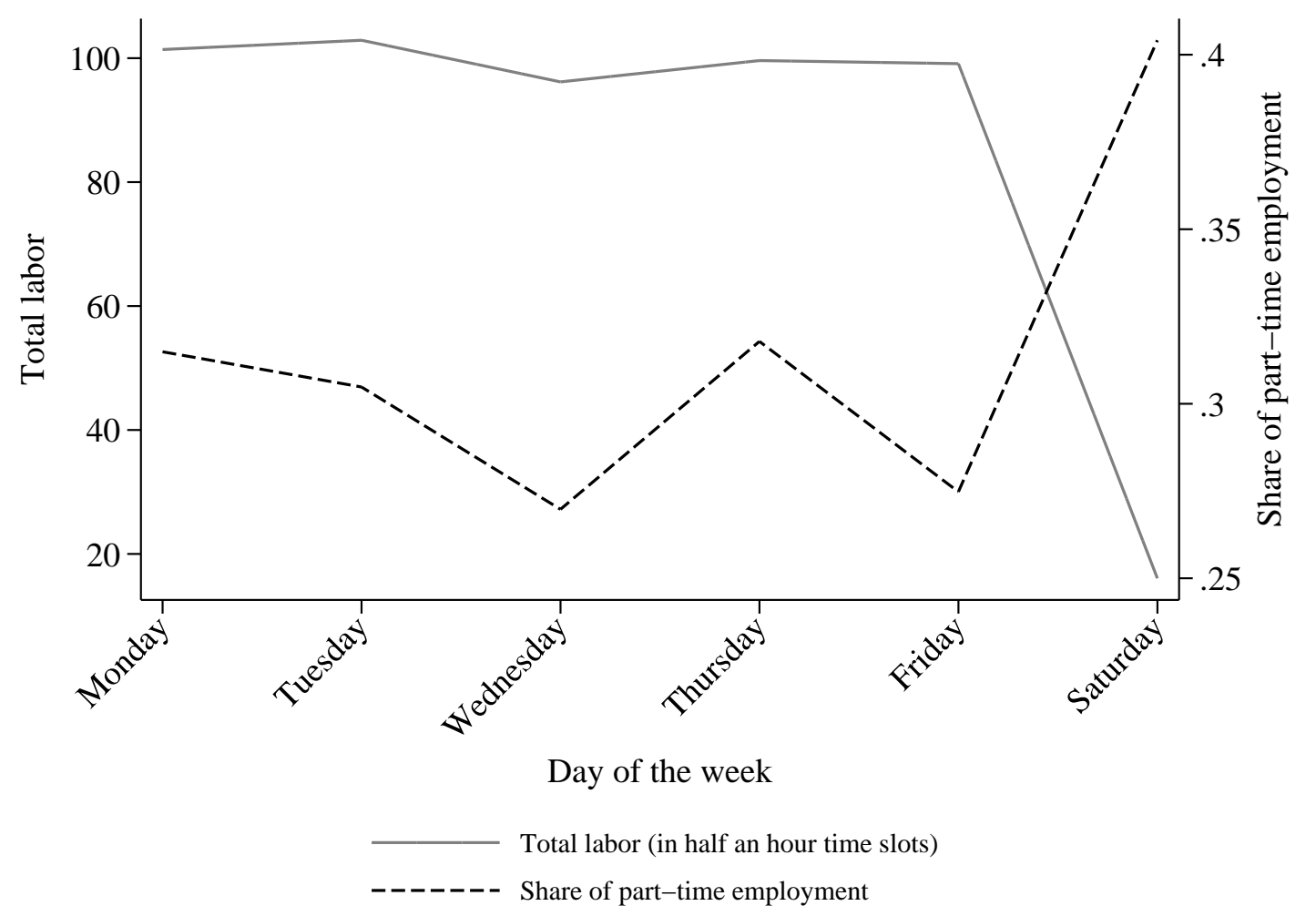

employees working in the firm on that day. The share of part-time employment is computed as the number of all time slots worked by part-time employees over the total number of time slots worked by all employees. 


\section{Firm Productivity}

Figure 4.4 shows small fluctuations in the total amount of labor deployed across days. ${ }^{27}$ Moreover, there seem to be some fluctuations in the share of part-time employment. Especially on Wednesday and Friday, the share of part-time employment is smaller than on other days; however, this seems to be supply driven, since children below age 12 do not have classes on Wednesday afternoon and, additionally, children below age seven do not have classes on Friday afternoon. Altogether, we have to conclude that Figure 4.4 does not show a clear relation between total labor needed on a day and employers' use of part-time employment over the week.

Figure 4.5 shows the allocation of workers over the work day. As far as fluctuations in total labor needed reflect fluctuations in customer demand, we do not observe much fluctuation in customer demand in the sector. The only exception is a daily low point during lunch time (between 12:00 PM and 1:30 PM); however, this is more likely to reflect the necessity of a lunch break for full-timers than a low point in customer demand. To see whether part-time employees are used to bridge the lunch breaks of full-time workers, we distinguish between firms that deploy no core employees and firms that do deploy core employees during lunch time. Figure 4.5 shows the average number of core employees and the fraction of part-time core employees for the first week of January 2010 (averaged over all firms), ${ }^{28}$ as well as several features that suggest allocation efficiencies provided by part-time employees.

- For all time slots, the fraction of part-time employees is larger in firms where no core employees are deployed at some time between 12:00 PM and 1:30 PM.

- In the sample of firms that deploy at least one core employee during lunch time (the "no lunch break" sample), the fraction of part-time employees is largest during lunch time. This suggests that part-time workers indeed bridge the lunch breaks of their full-time colleagues. Moreover, as Table 4.4 shows, it is not the case that part-time workers work for only one or two hours during the lunch break. Some part-time workers start in the morning and work until after lunch time, while others start before lunch and work until closing time. ${ }^{29}$

- As shown in Figure 4.4, the fraction of part-time core employees is smallest on Wednesdays and Fridays. More precisely, on these days, the fraction of part-time employees is smaller in the afternoon than in the morning. This

\footnotetext{
${ }^{27}$ Only on Saturday there is a clear drop in total labor deployed due to a large number of firms that are closed that day; firms that are open are often only open in the morning.

${ }^{28}$ Figures based on the other weeks look similar.

${ }^{29}$ The data used for our estimations in Section 4.5 do not include information on whether firms deploy core employees during lunch time. Therefore, we cannot estimate the productivity model separately for these two groups of firms.
} 
Figure 4.5: Timing of labor demand — week 1

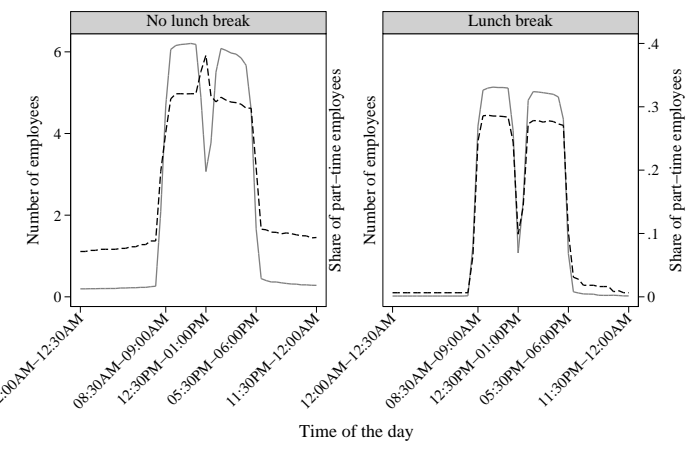

(a) Monday

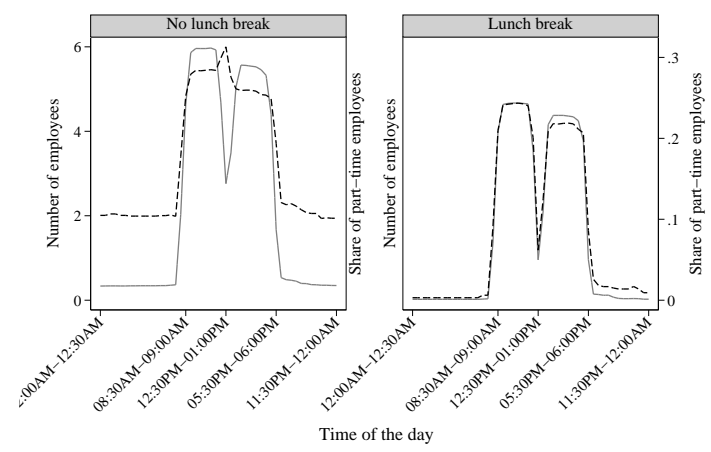

(c) Wednesday

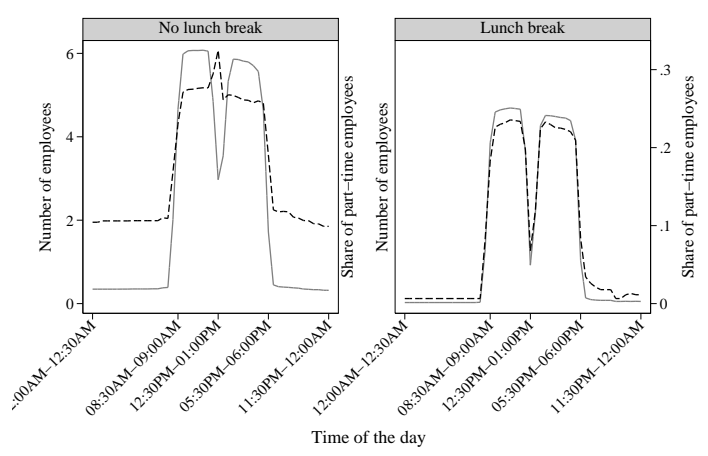

(e) Friday

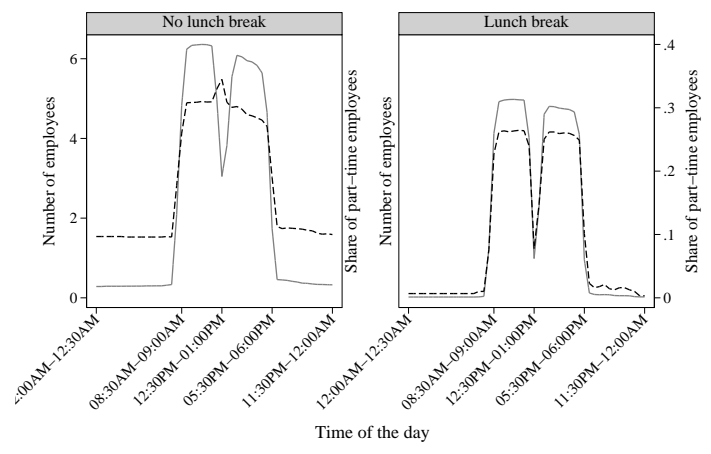

(b) Tuesday

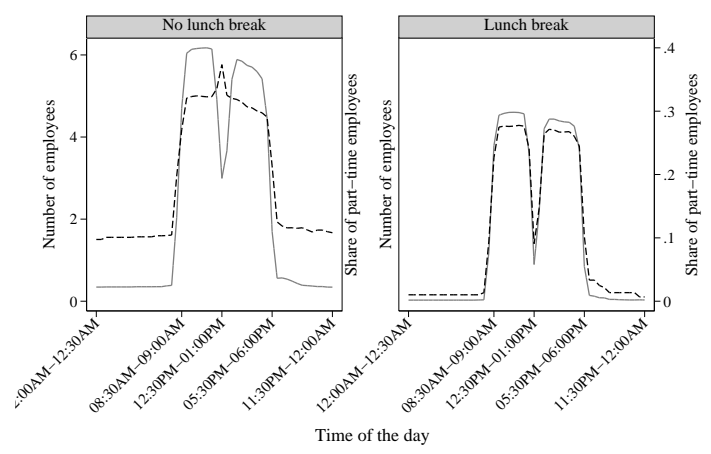

(d) Thursday

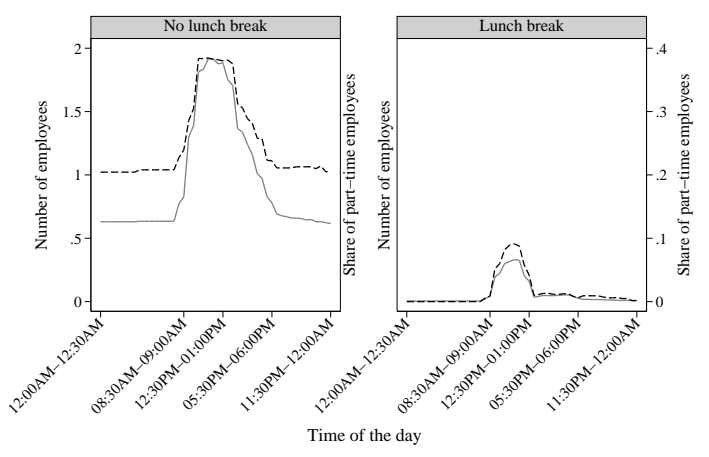

(f) Saturday

is noticeable because on Wednesday and Friday, children below ages 12 and seven, respectively, do not have classes in the afternoon.

We conclude that the allocation of part-time and full-time workers is quite different. Part-time workers work fewer hours per work day, as well as fewer days 


\section{Firm Productivity}

per week (month) than full-timers. In particular, they seem to bridge the lunch breaks of their full-time colleagues. Deploying a large fraction of part-time employees therefore seems to increase allocation efficiency over the work day, which contributes to greater firm productivity.

\subsection{Discussion}

Our findings raise the question of why service-sector firms do not employ solely part-time workers. We think the answer can be found in the literature on parttime labor demand. Montgomery (1988) discussed the determinants of employer demand for part-time workers. The author argued that the combination of part-time and full-time employees within firms depends upon the relative cost of providing labor services for each type of labor. These relative labor costs are determined by three factors: (1) the relative productivity of part-timers and full-timers, (2) the relative wages of part-timers and full-timers, and (3) quasi-fixed labor costs. There are no a priori reasons to assume that the productivity of part-time and fulltime workers differs in the hours they work. ${ }^{30}$ Moreover, as in most other Dutch occupations, the hourly wages of part-time and full-time pharmacy assistants are similar (Euwals and Hogerbrugge 2006). Therefore, we focus this discussion on quasifixed labor costs. ${ }^{31} \mathrm{Oi}$ (1962) demonstrated that firms bear quasi-fixed costs of labor. These consist of the administrative costs of supervising and maintaining records for each worker, costs related to searching for, hiring, and training new workers, and those components of benefits that are unrelated to hours worked. Higher quasifixed costs are expected to decrease the proportion of jobs going to part-timers. Owen (1978) gave other examples of quasi-fixed labor costs that can apply to the service sector, such as supervision, coordination, and communication costs. Since the number of employees increases due to the usage of part-time workers, supervisors must oversee more workers or increase the number of layers of supervision. Increased communication and coordination costs are especially relevant when part-time workers are used sequentially. In this case it is likely that two groups of workers are formed,

\footnotetext{
${ }^{30}$ As described in Section 4.4, all core workers share the same educational field and level. Moreover, there is no difference in training participation or training intensity between part-time and fulltime employees.

${ }^{31} \mathrm{With}$ respect to the relative wages of part-timers and full-timers, Montgomery (1988) referred to Rosen (1978), who showed that firm and job characteristics determine which wage-hour combination the firm chooses. Relative productivity may vary among industries. Owen (1978) referred to the following industry characteristics that may affect the relative productivity of part-timers and full-timers: the capital intensity of the industry, the degree to which demand varies predictably over the work week, and the lack of easy division of opening hours into shifts of standard length.
} 
with no obvious need for communication and coordination. Owen (1978) suggested the use of a full-time worker, a full-time supervisor, and overlapping shifts as possible ways of dealing with such a situation.

Montgomery (1988) investigated which firm, job, and industry characteristics influence the existence of part-time employment and the percentage of the firms' total employment force that works part-time. The author's results indicate that quasi-fixed labor costs have a negative impact on the proportion of part-timers in a firm's workforce. ${ }^{32}$

\subsection{Conclusion}

With this chapter, we are the first to analyze and explain the relation between parttime employment and firm productivity. Our unique data set allows analyses of heterogeneous labor shares based on employees' work hours on a "hard" measure of firm productivity. Using a production function with quality-adjusted labor, we divide firms' workforce into part-time and full-time core workers and other employees. Our focus on a particular occupation that employs almost exclusively women justifies our part-time definition of working fewer than 24 hours a week. We find that servicesector firms with a large part-time employment share are more productive than firms with a large share of full-time workers.

Furthermore, we show that allocation efficiencies provide an explanation for this difference in firm productivity. Additional data on the timing of labor demand show that part-time employees are allocated differently than full-time employees. Part-time workers work fewer hours per work day, and fewer days per week. We show that part-time employment increases allocation efficiency over work days. In particular, part-time workers are deployed in such a way that they can bridge the lunch breaks of their full-time colleagues.

In general, service sectors provide good conditions for exploiting the allocation efficiencies offered by part-time employees. In the retail sector, these conditions are opening hours that exceed the full-time work week and opening hours during lunch time. In other service sectors, such as restaurants and call centers, fluctuations in customer demand during the work day or work week could constitute such a condition. In both cases, allocation efficiencies of part-time employment can increase firm productivity in service sectors.

\footnotetext{
${ }^{32}$ Our data do not include any information on quasi-fixed costs that enable us to analyze the relation between such costs and firms' shares of part-time employment and productivity.
} 


\section{Firm Productivity}

\section{Appendix}

Table 4.5: Selectivity analyses

\begin{tabular}{|c|c|c|}
\hline \multirow{2}{*}{\multicolumn{3}{|c|}{$\begin{array}{l}\text { Dep. Var.: completed survey } \\
\text { Region dummies (Mid West is reference group) }\end{array}$}} \\
\hline & & \\
\hline North & $\begin{array}{l}0.373^{* *} \\
(0.145)\end{array}$ & $\begin{array}{l}0.361^{* *} \\
(0.146)\end{array}$ \\
\hline East & $\begin{array}{l}0.059 \\
(0.126)\end{array}$ & $\begin{array}{l}0.077 \\
(0.126)\end{array}$ \\
\hline North West & $\begin{array}{l}-0.035 \\
(0.134)\end{array}$ & $\begin{array}{l}-0.031 \\
(0.134)\end{array}$ \\
\hline South West & $\begin{array}{l}0.127 \\
(0.119)\end{array}$ & $\begin{array}{l}0.138 \\
(0.120)\end{array}$ \\
\hline South East & $\begin{array}{l}-0.290^{* *} \\
(0.139)\end{array}$ & $\begin{array}{l}-0.277^{* *} \\
(0.140)\end{array}$ \\
\hline Average age employees & $\begin{array}{l}-0.013 \\
(0.009)\end{array}$ & $\begin{array}{l}-0.009 \\
(0.010)\end{array}$ \\
\hline Percentage women & $\begin{array}{l}-0.065 \\
(0.474)\end{array}$ & $\begin{array}{l}-0.274 \\
(0.496)\end{array}$ \\
\hline Percentage pharmacy assistants & $\begin{array}{l}-0.015 \\
(0.358)\end{array}$ & $\begin{array}{l}-0.473 \\
(0.677)\end{array}$ \\
\hline Average tenure employees & $\begin{array}{l}0.004^{* * *} \\
(0.001)\end{array}$ & $\begin{array}{l}0.004^{* * *} \\
(0.001)\end{array}$ \\
\hline Average monthly wage employees & $\begin{array}{l}-0.000 \\
(0.000)\end{array}$ & $\begin{array}{l}-0.000 \\
(0.000)\end{array}$ \\
\hline Number of FTEs among employees & $\begin{array}{l}-0.048 \\
(0.038)\end{array}$ & $\begin{array}{l}-0.016^{*} \\
(0.009)\end{array}$ \\
\hline FTEs contributed to full-time assistants & $\begin{array}{l}0.030 \\
(0.047)\end{array}$ & \\
\hline FTEs contributed to part-time assistants & $\begin{array}{l}0.074 \\
(0.059)\end{array}$ & \\
\hline $\begin{array}{l}\text { Fraction of full-time assistants / total employees } \\
\text { (FTE) }\end{array}$ & & $\begin{array}{l}1.003 \\
(0.621)\end{array}$ \\
\hline $\begin{array}{l}\text { Fraction of part-time assistants / total employees } \\
\text { (FTE) }\end{array}$ & & $\begin{array}{l}0.886 \\
(0.766)\end{array}$ \\
\hline Constant & $\begin{array}{l}-0.538 \\
(0.744)\end{array}$ & $\begin{array}{l}-0.618 \\
(0.765)\end{array}$ \\
\hline Log likelihood & -652.77 & $\begin{array}{l}-648.39 \\
\end{array}$ \\
\hline $\mathrm{N}$ & 1626 & 1612 \\
\hline
\end{tabular}


5 Child Outcomes 


\section{Child Outcomes}

\subsection{Introduction}

This chapter focuses on the relation between part-time employment and intergenerational human capital transfer. We compare part-time with full-time maternal employment and with mothers who do not have paid work. ${ }^{1}$ Several studies deal with the relation between maternal employment and child outcomes (e.g., Ermisch and Francesconi 2002; Harvey 1999; Vandell and Ramanan 1992). Most of them have concentrated on maternal work status before the children go to school. Although various studies have provided contradictory evidence, most often a negative relation between maternal employment and child outcomes was found (e.g., Ruhm 2004, Baum 2003, Ermisch and Francesconi 2000).

Also public policies related to parental leave schemes focus on preschool-aged children. Therefore, mothers with children below the age of four often do not participate in the labor market or they choose to work part-time. Whereas there is great heterogeneity in the generosity of parental leave schemes, in most European countries these schemes end before children go to school. ${ }^{2}$ Nevertheless, working full-time may have adverse effects on children's development, when children go to school as well, since, in general, a child's school week comprises shorter hours than are in a full-time work week. Mothers of school-aged children may therefore choose not to work or to work part-time. This is indeed what we see in Table 5.1, which provides data for five European countries. Whereas the labor force participation of mothers with children aged between five and 14 is around $75 \%$ in all countries except for Spain, the number of average work hours is below 33 hours per week. This implies that mothers with school-aged children usually choose a part-time job. While in most countries the labor supply of mothers increases as children, in particular the youngest, grow older, this is not the case for the Netherlands. The labor supply of

\footnotetext{
${ }^{1}$ This chapter is based on joint research with Andries de Grip and Didier Fouarge. We thank Thomas Dohmen and participants of the 2010 Verein für Socialpolitik and the DUHR seminar for useful comments and suggestions. Moreover, we thank the research institute KAANS for providing the Moelejaan data, and Paul Jungbluth and Elma Nap-Kolhoff for data support.

${ }^{2}$ There is great variation in parental leave schemes across countries. The United States is the only Western country in which parents do not get any paid leave: Each parent has the right to take 12 unpaid weeks. In other Western countries, leave schemes are more generous. In the United Kingdom, for example, mothers get 52 weeks of paid leave and both parents get 13 weeks of unpaid leave. In Germany, mothers get 14 weeks fully paid; thereafter parents get 12 or 14 months, during which they are paid $65 \%$ of their previous wage with a certain maximum, depending on whether both parents decide for parental paid leave. Moreover, both parents together have the right to receive three years of unpaid leave before the child turns five years old. In the Netherlands, mothers get 16 weeks of fully paid maternity leave; thereafter both parents get 26 weeks of unpaid leave. This parental leave can be taken discontinuously and before the child turns eight years old.
} 
Dutch mothers remains low, irrespective of the age of the youngest child. Several studies have shown that this is due to the preference of mothers to combine work with caring for their children (e.g., Fouarge and Muffels 2008). ${ }^{3}$ Although Table 5.1 shows that mothers of (young) school-aged children tend to work part-time, research on the relation between maternal work status while the children go to school and child outcomes is sparse.

Table 5.1: Labor force participation and average work hours of mothers by age of youngest child

\begin{tabular}{lllllc}
\hline \hline & $\begin{array}{l}\text { Nether- } \\
\text { lands }\end{array}$ & $\begin{array}{l}\text { United } \\
\text { Kingdom }\end{array}$ & Germany & France & Spain \\
Labor force participation (\%) & & & & & \\
0-4 years old & 72 & 60 & 44 & 62 & 53 \\
5-9 years old & 74 & 75 & 65 & 74 & 55 \\
10-14 years old & 75 & 79 & 74 & 75 & 54 \\
& & & & & \\
Average work week (hours) & 22 & 25 & 24 & 32 & 31 \\
0-4 years old & 20 & 25 & 22 & 32 & 32 \\
5-9 years old & 21 & 28 & 23 & 32 & 32 \\
10-14 years old & & & & & \\
\hline \hline
\end{tabular}

Source: EU LFS 2005

Note: Average work hours are calculated among the working mothers.

In this chapter, we attempt to fill the gap in the literature by analyzing the relation between maternal work status and the cognitive outcomes of young schoolgoing children. When children go to school, the potential time working mothers miss out spending with their children is shorter than when the children do not yet attend school. When mothers' work hours match their children's school hours, working part-time can even result in the same amount of time as non-working mothers can spend with their children. Moreover, working may benefit children through greater family income (e.g., Aughinbaugh and Gittleman 2003, Blau 1999). Family income can be used for both good nutrition and a rich home environment that stimulates child development. Part-time work can therefore have the advantage that mothers can work during school hours and at the same time contribute to family income. As neither income nor parental time spend with children is included in our data set, we cannot directly test these hypotheses. Instead, we test the overall relation between maternal work status and child outcomes. Moreover, this chapter analyzes whether a quantitative measure for a rich home environment - the number of parent-

\footnotetext{
${ }^{3}$ Among Southern European countries, such as Spain, the main reason females work part-time is constraints in the labor supply due to the unavailability of jobs with longer hours.
} 


\section{Child Outcomes}

child activities - can explain this relation between maternal work status and child outcomes. The unique data set we use contains information on Dutch children in their first and second years of regular primary school and builds on two sources: language and sorting test scores provided by schools and information on parental, child, and family characteristics provided by parents.

The Dutch education system provides a good setting for analyzing the relation between maternal work status and the cognitive outcomes of young school-aged children. Children enter school at the age of four and attend two years of preparatory classes. So even though the children in our data set were already attending school, they did not yet have classes in reading, writing, or arithmetic. During these first two school years, children were tested on their language and sorting skills via validated national tests from Cito, a national testing institute. These tests therefore mainly reflect children's initial abilities and parental influences. Moreover, our focus on these young children lowers the risk of reverse causality that can occur when mothers adapt their work hours to children's grades in school.

We find that whereas children's language test score is not related to maternal work status, their sorting test score does depend on maternal work status. We find that this relation is different for girls than for boys. Girls perform best when their mothers have a part-time job of at least 12 and at most 32 hours per week, whereas boys perform best when their mothers work full-time. However, we do not find any evidence that a rich home environment plays a role in the relation between maternal employment status and child outcomes at the age of five.

The structure of this chapter is as follows: The next section briefly reviews the related literature. Section 5.3 describes the data and provides sample statistics. Section 5.4 presents the empirical strategy. Section 5.5 reports the results. Section 5.6 discusses the results and concludes the study.

\subsection{Related literature}

There is an extensive literature on the relation between maternal employment and child outcomes. This literature questions whether children profit more from a nonworking mother who takes care of her child herself or from a mother who works, thereby contributing to family income, but sends her child - at least for some time to some type of formal or informal child care. Only a few studies have distinguished between part-time and full-time maternal employment. The literature provides contradictory evidence on the effect of parents' work time on their children's school performance. Harvey (1999), Greenstein (1995), and Parcel and Menaghan (1994) 
found no detrimental effects of early maternal employment on child development. However, other studies have provided evidence of a negative effect of early maternal employment on child outcomes.

Baum (2003) found that maternal paid work in a child's first year has detrimental effects on the child's cognitive development. Additionally, the author found that working during the first quarter after childbirth decreases child outcomes (as measured by the Peabody Picture Vocabulary Test). Moreover, his results suggested that increased family income from maternal work partially offsets the negative effects of maternal employment. Ruhm (2004) showed that maternal employment during the first three years of a child's life has a negative effect on the cognitive abilities of children aged five and six years old. The effects found are greater for reading and mathematics than for verbal abilities. Evidence shows more favorable outcomes when mothers work part-time than full-time when the child is two or three years old. Using the British Household Panel Study, Ermisch and Francesconi (2000) found a negative effect of mothers' full-time employment during the time the child is zero to five years old on the child's educational attainment as a young adult. The effect of mothers' part-time employment status is also negative, but lesser and insignificant. Similarly, the effect of fathers' employment is small and negative but not always significant. Vandell and Ramanan (1992) showed that early maternal employment has a positive effect on reading and math scores for disadvantaged children.

Contradictory findings may not just result from differences in the time periods analyzed, data sets used, and methodologies applied, but may also be due to the difficulty of analyzing the relation between maternal work hours and child outcomes. Ruhm (2004) suggested that the labor supply decision of parents seems to involve a trade-off between time and goods investments in children. Since there is no data set that includes information on parental work hours, parental time investments, family income, and child outcomes, it is difficult to analyze whether and how parental work hours affect child outcomes. However, there have been studies examining parental work hours, on the one hand, and time or goods investments, on the other.

First, parental work hours affect the time parents have available for spending with their child. Bianchi (2000) showed that this relation does not have to be one to one. Using US time use data, the author showed that, compared to non-working mothers, working mothers selectively reduce their own leisure time, sleeping time, and time devoted to home production other than child care. As a result, mothers with paid employment spend, on average, nearly as many hours in direct child interactions as non-employed mothers. However, when Cawley and Liu (2007) analyzed whether working mothers spend less time with their children than non-working mothers, they 


\section{Child Outcomes}

found that employed women spend significantly less time reading to their children, helping with homework, and in educational activities in general. The authors found no evidence that these decreases in the time spent with the children are offset by increases in the time the husbands spent with the children. Thereby, the authors suggested that lower parental time investments may explain the frequently (but not always) found negative association between maternal employment and children's cognitive development in the United States.

Second, parental work hours affect family income. This, in turn, may affect child outcomes through good nutrition and a home environment that focuses on child development (Aughinbaugh and Gittleman 2003, Blau 1999). Ruhm (2008) analyzed the possibility that home environment is the driving force in the relation between early maternal employment and later child outcomes. The author's analyses on child outcomes included a variable measuring the home environment that consists of a mix of observational and parent-reported items assessing the emotional support and cognitive stimulation received by children through their home environment, planned events, and family surroundings. Ruhm found that a better home environment benefits child outcomes. Negative though not always significant signs of the interaction terms with maternal work hours suggest that this positive effect of home environment is smaller when mothers work more hours.

\subsection{Data and descriptive statistics}

\subsubsection{Dutch early school system}

In the Netherlands, parents are free to choose a primary school for their children. Attending school is obligatory from the age of five on. However, 98\% children enter primary school at the age of four (CBS 2003). The first two years of primary school in the Netherlands are comparable with kindergarten, though obligatory from the age of five on and part of primary school. At this age, children merely have preparatory activities. Only from the third school year onward do children have classes in reading, writing, and arithmetic. During the first two school years, children have to go to school for about 900 hours per year, which boils down to about 30 hours per week. ${ }^{4}$

Nevertheless, most children are tested on their language and sorting skills halfway through the first and second school years. These tests are developed and validated by the national testing institute Cito to determine possible cognitive prob-

\footnotetext{
${ }^{4}$ By law, schools must provide at least 880 hours and at most 940 hours of education per year. Most children have Wednesday afternoon off, but schools are free to institute their own schedules (source: http://www.rijksoverheid.nl/onderwerpen/schooltijden-en-onderwijstijd).
} 
lems at an early age. Although schools are not obliged to test children, about $62 \%$ of all schools test their pupils in the first school year, with this percentage increasing to $76 \%$ in the second school year (Jungbluth and Rodigas 2011).

\subsubsection{Data}

This chapter uses the Moelejaan data from research institute KAANS at Maastricht University. The Moelejaan project focuses on preschool and early-school education in the southern part of the Dutch province of Limburg. The data set builds on two sources: test scores provided by schools and survey information from parents.

Information from schools Schools provide the scores of tests held in the first and second school years, by which time children are aged four to seven. Children are tested on their sorting and language skills halfway through the first and second school years. We have information on these tests from two cohorts: Cohorts 1 and 2 took the tests in the first school year around January 2007 and January 2008, respectively, and in the second school year around January 2008 and January 2009, respectively. ${ }^{5}$

Parental questionnaire All parents of children attending the first two school years of all primary schools in the southern part of Limburg received a questionnaire via the school in September 2008. ${ }^{6}$ Parents could return the questionnaire to the school in a sealed envelope. The survey data contains information on parental work time, as well as information on activities parents undertook with their children. Moreover, the survey data includes detailed information on the children (e.g., various behavior characteristics and non-cognitive skills), their parents (e.g., educational level, parental views, and parenting goals), and their households (e.g., the number of children and the presence of other adults).

About $60 \%$ of all children attending the second year of primary school were tested in the first and second school years. The data set includes 5,232 children. Although the response rate of the parental questionnaire was almost 70\%, only $45 \%$ of the parents completed the survey. Therefore, our sample contains complete information on 2,315 children. Since some children only completed one type of test, our sample sizes for the analyses on child outcomes differ. Our sample for the language

\footnotetext{
${ }^{5}$ There are some exceptions: $2 \%$ of the children attended the first year of primary school twice. For these children, we use their first test scores to make sure the test scores are comparable to those children who did not attend the first year of school twice.

${ }^{6}$ One questionnaire per child, with the child's name, address, date of birth, and gender at the top.
} 


\section{Child Outcomes}

test includes 2,260 children, whereas that for the sorting test includes 1,895 children. $^{7}$ Table 5.2, reports the sample sizes for boys and girls, as the various analyses are performed separately by gender.

Table 5.2: Sample size per tests and children's gender

\begin{tabular}{llll}
\hline \hline & \multicolumn{2}{c}{ Sample for } \\
& Language outcomes & Sorting outcomes & Total sample \\
\hline Total & 2260 & 1895 & 2315 \\
\hline Girls & 1125 & 943 & 1153 \\
Boys & 1135 & 952 & 1162 \\
\hline \hline
\end{tabular}

Note: As we do not have both type of test scores for each child, the two samples relating to child outcomes differ in size. Every child who is in the sample for the time investments, is part of either the language or the sorting sample as well.

Human capital outcomes We use two test scores for children's cognitive outcomes: language and sorting. During the tests, the children worked in their own assignment books. The teacher read the assignment out loud and the children had to mark what they believed was the correct answer. The tests consisted of two parts, both taking about 20 to 30 minutes. The tests in the first and second years were similar. The test scores are the number of good answers.

The language test deals with passive vocabulary and critical listening, and involves 56 assignments. An example of such an assignment is a box showing four pictures of a little boy: a boy passing by a ball, a boy picking up a ball, a boy throwing a ball, and a boy kicking a ball. Children had to mark the picture in which the boy is picking up the ball. The sorting test involves 42 assignments that focus on three sorting principles: classifying subjects (placing them next to each other), ranking subjects, and comparing and counting them. One example of an assignment is a box with four different pictures of vehicles: a bus, an airplane, a car, and a truck. The children had to mark the vehicle that does not fit in the set.

Table 5.3 reports the raw test scores. On average, the children have 47 out of 56 questions right on the language test. With respect to the sorting test, the children have on average, about 34 out of 42 questions right. Group mean comparison tests show that girls perform significantly better in both tests than boys. ${ }^{8}$

\footnotetext{
${ }^{7}$ The sample of children included seems to be slightly positively selected. Children in our sample score on average one point per test higher than children from whom the parents did not complete the survey. For the distribution of test scores of the sample and the population, see Figure 5.5 in the appendix.

${ }^{8}$ Since the girls are not significantly older (in days) than the boys, this finding does not seem be due to differences in age.
} 
Table 5.3: Summary statistics of raw test scores

\begin{tabular}{rrrrrr}
\hline \hline & $\mathrm{N}$ & Mean & Sd. Dev & Min. & Max. \\
\hline Language test & 2260 & 47.4 & 5.4 & 21 & 56 \\
\hline Girls & 1125 & 47.7 & 5.4 & 23 & 56 \\
Boys & 1135 & 47.1 & 5.4 & 21 & 56 \\
\hline Sorting test & 1895 & 33.7 & 4.6 & 14 & 42 \\
\hline Girls & 943 & 33.9 & 4.5 & 16 & 42 \\
Boys & 952 & 33.5 & 4.7 & 14 & 42 \\
\hline \hline
\end{tabular}

Note: This table reports the number of good answers in the language and sorting test. The total number of questions in the language test equals 56 , the total number of questions in the sorting test equals 42 .

Maternal work status The questionnaire provides information on parental work time. The responding parent is asked to report whether they and their partner worked and, if so, how many hours a week. They could report this by selecting the following work statuses: not working, working in a small part-time job (fewer than 12 hours a week), a large part-time job (12 to 32 hours a week), or working in a full-time job (more than 32 hours a week). Figure 5.1 reports the distribution of maternal and paternal work status. Most children (64\%) have a mother with a large part-time job, $15 \%$ of the children has a mother who works full-time, and $5 \%$ has a mother with a small part-time job. The remaining $16 \%$ of the children has a mother without a paid job. We use the latter as the reference category in the analyses. Since almost all the fathers in the sample work full-time, we control for paternal work status but do not focus on the role it plays on child outcomes. About $4.5 \%$ of the fathers have a part-time job, and $3 \%$ of the children has a father without a paid job. ${ }^{9}$ The distribution of parental work hours is identical for boys and girls.

Rich home environment We measure the richness of a child's home environment by two sets of survey questions on parent-child activities: daily activities and planned activities. ${ }^{10}$ We include the number of activities parents undertook with their child in some of the analyses on child outcomes. Thereby, we analyze whether the relation between maternal work status and child outcomes is driven by children's home environment, that is, the number of parent-child activities provided at home.

Questions related to joint daily activities are asked in the following way: In

\footnotetext{
${ }^{9}$ Due to the small numbers of part-time working fathers, we do not distinguish between small and large part-time jobs.

${ }^{10}$ Our focus is on the richness of a child's environment in terms of the quantity of joint activities provided. Of course, the quality of the home environment provided is important for the richness as well.
} 


\section{Child Outcomes}

Figure 5.1: Parental work status

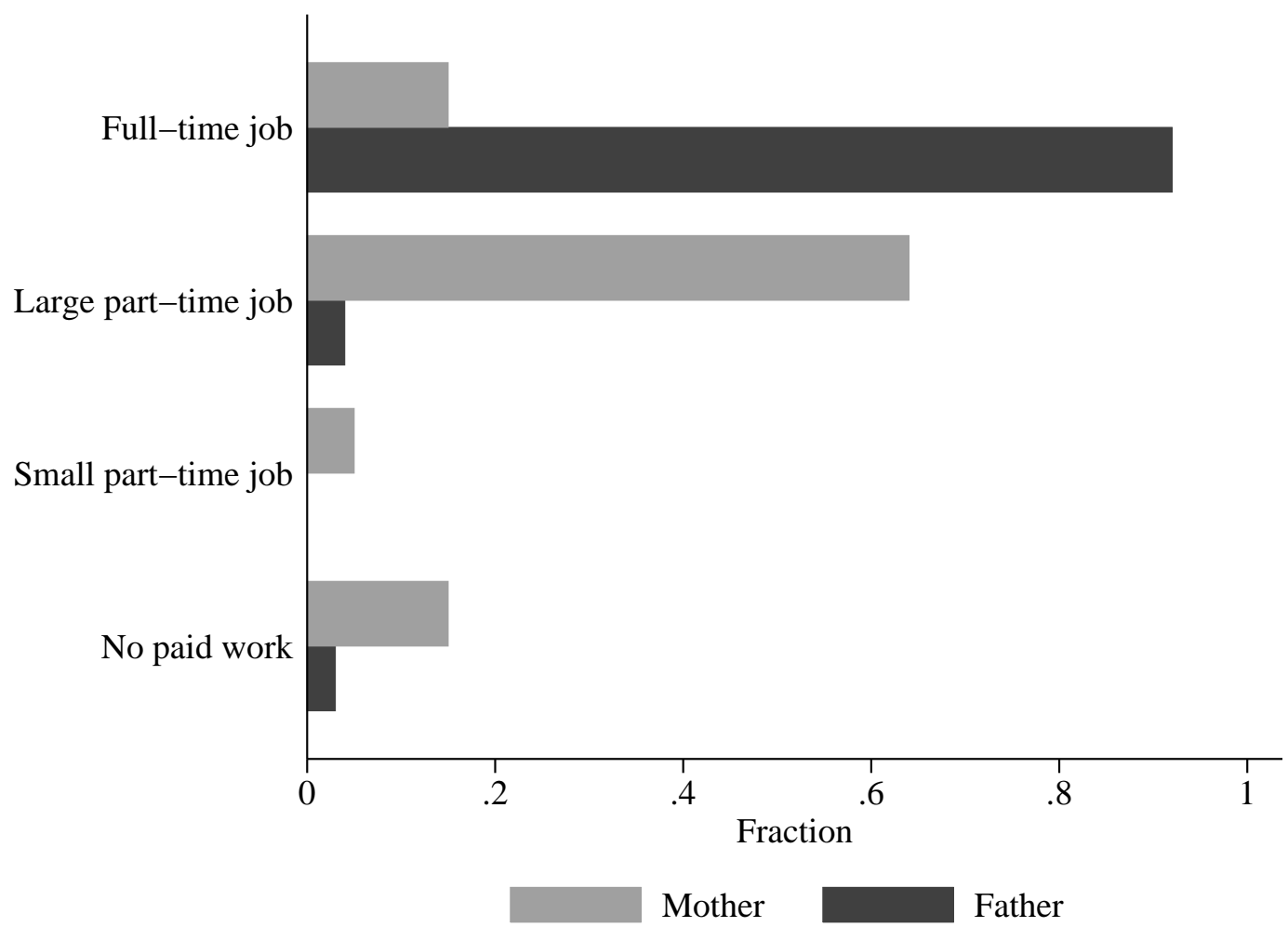

their joint daily activities, children do lots of things together with their parents. What applies to your child? The activities referred to are the following:

- Watching children's programs on TV with your child

- Watching TV/video (other programs) with your child

- Playing with toys inside with your child

- Playing outside with your child

- Playing on a computer with your child
- Drawing/painting with your child

- Making up stories with your child

- Going to the sports club or swimming pool with your child

- Reading stories to your child

- Reading stories focused on development to your child

- Talking about school with your child

We know when at least one of the parents undertook the abovementioned ac- 
tivities with the child, but we do not know which parent. We construct a variable measuring the number of joint activities parents undertook with their child. ${ }^{11}$

Questions dealing with planned activities are asked in the following way: When was the last time you (or your partner) went on a trip together with your child? The trips referred to are the following:

- visiting a museum with your child

- going to a swimming pool with your child

- going to a sports club with your child

- going to a zoo with your child
- going to a library with your child

- going to a park or forest with your child

- going to an amusement park with your child

Possible answers are 'today', 'in the last week', 'some weeks ago', 'some months ago', 'more than half a year ago', and 'I rarely do'. When a parent answered 'I rarely do', we do not count this activity as part of the list of activities undertaken with their child. In case another answer was given, this activity is included in the list of activities undertaken with their child. Then we construct a variable reporting the number of planned activities parents undertook with their child.

Figure 5.2: Distribution of joint parent-child activities

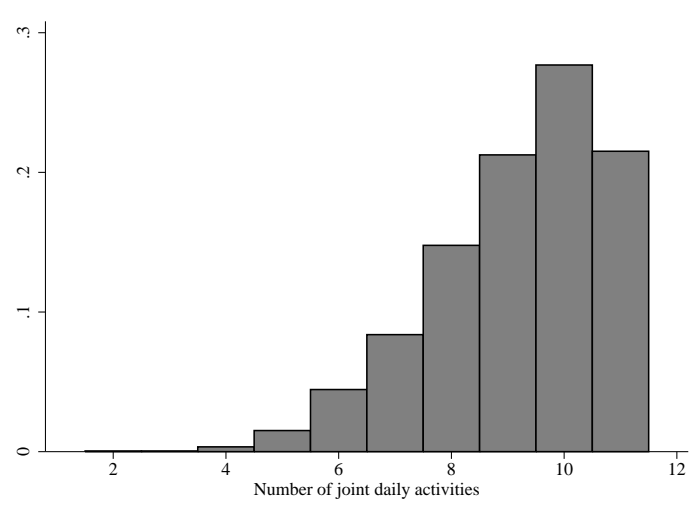

(a) Joint daily activities

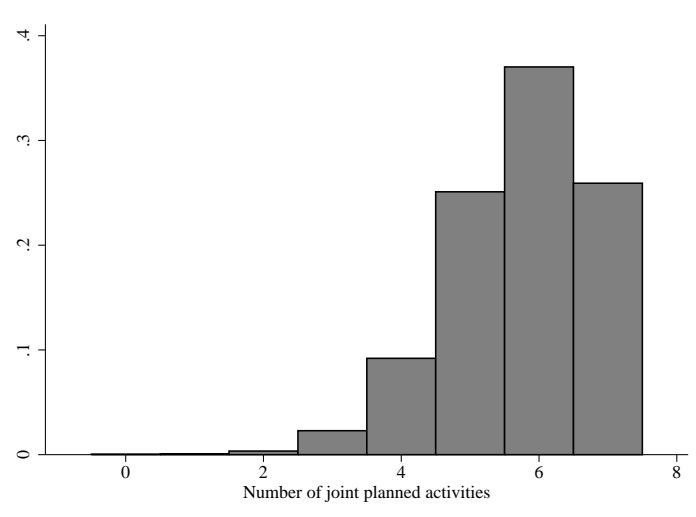

(b) Joint planned activities

Figure 5.2 plots the distribution of the number of joint daily and planned activities: Panel (a) shows that only a few parents undertook fewer than five joint daily

\footnotetext{
${ }^{11}$ Results are similar when leaving out the items "Watching children's programs on TV with your child" and "Watching TV/video (other programs) with your child".
} 


\section{Child Outcomes}

activities with their child. About $10 \%$ of the parents undertook 7 out of the 11 activities with their child. Undertaking 9, 10, or even 11 joint activities is most common in the sample. Panel (b) shows that most parents undertook at least five out of eight planned activities with their child. Both distributions seem to be truncated. ${ }^{12}$

Control variables The questionnaire contains detailed information on the children, their parents, and the household the children live in. As suggested by earlier research, we include parental education levels (e.g., Carneiro, Meghir, Parey, and Street 2007) from the parental questionnaire. Additionally, we include test scores in the first year at school to control for the children's human capital level at school entrance. We only show these two key control variables in the estimation tables.

Other control variables are also included but not reported in the tables with the estimation results. With respect to the children, we include the following control variables: a cohort dummy, a dummy for whether the child speaks Dutch with friends, and a variable denoting the religion of each child. We also include additional information that shows whether the child had specific problems. In this context, we know whether a fundamental event occurred that may have had consequences for the child's development (e.g., 'divorce of the parents') and the extent to which the child suffers from difficulties with respect to emotions, concentration, behavior, and relationships with other people. Moreover, the parental questionnaire includes 50 items on the child's non-cognitive skills. Factor analyses show that we can distinguish four factors, related to the following characteristics: inquisitive (e.g., 'interested'), individual (e.g., 'independent'), difficult (e.g., 'bothersome'), and sociable (e.g., 'oriented toward other children'). The standardized values of these factors are included in all estimations on children's outcomes. ${ }^{13}$

Regarding the parents, we include in addition to their educational level their age, religion, and whether they speak Dutch with their child. We also have information on various parental views and parenting goals. These variables may convey information on heterogeneity in parenting style. Parental views are measured by the extent to which they agree on a five-point Likert scale to 16 statements (e.g., 'child care is important for children's development'). With respect to parenting goals, parents were asked to state on a five-point Likert scale how they viewed the importance of 12 goals for their children (e.g., 'developing imagination'). The analyses

\footnotetext{
${ }^{12}$ This suggests that not all activities parents undertook with their children are mentioned in the questionnaire. However, since the distribution is similar for boys and girls, this is not a problem in our analyses.

${ }^{13}$ The factor loadings for this factor analysis and the upcoming ones can be found in Table 5.7 to 5.9 in the appendix.
} 
include parental values and parenting goals measured by two standardized factors constructed by factor analysis. At the household level, we include the number of children living in the household and whether or not there are grandparents, uncles or aunts, or other adults living in the household. Summary statistics of the control variables are reported in Table 5.6 in the appendix.

Since we have school identifiers, we include school fixed effects to control for differences in school performance and school environment. Since the average distance between home and school for children attending primary school in Limburg is 0.7 $\mathrm{km}$, we thereby indirectly control for differences in neighborhood characteristics as well. ${ }^{14}$

\subsubsection{Descriptive evidence}

Figures 5.3 and 5.4 plot the distributions of the two test scores by maternal work status and gender. Figure 5.3 does not show a significant difference in either the

Figure 5.3: Distribution of language test score by maternal work status and gender
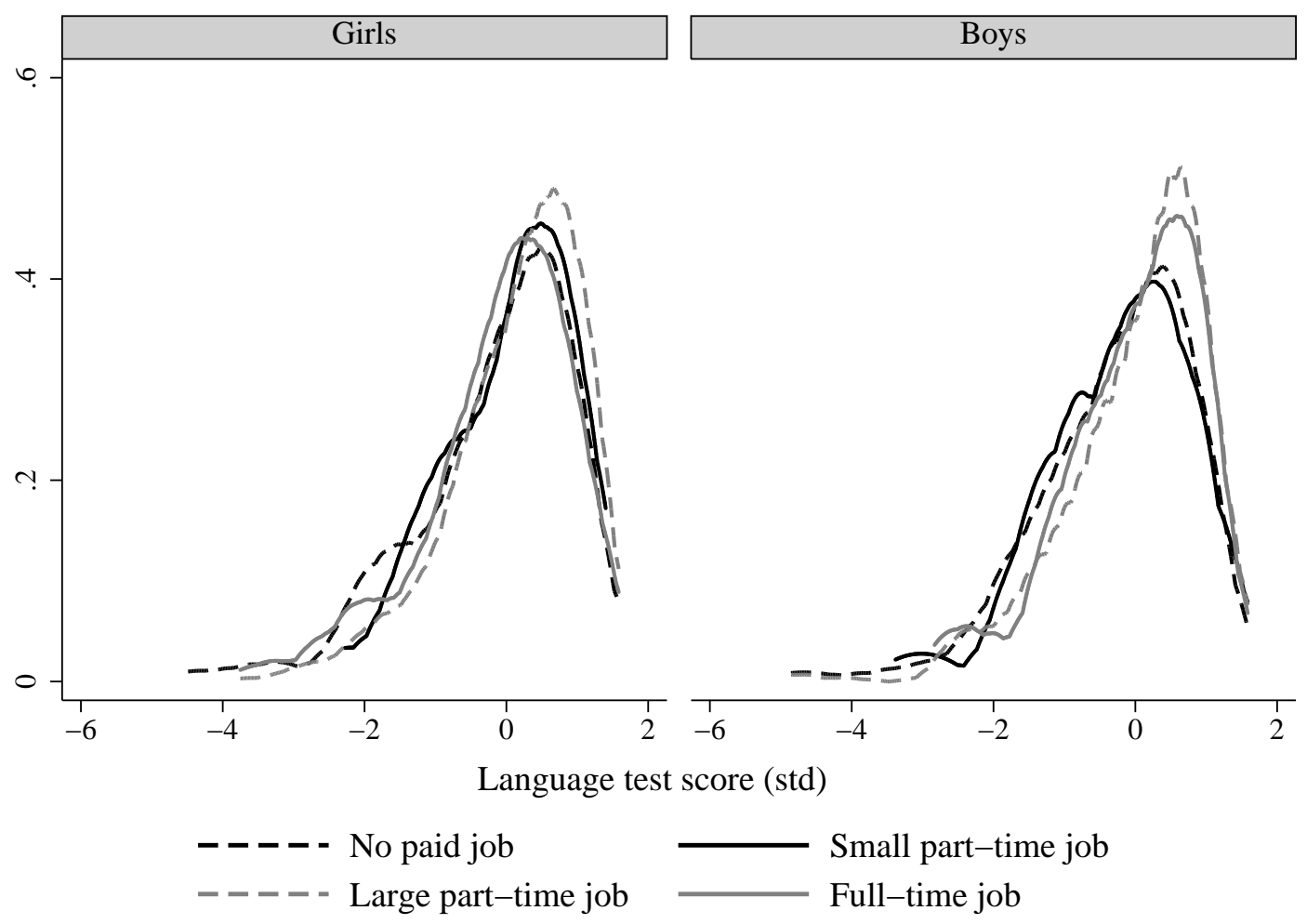

$\begin{array}{ll}---ー- & \text { No paid job } \\ ----- & \text { Large part-time job }\end{array}$

Small part-time job

Full-time job

\footnotetext{
${ }^{14}$ Source: CBS Statline. Regional information: Limburg: years 2006, 2007, 2008.
} 


\section{Child Outcomes}

mean or the distribution of the language test score for children with working and non-working mothers. Moreover, whether a mother works part-time or full-time does not seem to matter. This is in sharp contrast to Figure 5.4, where for both girls and boys the distributions of sorting test scores seem to be shifted to the right and more

Figure 5.4: Distribution of sorting test score by maternal work status and gender
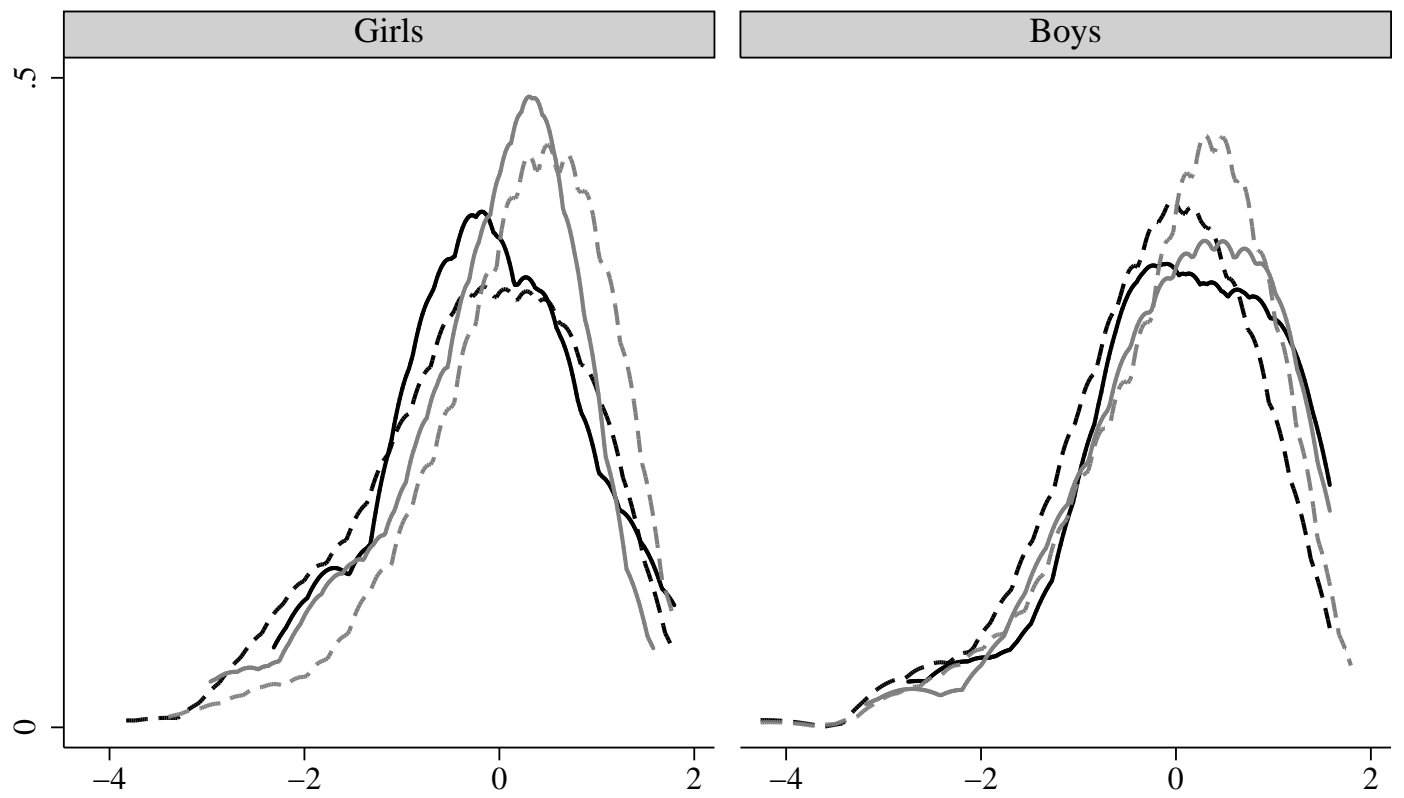

Sorting test score (std)

- - - - No paid job

Small part-time job

----- Large part-time job

Full-time job

compressed when the mother has a large part-time or full-time job, compared to the distributions for children with a mother with a small part-time job or without a paid job. While the mean standardized test scores for girls are highest when their mothers had a large part-time job, those for boys were highest when their mothers had a full-time job. This difference is small and may be caused by other factors driving both maternal work hours and child outcomes, such as maternal education. Section 5.5 analyzes whether maternal work status indeed matters for child outcomes while controlling for, among other things, parental education. 


\subsection{Empirical strategy}

The relation between maternal work status and child outcomes is estimated by Equation (5.1), in which the test scores are standardized:

$$
\begin{aligned}
C_{k, t+1} & =\alpha_{k, t}+\beta_{k 1, t} P T s_{m}+\beta_{k 2, t} P T l_{m}+\beta_{k 3, t} F T_{m} \\
& +\gamma_{k 1, t} N W_{f}+\gamma_{k 2, t} P T_{f}+\delta_{k, t} \mathbf{X}+ \\
& +\lambda_{k, t} \mathbf{C}_{k, t}+\zeta_{k, t} S+\varepsilon_{k, t+1}
\end{aligned}
$$

where $C_{k, t+1}$ denotes either the language test score $(k=1)$ or the testing score $(k=2)$ in the children's second year at primary school. The variables $P T s_{m}, P T l_{m}$, and $F T_{m}$ are dummy variables that denote whether the mother has a small parttime job, a large part-time job, or a full-time job, respectively. The reference group consists of mothers without a paid job. For fathers, we include two dummy variables denoting deviation from the most common work statuses among fathers. We include a dummy for having no paid employment $\left(N W_{f}\right)$ and another for having a part-time job $\left(P T_{f}\right)$. Because the number of fathers belonging to either of these two categories is very small, we do not report these coefficients.

The vector $\mathbf{X}$ denotes control variables as described in Section 5.3. It includes the characteristics of children, parents, and households in general. The variable $C_{k}$ denotes children's test scores in their first year at primary school. ${ }^{15}$ The variable $S$ denotes the school fixed effects. We estimate Equation (5.1) separately for boys and girls, since it turns out that maternal work status affects child outcomes differently for boys and girls.

We estimate whether the relation between maternal work status and child outcomes is driven by parent-child activities provided at home via Equation (5.2):

$$
\begin{aligned}
C_{k, t+1} & =\alpha_{k, t}^{\prime}+\beta_{k 1, t}^{\prime} P T s_{m}+\beta_{k 2, t}^{\prime} P T l_{m}+\beta_{k 3, t}^{\prime} F T_{m} \\
& +\gamma_{k 1, t}^{\prime} N W_{f}+\gamma_{k 2, t}^{\prime} P T_{f}+\delta_{k, t}^{\prime} \mathbf{X}+\lambda_{k, t}^{\prime} \mathbf{N C} \\
& +\zeta_{k, t}^{\prime} \mathbf{C}_{k, t}+\theta_{k, t}^{\prime} \mathbf{D A}+\kappa_{k, t}^{\prime} \mathbf{P A}+\varphi_{k, t}^{\prime} S+\varepsilon_{k, t+1}^{\prime}
\end{aligned}
$$

where DA and PA show the number of joint daily activities and joint planned activities, respectively. A comparison of the coefficients of maternal work status between Equations (5.1) and (5.2) shows the extent to which the relation between maternal

\footnotetext{
${ }^{15}$ When the test scores from the first year are omitted, the education level of the mother becomes more important. The role of maternal employment is robust to omitting earlier test scores in all analyses.
} 
work status and child outcome is affected by the inclusion of joint activities, in other words, whether the relation between maternal work status and child outcomes is (partly) driven by the richness of the children's home environment. ${ }^{16}$

\subsection{Results}

Table 5.4 reports the ordinary least squares (OLS) results of Equations (5.1) and (5.2) for girls (Columns (1) and (2)) and boys (Columns (3) and (4)) separately. ${ }^{17}$ The estimation results show that maternal work status at time $t$ is not related to language test scores at $t+1$; instead, the educational level of the mother seems to be important for children's language test score. The more educated a child's mother, the better the child performs at the language test in the second school year. Because we control for children's test scores in the first year at school, children from highly educated mothers experience larger increases in their human capital than those from less educated mothers.

The relation between maternal work status and child outcomes does not change after including the joint parent-child activities in the regression. Nevertheless, we do find that the richness of the home environment as measured by the number of joint planned activities is positively and significantly related to girls' as well as boys' language test scores, although this relation is only weakly significant for girls. The number of joint daily activities does not seem to relate to children's language test scores. This is somewhat surprising, and suggests that not the quantity of joint daily activities matters for child outcomes but the quality of joint daily activities, or even general interaction, is important instead. The clear positive relation between maternal education and children's language test score is in line with this idea.

\footnotetext{
${ }^{16}$ Unfortunately, our data are cross-sectional, with the exception that test scores are measured in two successive years. Therefore, our estimations should be interpreted with caution since they do not allow for a causal interpretation. However, since the children are very young and have not yet started learning how to read, write, or do arithmetic at school, it is likely that both parental work hours and the number of joint parent-child activities are exogenous with respect to child outcomes, because at preschool ages the child endowments we analyze are not revealed to parents (cf. Ermisch and Francesconi 2000, Rosenzweig and Wolpin 1995). Due to the unique control variables included in the estimations, such as non-cognitive skills, parental views, and parenting goals, unobserved heterogeneity and the associated likelihood of spurious effects is not likely to be a serious issue. There might be another source for endogeneity as well: Parents who are less productive in raising their children could also be less productive in the labor market. This could lead to an upward bias of our findings. Nevertheless, as we include parental education in the analyses to control for this possible source of unobserved heterogeneity, the bias is likely to be small. However, our findings should not be interpreted in a causal way.

${ }^{17}$ Since both figures show a slightly truncated distribution, we perform Tobit analyses when estimating the relation between maternal work status and child outcomes. Since these Tobit estimates are similar to the OLS estimates, we report the OLS estimations in this chapter.
} 
Table 5.4: OLS results on the language test in the second school year

\begin{tabular}{lllll}
\hline \hline & \multicolumn{3}{c}{ Girls } & \multicolumn{2}{c}{ Boys } \\
Dep. Var.: Language test score year 2 (std) & $(1)$ & $(2)$ & $(3)$ & $(4)$ \\
Small part-time job & 0.104 & 0.090 & 0.052 & 0.049 \\
& $(0.137)$ & $(0.137)$ & $(0.140)$ & $(0.140)$ \\
Large part-time job & 0.068 & 0.063 & 0.067 & 0.070 \\
& $(0.080)$ & $(0.080)$ & $(0.076)$ & $(0.076)$ \\
Full-time job & -0.042 & -0.052 & 0.138 & 0.148 \\
& $(0.100)$ & $(0.100)$ & $(0.097)$ & $(0.097)$ \\
Education level mother & $0.043^{* * *}$ & $0.039^{* * *}$ & $0.049^{* * *}$ & $0.046^{* * *}$ \\
& $(0.014)$ & $(0.014)$ & $(0.015)$ & $(0.015)$ \\
Education level father & -0.016 & -0.017 & 0.016 & 0.013 \\
& $(0.013)$ & $(0.013)$ & $(0.014)$ & $(0.014)$ \\
Language test score year 1 (std) & $0.487^{* * *}$ & $0.483^{* * *}$ & $0.411^{* * *}$ & $0.408^{* * *}$ \\
& $(0.030)$ & $(0.030)$ & $(0.030)$ & $(0.030)$ \\
Daily parent-child activities & & 0.014 & & -0.004 \\
& & $(0.018)$ & & $(0.017)$ \\
Planned parent-child activities & & $0.051^{*}$ & & $0.061^{* *}$ \\
& & $(0.026)$ & & $(0.027)$ \\
\hline Adjusted R-squared & & 0.195 & 0.156 & 0.158 \\
N & & 1125 & 1135 & 1135 \\
\hline \hline
\end{tabular}

Note: all specifications include mother, father, child, household characteristics as well as parental values and parenting goals. Standard errors in parentheses; ${ }^{*} \mathrm{p}<0.1 ;{ }^{* *} \mathrm{p}<0.05 ; * * * \mathrm{p}<0.01$

Table 5.5: OLS results on the sorting test in the second school year

\begin{tabular}{lllll}
\hline \hline & \multicolumn{3}{c}{ Girls } & \multicolumn{2}{c}{ Boys } \\
Dep. Var.: Sorting test score year 2 (std) & $(1)$ & $(2)$ & $(3)$ & $(4)$ \\
Small part-time job & -0.042 & -0.038 & 0.200 & 0.190 \\
& $(0.151)$ & $(0.151)$ & $(0.164)$ & $(0.165)$ \\
Large part-time job & $0.176^{* *}$ & $0.177^{* *}$ & 0.034 & 0.032 \\
& $(0.085)$ & $(0.085)$ & $(0.086)$ & $(0.086)$ \\
Full-time job & 0.061 & 0.067 & $0.297^{* * *}$ & $0.296^{* * *}$ \\
& $(0.108)$ & $(0.109)$ & $(0.110)$ & $(0.110)$ \\
Education level mother & 0.016 & 0.017 & -0.001 & -0.001 \\
& $(0.015)$ & $(0.016)$ & $(0.017)$ & $(0.017)$ \\
Education level father & 0.006 & 0.007 & $0.040^{* * *}$ & $0.041^{* * *}$ \\
& $(0.014)$ & $(0.014)$ & $(0.015)$ & $(0.016)$ \\
Sorting test score year 1 (std) & $0.483^{* * *}$ & $0.484^{* * *}$ & $0.421^{* * *}$ & $0.421^{* * *}$ \\
& $(0.032)$ & $(0.032)$ & $(0.034)$ & $(0.034)$ \\
Daily parent-child activities & & -0.012 & & 0.011 \\
& & $(0.019)$ & & $(0.020)$ \\
Planned parent-child activities & & -0.014 & & 0.002 \\
& & $(0.028)$ & & $(0.031)$ \\
\hline Adjusted R-squared & & 0.213 & 0.124 & 0.122 \\
N & 943 & 943 & 952 & 952 \\
\hline \hline
\end{tabular}

Note: all specifications include mother, father, child, household characteristics as well as parental values and parenting goals. Standard errors in parentheses; ${ }^{*} \mathrm{p}<0.1 ;{ }^{* *} \mathrm{p}<0.05 ;{ }^{* * *} \mathrm{p}<0.01$. 


\section{Child Outcomes}

Table 5.5 shows the results from the analyses on the sorting test scores for both girls (Columns (1) and (2)) and boys (Columns (3) and (4)). In contrast to the language test scores, children's sorting test scores appear to relate to maternal work hours. Girls with mothers with a large part-time job perform better than girls with mothers without a paid job. ${ }^{18}$ We also find that maternal work status plays a role in explaining boys' scores on the sorting test. However, in contrast to girls, boys perform best when their mothers have a full-time job. Additionally, we observe a significant relation between boys' sorting test scores and their fathers' level of education.

Table 5.5, shows that joint parent-child activities are not significantly related to children's sorting test scores. It comes therefore as no surprise that the relation between test scores and maternal work status is not affected by the inclusion of the number of joint parent-child activities.

Overall, the richness of the home environment does not seem to play a large role for children's test scores. Whereas the number of planned parent-child activities is, at least to some degree, related to children's language test scores, the number of daily parent-child activities are not related to both test scores. The absence of a clear relation between home environment and child outcomes could imply that not the quantity but the quality of parent-child activities is important for child outcomes. ${ }^{19}$ Moreover, it might be the case that the relation between the number of joint activities and child outcomes is only present if we would have had the full distribution of joint activities. As we have seen in Figure 5.2, the data does not cover the full distribution of planned and daily joint activities as the distributions appear to be censored. This holds even more for the joint daily activities than for the joint planned activities. Therefore, if especially the right tail of the distribution of joint activities is related to higher child outcomes, this would explain why we do barley find relationships between home environment and child outcomes.

Our findings show that a distinction between the determinants of the test scores of boys and girls is valuable, since boys' and girls' test scores seem to be differently related to maternal work status. Whereas girls with mothers with a large part-time job perform significantly better at the sorting test than girls with mothers without a paid job, boys perform significantly better when their mothers work full-time. ${ }^{20}$

\footnotetext{
${ }^{18}$ Even though the children of full-time working mothers do not perform significantly better than the children of non-working mothers, we do not find a significant difference between the coefficients for a large part-time job and a full-time job either.

${ }^{19}$ The measure of home environment used in Ruhm (2008), includes both quantity and quality measures and is indeed significantly related to child outcomes.

${ }^{20}$ Whereas we are not aware of studies differentiating between boys and girls when it comes to ma-
} 
With respect to the sorting test scores, we find that children benefit when their mothers work. This is probably related to the fact that the children in our sample all attend school about 30 hours a week. The possible difference in the time spent with children between a non-working mother and a mother with a large part-time, or even a full-time job, is therefore much less than when children do not yet attend school. In our sample of young school-aged children, part-time working mothers may work during school hours. Even in the case where mothers have to work when the children are not at school, the difference in the number of joint parent-child activities between working and non-working mothers seems to be of less importance than the advantages maternal employment can bring. The most straightforward advantage is a higher family income. In our sample, where almost all fathers work full-time, families with a mother with a large part-time or full-time job probably have a higher family income than families in which the mother does not work. This additional income may benefit children by better nutrition and goods or services that benefit children's cognitive development. However, we do not find any significant evidence for a richer environment in terms of the number of joint parent-child activities to explain the better cognitive outcomes of children with a mother who works at least 12 hours per week.

\subsection{Conclusion}

In this chapter, we analyze the relation between maternal work status and child outcomes. In contrast to most earlier research, our analyses focus on the work status of mothers of young school-aged children. When children attend school, the potential time working mothers miss out spending with their children is much less than when children do not yet attend school. Mothers who work part-time especially may work entirely during school hours. At the same time, working can benefit children, for example, through greater family income.

We do not find a negative relation between maternal employment and child outcomes as is often found for preschool aged children. Instead, we find that boys'

\footnotetext{
ternal employment and child outcomes around age 4, literature focusing on the relation between maternal employment (and child care) in the first year and child outcomes is not consistent with respect to different findings for boys and girls. Often no differentiated relation is found (Ruhm 2004, Han, Waldfogel, and Brooks-Gunn 2001, Hill, Waldfogel, Brooks-Gunn, and Han 2005). Nevertheless, when differences are found, the relation between maternal employment and child outcomes seems to be stronger negative for boys than for girls (Brooks-Gunn, Han, and Waldfogel 2002, Desai, Chase-Lansdale, and Michael 1989). This is often attributed to the findings of Zaslow and Hayes (1986) and Rutter (1985) which suggest that boys are more vulnerable than girls in their first year.
} 


\section{Child Outcomes}

and girls' sorting test scores are higher when their mothers have a large part-time or full-time job, respectively. In contrast to our expectations, part-time employment - allowing for working during school hours - does not seem to be most beneficial for all children, since boys with full-time working mothers perform better than boys of mothers with a part-time job. Since the test scores for girls with a full-time working mother are as good as those for girls with mothers with another employment status, our findings suggest that full-time employment may be most beneficial for the cognitive outcomes of young school-aged children. ${ }^{21}$ This finding, that working mothers benefit school-aged children, is in line with the findings of O'Brien and Jones (1999), who found that children aged 13 to 15 perform best when their mother is employed, although these gains are not as strong when both parents work full-time.

We also show that maternal employment benefits children in a way that cannot be explained by a richer home environment in terms of joint parent-child activities. Instead, greater monetary resources may play a role in the relation found. Several studies indeed show a positive although small effect of parental income on child development (e.g., Aughinbaugh and Gittleman 2003, Blau 1999). In Brooks-Gunn, Han, and Waldfogel (2010) it is shown that maternal employment is positively associated with mothers' earnings and that this offsets the negative direct association between early maternal employment and child outcomes at age 4.5 in the United States.

Another channel through which maternal work hours and child outcomes may be related is the quality of the home environment. At work, mothers may exchange information and experience regarding time allocation, good child care centers, and child-raising activities with their colleagues. So, whereas joint parent-child activities do not explain the relation between maternal work status and child outcomes, the quality of parent-child interactions may be important. The quality of parent-child activities may also be higher, because mothers who work are happier and reflect this in their parenting. Especially for the generation of mothers analyzed in this study, women may be happier when they are able to combine family life with a paid (part-time) job. However, while several studies have addressed the question of whether partnered women in the Netherlands prefer part-time jobs over full-time jobs (e.g., Booth and Van Ours 2010, Bosch, Deelen, and Euwals 2010, Portegijs, Clon, Ooms, and Eggink 2006), we are not aware of any studies that have analyzed whether working mothers are indeed happier than non-working mothers.

\footnotetext{
${ }^{21}$ Since we do not find a significant difference between the test scores for girls with full-time working mothers and girls with mothers with a large part-time job, a larger sample size would probably result in a significant coefficient for full-time maternal employment as well.
} 
Our findings suggest that a high rate of labor market participation among mothers of school-aged children is positively related to the intergenerational transfer of cognitive skills, provided that the mothers work for a substantial number of hours (at least in a large part-time job). This is an important conclusion, since research (e.g., Currie and Thomas 2001) has shown that early child outcomes are good predictors of economic outcomes at later ages.

Moreover, our findings suggest that governments may encourage the mothers of school-aged children to re-enter the labor market or increase their work hours, since maternal employment benefits child outcomes. In the Netherlands, for example, mothers do not usually return to their pre-maternity work hours, even after their children are older and start school (Bosch, Deelen, and Euwals 2010, Paull 2008). Also other European countries have a scope to increase the labor supply of mothers with school-aged children (see Table 5.1) to deal with the ageing of the population. 


\section{Child Outcomes}

\section{Appendix}

Figure 5.5: Distribution of test scores for sample and population

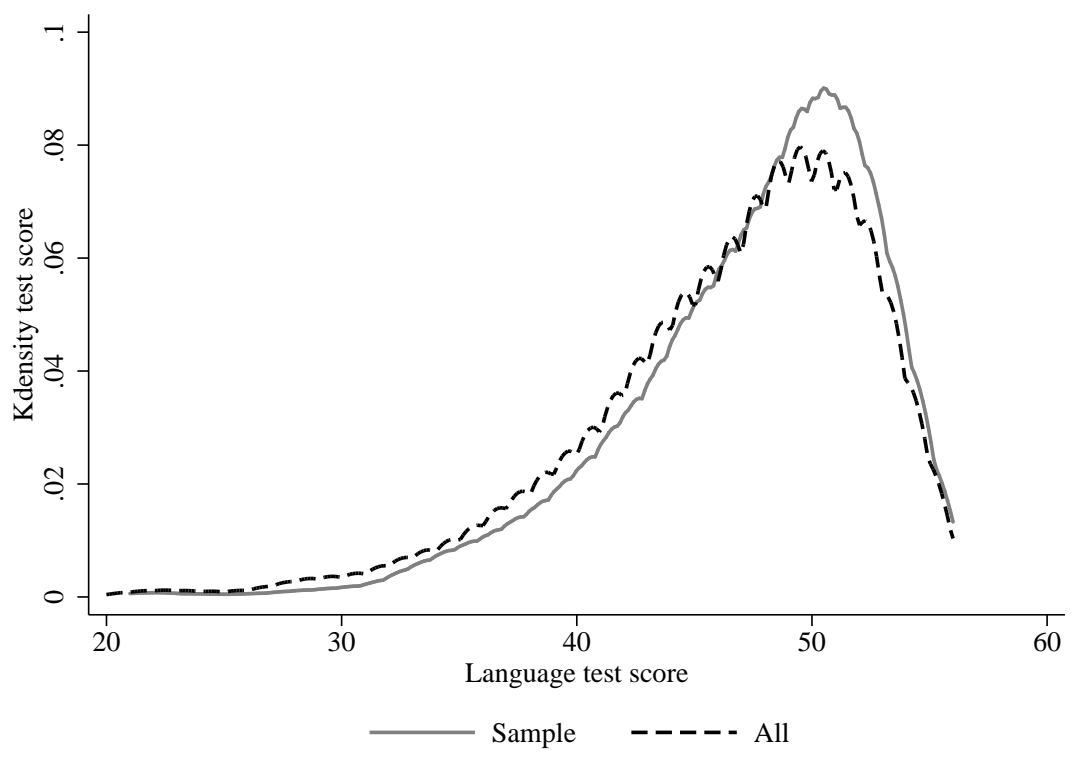

(a) Language test

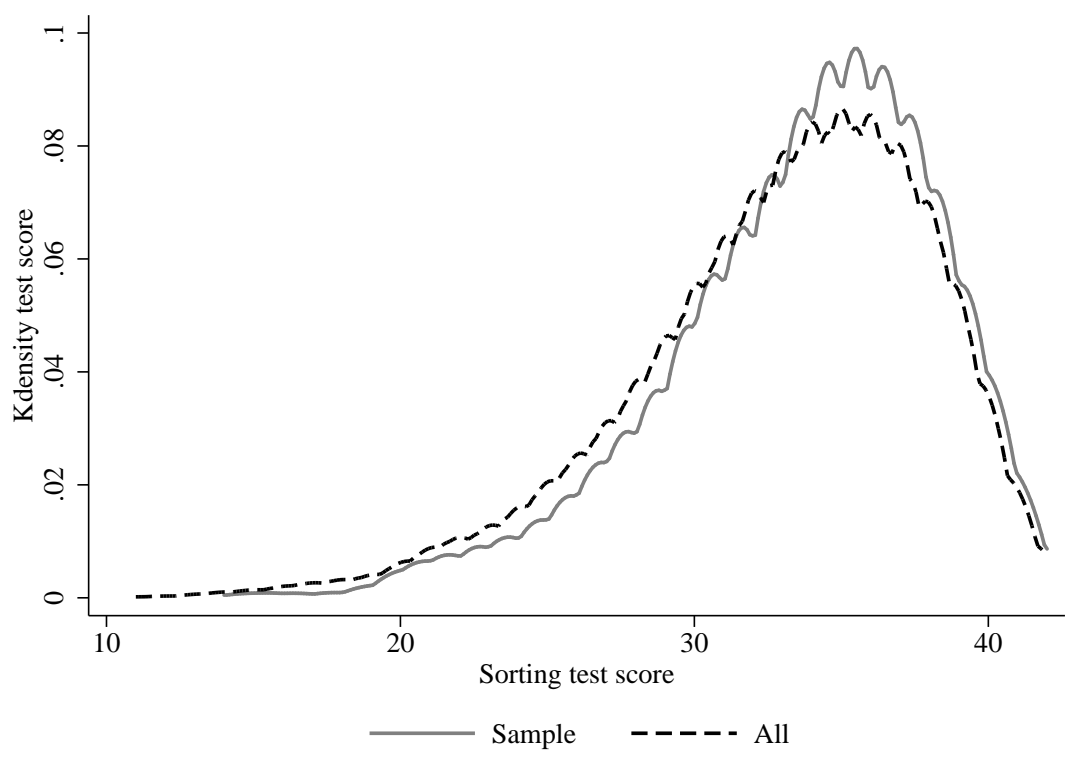

(b) Sorting test 
Table 5.6: Summary statistics of control variables by gender of child

\begin{tabular}{|c|c|c|c|c|c|}
\hline & $\mathrm{N}$ & Mean & Std. Dev. & Min & $\operatorname{Max}$ \\
\hline Education level mother & 2315 & 6.39 & 2.22 & 0 & 9 \\
\hline Year of birth mother & 2315 & 1971 & 3.89 & 1960 & 1998 \\
\hline Mother speaks Dutch with the child & 2315 & 0.95 & 0.22 & 0 & 1 \\
\hline Education level father & 2315 & 6.51 & 2.36 & 0 & 9 \\
\hline Year of birth father & 2315 & 1969 & 4.06 & 1959 & 1985 \\
\hline Father speaks Dutch with the child & 2315 & 0.95 & 0.22 & 0 & 1 \\
\hline Gender & 2315 & 0.50 & 0.50 & 0 & 1 \\
\hline Number of children living in the household & 2315 & 3.09 & 0.71 & 1 & 7 \\
\hline Are there any grandmoms/dads living in the household? & 2273 & 0.01 & 0.09 & 0 & 1 \\
\hline Are there any aunts/uncles living in the household? & 2214 & 0.00 & 0.04 & 0 & 1 \\
\hline Are there any other adults living in the household? & 2212 & 0.00 & 0.06 & 0 & 1 \\
\hline Cohort & 2315 & 2.48 & 0.50 & 2 & 3 \\
\hline Child speaks Dutch with friends & 2315 & 0.99 & 0.11 & 0 & 1 \\
\hline $\begin{array}{l}\text { Did a fundamental event occur that affected } \\
\text { child's development? }\end{array}$ & 2315 & 0.06 & 0.23 & 0 & 1 \\
\hline Extent to which child has difficulties with emotions & 2290 & 0.19 & 0.45 & 0 & 3 \\
\hline Extent to which child has difficulties with concentration & 2291 & 0.29 & 0.56 & 0 & 3 \\
\hline Extent to which child has difficulties with behavior & 2289 & 0.15 & 0.40 & 0 & 3 \\
\hline $\begin{array}{l}\text { Extent to which child has difficulties with dealing } \\
\text { with other people }\end{array}$ & 2278 & 0.07 & 0.30 & 0 & 3 \\
\hline
\end{tabular}

Note: Whereas the sample size is 2315 , some variables in the table have lower numbers of observations. This is due to missing values. In the analyses, we include dummy variables for all possible values of these values, including a dummy for missing values. Other control variables not mentioned in the table are standardized (factor) variables with mean equal to zero and a standard deviation equal to one. It concerns parental views, parenting goals, and the four noncognitive skills (inquisitive, individual, difficult and sociable). Moreover, the table excludes summary statistics on mothers', fathers' and children's religion as we include several religion dummies that are not so informative. 
Table 5.7: Factor loadings on children's non-cognitive skills

\begin{tabular}{|c|c|c|c|c|}
\hline Items & Factor 1 & Factor 2 & Factor 3 & Factor 4 \\
\hline & Inquisitive & Individual & Difficult & Sociable \\
\hline Oriented towards other children & & & 0.3033 & 0.7324 \\
\hline Adapts easily & & & & 0.6226 \\
\hline Independent & & 0.7464 & & \\
\hline Smart & 0.4799 & & & \\
\hline Imagination in somebody else's situation & & 0.7225 & & \\
\hline Chaotic & & 0.4895 & & \\
\hline Easygoing & & 0.7463 & & \\
\hline Can amuse oneself & & & 0.5426 & \\
\hline Focussed on herself/ himself & & & & 0.7062 \\
\hline Cheerful & & & & 0.7318 \\
\hline To be quick on the uptake & 0.5033 & & & \\
\hline Friskily & 0.7846 & & & \\
\hline Complaining & 0.7523 & & & \\
\hline Quiet & 0.4906 & 0.3309 & & \\
\hline Bothersome & 0.3484 & & 0.4554 & \\
\hline Talks a lot & & 0.312 & 0.6138 & \\
\hline Precise & & & -0.3269 & \\
\hline Frivolous & & & & \\
\hline Nice & & 0.4649 & & \\
\hline Scared & & & & 0.3543 \\
\hline Leisurely & 0.7631 & & & \\
\hline Creative & 0.7901 & & & \\
\hline Thoughtful & 0.7683 & & & \\
\hline Systematic & 0.3622 & & 0.5873 & \\
\hline Timid & & 0.3697 & 0.3454 & \\
\hline Spontaneous & & & 0.3056 & \\
\hline Gripped & & & 0.7254 & \\
\hline Easy & -0.4006 & 0.6226 & & \\
\hline Irascible & & & 0.7804 & \\
\hline Inquisitive & 0.3997 & & & \\
\hline Interested & 0.5996 & & & \\
\hline Active & & 0.6686 & & \\
\hline Nasty & 0.7181 & & & \\
\hline Gets tired easily & & 0.3858 & 0.3532 & \\
\hline Keeps distance & & & 0.5976 & \\
\hline Kind & & & & 0.5168 \\
\hline Slowly & -0.3066 & 0.364 & 0.604 & 0.3539 \\
\hline Reserved & & 0.6904 & & \\
\hline Contacts others easily & 0.8021 & & & \\
\hline Jumpy & & 0.4155 & 0.4582 & \\
\hline Healthy & 0.6826 & & & \\
\hline Imaginative & 0.6642 & & & \\
\hline
\end{tabular}


Table 5.8: Factor loadings on parental views

\begin{tabular}{lr}
\hline \hline & Factor 1 \\
To what extent do you agree/disagree to the following statements: & Parental views \\
Going to college is more important for boys than for girls. & 0.2290 \\
Marriage is old-fashion. & 0.0276 \\
Our children will have a better life than we have . & 0.3506 \\
Home work is at least as satisfying as is paid work. & 0.2072 \\
Men are often better politicians than women. & 0.5067 \\
Children need a family with both a mother and a father. & 0.2267 \\
Religion is very important to me. & 0.2360 \\
I am jealous at the opportunities of the youngest generation. & 0.3122 \\
Children need to be prepared to school at an early stage. & 0.2871 \\
Early child care is important for children's development. & 0.0754 \\
It is important that children do well at school. & 0.4049 \\
Women are allowed to be mother without a stable relationship. & -0.2948 \\
Men do mostly a better job in managing occupations. & 0.5449 \\
My child needs to go to a school nearby. & 0.1287 \\
I assume that our children will have a better life than we have. & 0.2966 \\
At school children should have to work hard. & 0.3635 \\
\hline \hline
\end{tabular}

Table 5.9: Factor loadings on parenting goals

\begin{tabular}{lr}
\hline \hline & Factor 1 \\
How important is it to you that your child learns: & Parenting goals \\
to be economical & 0.4436 \\
to know what is going on in the world & 0.4309 \\
to be hardworking & 0.3737 \\
to stand one's ground & 0.4038 \\
to take time for her/hisself & 0.6110 \\
to fight for her/hisself & 0.5967 \\
to develop imagination & 0.5304 \\
to indulge her/hisself & 0.5629 \\
to be tolerant towards others' opinions & 0.5792 \\
to be independent & 0.5575 \\
to not let her/hisself be rushed & 0.6073 \\
to be satisfied with what she/he has & 0.6081 \\
to show persistence & 0.5884 \\
to be religious & 0.2766 \\
to show solidarity & 0.5129 \\
to obey & 0.4628 \\
\hline \hline
\end{tabular}



6 Conclusions 


\section{Conclusions}

\subsection{Summary}

This thesis aims to investigate the relation between part-time employment and intraand intergenerational human capital investments, and how these relations can explain differences in workers' careers, firm productivity, and children's human capital outcomes. The thesis consists of four chapters on different aspects of part-time work in the context of human capital accumulation. Whereas Chapters 2 and 3 investigate the worker perspective, Chapter 4 focuses on the firm perspective. Finally, Chapter 5 analyzes the intergenerational perspective.

In Chapter 2, we find that the human capital development of part-timers lags behind that of full-timers. This seems to be due to a lower incentive for employers to invest in the human capital development of part-timers compared to full-timers. While full-time workers are positively affected by the human resource practices of the firm in which they are employed, this does not hold for part-time workers. Part-time workers can only partly compensate for this lack of firm support when they have high learning motivation and a good imagination of their future development.

In Chapter 3, we find that human capital development is important in explaining the part-time pay penalty. We show that the pay penalty related to the occupational segregation of part-timers is largely related to differences in average human capital investments across occupations. Moreover, we show that the part-time pay penalty is heterogeneous across occupations. We find that one-fifth of the differences in parttime pay penalties across occupations can be explained by differences in the relative human capital investments of part-timers compared to full-timers.

In Chapter 4, we find that service-sector firms with a large share of part-time employment are more productive than those with a large share of full-time employment. We explain this by the allocation efficiencies offered by part-time employment and show that part-time employees are allocated differently than full-time employees. Part-time workers work both fewer hours per work day and fewer days per week. In particular, part-time workers are deployed in such a way that they can bridge the lunch breaks of their full-time working colleagues.

In Chapter 5, we find that maternal employment during children's first school years is related to child outcomes (measured by a language and a sorting test). Children from non-working mothers perform worst in the sorting test. Children's sorting test score is higher when their mothers work at least 12 hours per day. Whereas girls perform best when their mothers have a large part-time job, boys perform best when their mothers work full-time. Even though this finding is likely 
to relate to a larger family income, we do not find that a richer home environment can explain this relation.

\subsection{Part-time employment: Good or bad for human capital development?}

In this concluding section, we make an overall judgment on the relation between part-time employment and human capital development based on the findings of this thesis. We focus on the three perspectives of part-time employment studied throughout this thesis: the part-timers themselves, the firms they work in, and their children. For each perspective, we discuss our findings, ideas for further research, and policy implications. Since most of the relations we study are not causal, our policy implications should be interpreted carefully.

Worker perspective With respect to the consequences of part-time employment for the workers themselves, the literature is quite negative (e.g., Connolly and Gregory 2008, Manning and Petrongolo 2008). This thesis shows that, on average, parttime workers are indeed less stimulated to keep their human capital up-to-date than full-timers (see Chapter 2). However, Chapter 3 shows that it is crucial to allow for heterogeneity in the consequences of part-time employment on workers' human capital development and wages. Chapter 3 shows that it is important to differentiate across occupations. The relative human capital development of part-timers compared to that of full-timers appears to be different across occupations. We find that only in low-skilled occupations part-timers invest less in their human capital than full-timers. This heterogeneity in the relation between part-time employment and human capital development is reflected in a heterogeneous part-time pay penalty across occupations. Whereas we find a part-time pay penalty among workers in low-skilled occupations, we do not find one among workers in high-skilled occupations.

Heterogeneity in the consequences of part-time employment for the workers themselves is probably not only present across occupations. The sector of industry in which they are employed probably provides a source for heterogeneity in the effects of part-time employment as well. Sectors indeed vary, e.g., in the degree to which human capital accumulation is important for workers. More innovative sectors have, among other things, large expenditures in research and development, and a high share of their workforce participates in training. In such innovative sectors of industry, the possibilities of working part-time, as well as the consequences in terms of training 


\section{Conclusions}

participation and wages if working part-time, are likely to be different compared to less innovative sectors. Further research on the heterogeneity in the worker effects of part-time employment across sectors of industry is therefore required. These studies should focus particularly on the differences between the manufacturing and service sectors. In the manufacturing sector, the lower human capital development of part-timers compared to full-timers may be reflected in lower productivity, whereas in service sectors the lower human capital development of part-timers compared to full-timers may lead to a direct loss of customers. Therefore, we expect that in service sectors the training participation of part-timers is similar to that of fulltimers. The Dutch pharmacy sector, which is examined in Chapter 4, is one example of a service sector in which part-timers and full-timers are trained equally. Moreover, it is interesting to determine whether part-timers have to pay more for their training themselves than full-timers in service sectors.

On average, part-timers lag behind full-timers in terms of human capital. Because the human capital investments of part-timers are only stimulated by their own learning motivation and imagination of one's own future development, it is important that they obtain more information about the importance of keeping their skills up-to-date for their labor market position.

Depending on who benefits most from part-time employment, the firm (in case of service sectors) or the worker, either the employer or the part-time worker should pay for (part of) the training costs. Part-timers should see this as a levy for being able to work part-time when part-time employment is not the most efficient type of employment for these firms.

Firm perspective There may be differences in the consequences of part-time work for firm productivity between sectors of industry as well. Chapter 4 shows that part-time employment is beneficial for firm productivity in service sectors. Service sectors provide good conditions for exploiting allocation efficiencies offered by parttime employment. In the retail sector, these conditions include opening hours that exceed the full-time work week and opening hours during lunch time. In other service sectors, such as restaurants and call centers, fluctuations in customer demand during the work day or work week can constitute such a condition. The finding that parttime employment is beneficial for firm productivity in the service sector is in line with the observation in Chapter 3, that a part-time pay penalty is not found in most service occupations.

In manufacturing sectors, part-time employment is probably not beneficial for firm productivity. First, as mentioned above, part-timers in goods sectors are likely 
to invest less in their human capital development than full-timers, making parttimers less productive than full-timers. Since the manufacturing sector does not provide similar conditions to exploit allocation efficiencies offered by part-time employment, firm productivity will be lower if the share of part-time employees is large. Second, quasi-fixed labor costs per hour worked are larger for part-timers than for full-timers. Quasi-fixed labor costs consist of the administrative costs of supervising and maintaining records for each worker, costs related to searching for, hiring, and training new workers, as well as communication and coordination costs (Owen 1978). However, the relation between part-time employment and firm productivity in the manufacturing sector has not been studied yet. Future research on this relation is important before an overall statement on the relation between part-time employment and firm productivity can be given.

Since part-time employment can be beneficial for firm productivity in the service sector, it is important that the government reconsiders the value of part-time employment for economic prosperity. In the Netherlands, the government should not continue its unfocused efforts to stimulate all workers to work at least 24 hours per week, since this will reduce the possibility of allocating labor efficiently in many service sectors.

Child perspective The relation between maternal part-time employment and the human capital development of children is not univocal either. Literature on early maternal employment provides contradictory evidence and does not always include part-time maternal employment. Most often no relation or a negative relation between early maternal (part-time) employment and child outcomes is found (e.g., Ruhm 2004, Baum 2003, Ermisch and Francesconi 2000). If studies indeed show that working (part-time) hurts the cognitive outcomes of preschool aged children, this is often attributed to lower time investments in children's development. However, research on the mechanism driving the relation between early maternal (part-time) employment and child outcomes is lacking. Such research is needed to confirm the effects of early maternal employment on child outcomes.

In Chapter 5, we examine the relation between maternal employment status and the outcomes of young school-aged children. We find that working part-time or full-time does not hurt children's human capital outcomes. Children's sorting test score in their second year at school is even better when their mother work at least 12 hours per week. This is likely due to a larger family income. However, we do not find that higher test scores can be attributed to a richer environment at home. 


\section{Conclusions}

Therefore, further research is needed to determine the driving mechanism behind the positive relation between maternal employment and child outcomes.

The observation that children from working mothers in their first years at school perform at least as well as the children of non-working mothers, suggests that governments might stimulate mothers of school-aged children to re-enter the labor market or to increase their work hours. In the Netherlands, for example, mothers do not usually return to the work hours they held before they gave birth, even when their children start school (Bosch, Deelen, and Euwals 2010, Paull 2008). Similar evidence has been found for the United Kingdom (Paull 2008). Governments may therefore provide more information to mothers that working in large part-time or full-time jobs does not hurt child outcomes.

In conclusion, the answer to the question of whether part-time employment is positively related to human capital development or not is it depends. For workers, it depends on their occupation and, for firms, it depends on their sector of industry. Finally, for children, it seems to depend on the timing of maternal employment. 


\section{Bibliography}

Aaronson, D., and E. French (2004): "The Effect of Part-Time Work on Wages: Evidence from the Social Security Rules," Journal of Labor Economics, 22(2), 329352.

Arrow, K. (1962): "The Economic Implications of Learning by Doing," The Review of Economic Studies, 29, 155-173.

Arthur, J. B. (1994): "Effects of Human Resource Systems on Manufacturing Performance and Turnover," Academy of Management Journal, 37(3), 670-687.

Arvanitis, S. (2005): "Modes of Labor Flexibility at Firm Level: Are there any Implications for Performance and Innovation? Evidence for the Swiss Economy," Industrial and Corporate Change, 14(6), 993-1016.

Aughinbaugh, A., And M. Gittleman (2003): "Does Money Matter? A Comparison of the Effect of Income on Child Development in the United States and Great Britain," The Journal of Human Resources, 38(2), 416-440.

Baffoe-Bonnie, J. (2004): "Interindustry Part-Time and Full-Time Wage Differentials: Regional and National Analysis," Applied Economics, 36(2), 107-118.

Baum, C. L. (2003): "Does Early Maternal Employment Harm Child Development? An Analysis of the Potential Benefits of Leave Taking," Journal of Labor Economics, 21(2), 381-408.

Beblo, M., D. Beninger, A. Heinze, and F. Laisney (2003): "Measuring Selectivity-Corrected Gender Wage Gaps in the EU," ZEW Discussion Paper 0374 . 


\section{Bibliography}

Beblo, M., And E. Wolf (2002): "How Much does a Year Off Cost? Estimating the Wage Effects of Employment Breaks and Part-Time Periods," Cahiers Économique de Bruxelles, 45(2).

Becker, B., And M. Huselid (1998): "High Performance Work Systems and Firm Performance: a Synthesis of Research and Managerial Implications," in Research in Personnel and Human Resources, ed. by G. Ferris, vol. 16, pp. 53-101. CT: JAI Press, Stamford.

Becker, G. S. (1964): Human Capital. University of Chicago Press, USA: Chigaco.

Bianchi, S. (2000): "Maternal Employment and Time with Children: Dramatic Change or Surprising Continuity?," Demography, 37(4), 401-414.

Birdi, K., C. Allan, and P. Warr (1997): "Correlates and Perceived Outcomes of 4 Types of Employee Development Activity," Journal of Applied Psychology, $82(6), 845-857$.

Black, S. E., ANd L. M. Lynch (2001): "How to Compete: the Impact of Workplace Practices and Information Technology on Productivity," Review of Economics and statistics, 83(3), 434-445.

Blau, D. (1999): "The Effect of Income on Child Development," Review of Economics and Statistics, 81(2), 261-276.

Booth, A., And J. Van Ours (2010): "Part-Time Jobs: What Women Want?," IZA Discussion Paper 4686.

Booth, A., And M. Wood (2008): "Back-to-Front Down Under? Part-Time/FullTime Wage Differentials in Australia," Industrial Relations, 47(1), 114-135.

Borghans, L., A. Duckworth, J. Heckman, and B. Ter Weel (2008): "The Economics and Psychology of Personality Traits," Journal of Human Resources, 43(4), 972-1059.

Borghans, L., B. Golsteyn, and A. De Grip (2007): "Werkend Leren," ESB, 92(4509), 260-263.

Bosch, N., A. Deelen, and R. Euwals (2010): "Is Part-time Employment Here to Stay? Working Hours of Dutch Women over Successive Generations," Labour, 24(1), 35-54. 
Brooks-GunN, J., W. Han, And J. WAldfogel (2002): "Maternal employment and child cognitive outcomes in the first three years of life: The NICHD study of early child care," Child Development, 73(4), 1052-1072.

Brooks-Gunn, J., W.-J. HAn, And J. WAldfogel (2010): "VII. Structural equation modeling analyses of the links between 1st-year maternal employment and child development," Monographs of the Society for Research in Child Development, 75(2), 83-95.

Brown, C., And J. Medoff (1978): "Trade unions in the production process," The Journal of Political Economy, 86(3), 355-378.

Cameron, A., and P. Trivedi (1998): Regression Analysis of Count Data. Cambridge University Press, UK: Cambridge.

Carneiro, P., C. Meghir, M. Parey, and G. Street (2007): "Maternal education, home environments and the development of children and adolescents," IZA Discussion Paper 3072, forthcoming in Journal of European Economic Association 2012.

Cawley, J., And F. Liu (2007): "Mechanisms for the Association between Maternal Employment and Child Cognitive Development," NBER Working Paper 13609.

CBS (2003): Jeugd 2003, cijfers en feiten. CBS.

Colquitt, J. A., J. A. LePine, And R. A. Noe (2000): "Toward an Integrative Theory of Training Motivation: A Meta-Analytic Path Analysis of 20 Years of Research," Journal of Applied Psychology, 85(5), 678-707.

Colquitt, J. A., And M. J. Simmering (1998): "Conscientiousness, Goal Orientation, and Motivation to Learn during the Learning Process: A Longitudinal Study," Journal of Applied Psychology, 83(4), 654-665.

Connolly, S., And M. Gregory (2008): "Moving Down: Women's PartTime Work and Occupational Change in Britain 1991-2001," Economic Journal, 118(526), F52-F76.

Craine, R. (1973): "On the Service Flow from Labour," The Review of Economic Studies, 40(1), 39-46. 


\section{Bibliography}

Currie, J., And D. Thomas (2001): "Early Test Scores, Socioeconomic Status, School Quality and Future Outcomes," Research in Labor Economics, 20, 103-132.

De Grip, A., And J. Hoevenberg (1997): "Atypical employment in the European Union," International Labour Review, 136(1), 49-71.

De Grip, A., And I. Sieben (2005): "The Effects of Human Resource Management on Small Firms' Productivity and Employees' Wages," Applied Economics, 37(9), $1047-1054$.

Dearden, L., H. Reed, and J. Van Reenen (2006): "The Impact of Training on Productivity and Wages: Evidence from British Panel Data," Oxford Bulletin of Economics and Statistics, 68(4), 397-421.

Della Vigna, S., and M. D. Paserman (2005): "Job Search and Impatience," Journal of Labor Economics, 23(3), 527-588.

Delsen, L. E. (2006): Operating Hours and Working Time: A Survey of Capacity Utilisation and Employment in the European Union. Springer Press, USA: New York.

Desai, S., P. Chase-Lansdale, and R. Michael (1989): "Mother or market? Effects of maternal employment on the intellectual ability of 4-year-old children," Demography, 26(4), 545-561.

Dustmann, C., J. Ludsteck, And U. Schönberg (2009): "Revisiting the German wage structure," The Quarterly Journal of Economics, 124(2), 843-881.

Ermisch, J., And M. Francesconi (2000): "The Effect of Parents' Employment on Children's Educational Attainment," IZA Discussion Paper 215, forthcoming in Journal of Applied Econometrics 2012.

Ermisch, J. F., And R. E. Wright (1993): "Wage Offers and Full-Time and Part-Time Employment by British Women," Journal of Human Resources, 28(1), $111-133$.

EuwALs, R. (2001): "Female Labour Supply, Flexibility of Working Hours, and Job Mobility," The Economic Journal, 111(471), 120-134.

Euwals, R., And M. Hogerbrugge (2006): "Explaining the Growth of PartTime Employment: Factors of Supply and Demand," Labour, 20(3), 533-557. 
Facteau, J. D., G. H. Dobbins, J. E. A. Russell, R. T. Ladd, and J. D. Kudisch (1995): "The Influence of General Perceptions of the Training Environment on Pretraining Motivation and Perceived Training Transfer," Journal of Management, 21(1), 1-25.

Feldstein, M. (1967): "Specification of the Labour Input in the Aggregate Production Function," The Review of Economic Studies, 34(4), 375-386.

Fernández-Kranz, D., and N. Rodriguez-Planas (2011): "The Part-Time Pay Penalty in a Segmented Labor Market," Labour Economics, 18(2).

Fersterer, J., and R. Winter-Ebmer (2003): "Smoking, Discount Rates, and Returns to Education.," Economic Educational Review, 22, 561-566.

Fouarge, D., and R. Muffels (2008): "Part-Time Work and Childbirth in Europe: Scarring the Career or Meeting Working-Time Preferences?," in Flexibility and Employment Security in Europe: Labour Markets in Transition, ed. by R. Muffels, pp. 223-254. Edward Elgar, UK: Cheltenham.

Frick, J., AND M. GrabKa (2010): "Item Nonresponse and Imputation of Annual Labor Income in Panel Surveys from a Cross-National Perspective," in Survey Methods in Multinational, Multiregional, and Multicultural Contexts, ed. by J. A. Harkness, M. Braun, B. Edwards, T. P. Johnson, L. Lyberg, P. P. Mohler, B.-E. Pennell, and T. W. Smith, pp. 355-372. John Wiley \& Sons, Inc., USA: Hoboken, NJ.

Golsteyn, B. (2007): "The Ability to Invest in Human Capital," Ph.D. thesis, Maastricht University.

Görlich, D., And A. De Grip (2009): "Human Capital Depreciation During Hometime," Oxford Economic Papers, 61, 98-121.

Greenhalgh, C., and G. Mavrotas (1996): "Job Training, New Technology and Labour Turnover," British Journal of Industrial Relations, 34(1), 131-150.

Greenstein, T. N. (1995): "Are the "Most Advantaged" Children Truly Disadvantaged by Early Maternal Employment?: Effects on Child Cognitive Outcomes," Journal of Family Issues, 16(2), 149-169.

Gregory, M., and S. Connolly (2008): "Feature: The Price of Reconciliation: Part-Time Work, Families and Women's Satisfaction," The Economic Journal, 118(526), F1-F7. 


\section{Bibliography}

Han, W., J. Waldfogel, And J. Brooks-GunN (2001): "The effects of early maternal employment on later cognitive and behavioral outcomes," Journal of Marriage and Family, 63(2), 336-354.

Hartog, J., And H. Oosterbeek (1988): "Education, allocation and earnings in the Netherlands: 0verschooling?," Economics of Education Review, 7(2), 185-194.

Harvey, E. (1999): "Short-Term and Long-Term Effects of Early Parental Employment on Children of the National Longitudinal Survey of Youth," Development Psychology, 35(2), 445-459.

Hellerstein, J. K., D. Neumark, and K. R. Troske (1999): "Wages, Productivity, and Worker Characteristics: Evidence from Plant-Level Production Functions and Wage Equations," Journal of Labor Economics, 17(3), 409-446.

Hill, J., J. Waldfogel, J. Brooks-Gunn, and W. Han (2005): "Towards a Better Estimate of the Causal Links in Child Policy: the Case of Maternal Employment and Child Outcomes," Development Psychology, 41(6), 833-850.

Hirsch, B. T. (2005): "Why do Part-Time Workers Earn Less? The Role of Worker and Job Skills," Industrial and Labor Relations Review, 58(4), 525-551.

Hunt, J. (1999): "Has work-sharing worked in Germany?," The Quarterly Journal of Economics, 114(1), 117-148.

Ichniowski, C., T. A. Kochan, D. Levine, C. Olson, and G. Strauss (1996): "What Works at Work: Overview and Assessment," Industrial Relations, 35(3), 299-333.

IChniowski, C., S. K., And G. Prennushi (1997): "The Effects of Human Resource Management Practices on Productivity: A Study of Steel Finishing Lines," American Economic Review, 87(3), 291-313.

Ilmakunnas, P., And M. MaliRanta (2005): "Technology, Labour Characteristics and Wage-Productivity Gaps," Oxford Bulletin of Economics and Statistics, $67(5), 623-645$.

Iranzo, S., F. Schivardi, and E. Tosetti (2008): "Skill Dispersion and Firm Productivity: An Analysis with Employer-Employee Matched Data," Journal of Labor Economics, 26(2), 247-285. 
Jensen, J. B., R. H. McGuckin, and K. J. Stiroh (2001): "The Impact of Vintage and Survival on Productivity: Evidence from Cohorts of U.S. Manufacturing Plants," The Review of Economics and Statistics, 83(2), 323-332.

Jungbluth, P., And R. Rodigas (2011): "Kleuter in Zuid-Limburg: Hoe Staan de Kansen? Regiobrede 'Nulmeting' bij de Start van de Zuid-Limburgse Pilot voor Voorschoolse Educatie 'Moelejaan'," Discussion paper, Maastricht University.

Kahneman, D., and A. Tversky (1979): "Prospect Theory: An Analysis of Decision under Risk," Econometrica, 47(2), 263-291.

Leslie, D., And J. Wise (1980): “The Productivity of Hours in UK Manufacturing and Production Industries," The Economic Journal, 90(357), 74-84.

LindBeck, A., And D. Snower (2000): "Multi-Task Learning and the Reorganization of Work," Journal of Labor Economics, 18(3), 353-376.

Lynch, L. M., And S. E. Black (1998): "Beyond the Incidence of EmployerProvided Training," Industrial and Labor Relations Review, 52(1), 64-81.

Mabert, V., And M. Showalter (1990): "Measuring the Impact of Part-Time Workers in Service Organisations," Journal of Operations Management, 9(2), 209229.

Macduffie, J. P. (1995): "Human Resource Bundles and Manufacturing Performance: Organizational Logic and Flexible Production Systems in the World Auto Industry," Industrial and Labor Relations Review, 48(2), 197-221.

Manning, A., And B. Petrongolo (2008): "The Part-Time Pay Penalty for Women in Britain," Economic Journal, 118(526), F28-F51.

Maximiano, S., And H. Oosterbeek (2007): "On the determinants of workers' and firms' willingness to train," Unpublished manuscript.

McFarland, C., and D. T. Miller (1994): "The framing of relative performance feedback: Seeing the glass as half empty or half full," Journal of Personality and Social Psychology, 66(6), 1061-1073.

Mocan, H., And E. Tekin (2003): "Nonprofit Sector and Part-Time work: An Analysis of Employer-Employee Matched Data on Child Care Workers," Review of Economics and Statistics, 85(1), 38-50. 


\section{Bibliography}

Montgomery, M. (1988): "On the Determinants of Employer Demand for PartTime Workers," Review of Economics and Statistics, 70(1), 112-117.

Munasinghe, L., And N. Sicherman (2006): "Why do Dancers Smoke? Time Preference, Occupational Choice, and Wage Growth," Eastern Economic Journal, 32(4), 595-616.

Nelen, A., And A. De Grip (2009): "Why do Part-Time Workers Invest Less in Human Capital than Full-Timers?," Labour, 23(s1), 61-83.

Noe, R. A., And N. Schmitt (1986): "The Influence of Trainee Attitudes on Training Effectiveness: Test of a Model," Personnel Psychology, 39(3), 497-523.

O'Brien, M., and D. Jones (1999): "Children, Parental Employment and Educational Attainment: An English Case Study," Cambridge Journal of Economics, 23(5), 599-621.

O'Connell, P., and V. Gash (2003): "The Effects of Working Time, Segmentation and Labour Market Mobility on Wages and Pensions in Ireland," British Journal of Industrial Relations, 41(1), 71-95.

O'Dorchai, S., R. Plasman, and F. Rycx (2007): "The Part-Time Wage Penalty in European Countries: How Large is it for Men?," International Journal of Manpower, 28(7), 571-603.

OI, W. (1962): "Labor as a Quasi-Fixed Factor," The Journal of Political Economy, 70(6), 538-555.

Osterman, P. (1994): "How Common is Workplace Transformation and Who Adopts it?," Industrial and Labor Relations Review, 47(2), 173-188.

(2000): "Work Reorganization in an era of Restructuring: Trends in Diffusion and Effects on Employee Welfare," Industrial and Labor Relations Review, 53(2), 179-196.

Owen, J. D. (1978): Working Hours: An Economic Analysis. Lexington, Canada: Toronto.

Parcel, T., and E. Menaghan (1994): Parents' Jobs and Children's Lives. Adline de Gruyter, USA: New York.

Paull, G. (2008): "Children and Women's Hours of Work," The Economic Journal, 118(526), F8-F27. 
PÉrotin, V., And A. Robinson (2000): "Employee Participation and Equal Opportunities Practices: Productivity Effect and Potential Complementarities," British Journal of Industrial Relations, 38(4), 557-583.

Portegijs, W., M. Clon, I. Ooms, and E. Egaink (2006): "Hoe het Werkt met Kinderen. Moeders over Kinderopvang en Werk," SCP Publication 2006/5.

Román, A., D. Fouarge, and R. LuiJkx (2004): "Career Consequences of PartTime Work: Results from Dutch Panel Data 1990-2001," OSA Publication 206.

Rosen, S. (1972): "Learning and Experience in the Labour Market," Journal of Human Resources, 7, 326-342.

Rosen, S. (1978): "The Supply of Work Schedules and Employment," in Work Time and Employment. National Commission on Manpower Policy, USA: Washington D.C.

Rosenzweig, M., And K. Wolpin (1995): "Sisters, Siblings, and Mothers: The Effect of Teen-Age Childbearing on Birth Outcomes in a Dynamic Family Context," Econometrica, 63(2), 303-326.

Roux, S. (2007): "Les Gains de la Flexibilité d'Emploi pour les Entreprises : Le Travail à Temps Partiel et de Courte Durée," Reflets et perspectives de la vie Économique, XLVI 2007/2-3, 117-140.

Ruhm, C. (2008): "Maternal Employment and Adolescent Development," Labour Economics, 15(5), 958-983.

Ruhm, C. J. (2004): "Parental Employment and Child Cognitive Development," Journal of Human Resources, 39(1), 155-192.

RutTer, M. (1985): "Family and school influences on cognitive development," Journal of Child Psychology and Psychiatry, 26(5), 683-704.

Schwarze, J. (1998): "Wer trägt die Pauschale Lohnsteuer bei Geringfügiger Beschäftigung? Eine Analyse der Stundenlöhne Erwerbstätiger Frauen," in Empirische Forschung und wirtschaftspolitische Beratung, ed. by H. Galler, and H. Krupp, pp. 215-225. Campus Verlag, Germany: Frankfurt.

Thaler, R. (1999): "Mental Accounting Matters," Journal of Behavioral Decision Making, 12, 183-206. 


\section{Bibliography}

VAndell, D., And J. Ramanan (1992): "Effects of Early and Recent Maternal Employment on Children from Low-Income Families," Child Development, 63(4), 938-949.

Webster, J., and J. J. Marrocchio (1993): "Turning Work into Play: Implications for Microcomputer Software Training," Journal of Management, 19(1), 127-146.

Wolf, E. (1998): "Do Hours Restrictions Matter? A Discrete Family Labor Supply Model with Endogenous Wages and Hours Restrictions," ZEW Discussion Paper 98-44.

(2002): "Lower Wage Rates for Fewer Hours? A Simultaneous Wage-Hours Model for Germany," Labour Economics, 9(5), 643-663.

Wood, S. (1999): "Human Resource Management and Performance," International Journal of Management Reviews, 1(4), 367-413.

Woods, R. (2009): "Industry output and employment projections to 2018," Monthly Labor Review, 132(11), 52-81.

Wooldridge, J. M. (2002): Econometric Analysis of Cross Section and Panel Data. MIT Press, USA: Cambridge.

Yerkes, M., AND J. Visser (2006): “Women's Preferences or Delineated Policies? The development of part-time work in the Netherlands, Germany and the United Kingdom," in Decent working time, ed. by J.-Y. Boulin, M. Lallement, J. Messenger, and F. Michon, pp. 235-261. International Labour Office, Switzerland: Geneva.

Youndt, M. A., S. A. Snell, J. W. Dean, Jr., and D. P. LepaK (1996): "Human Resource Management, Manufacturing Strategy, and Firm Performance," Academy of Management Journal, 39(4), 836-866.

Zaslow, M., and C. Hayes (1986): "Sex differences in children's response to psychosocial stress: Toward a cross-context analysis," in Advances in developmental psychology, ed. by M. Lamb, A. Brown, and B. Rogoff, vol. 4, pp. 285-337. Lawrence Erlbaum, Hillsdale, N.J.

ZwICK, T. (2006): "The Impact of Training Intensity on Establishment Productivity," Industrial Relations, 45(1), 26-46. 


\section{Summary in Dutch}

Het doel van deze studie is het analyseren van de relatie tussen deeltijdwerk en de ontwikkeling van menselijk kapitaal. Bovendien wordt bekeken hoe deze relatie verschillen in de carriëre van mensen, de productiviteit van bedrijven en de ontwikkeling van kleuters kunnen verklaren. Dit onderzoek is erg relevant omdat er in verschillende Europese landen veel in deeltijd gewerkt wordt. Nederland is het land waarin verreweg het meest in deeltijd gewerkt wordt: ongeveer $70 \%$ van alle werkende vrouwen in Nederland werkt in deeltijd. Deeltijdwerk wordt vaak gezien als een goede manier om betaald werk en zorg voor kinderen te combineren.

Echter, studies die zich bezighouden met de gevolgen van deeltijdwerk rapporteren met name negatieve effecten. De economische literatuur over deeltijdwerk richt zich voornamelijk op de gevolgen van deeltijdwerk op het loon dat men verdient en de kans op neerwaartse baanmobiliteit. In landen als de Verenigde Staten, het Verenigd Koninkrijk en Duitsland, is het uurloon van mensen met een deeltijdbaan vaak lager dan het uurloon van mensen met een vergelijkbare voltijdbaan. Dit verschil in uurloon wordt weliswaar kleiner naarmate men rekening houdt met persoonsen bedrijfsfactoren, maar een klein verschil blijft bestaan (Ermisch en Wright 1993, Aaronson en French 2004, Hirsch 2005 en Baffoe-Bonnie 2004). In Nederland wordt een zogenaamde part-time pay penalty niet gevonden (Euwals en Hogerbrugge 2004). Dit is waarschijnlijk toe te schrijven aan een totaal andere deeltijdcultuur.

Binnen de internationale literatuur wordt de part-time pay penalty vaak toegeschreven aan een relatief lagere hoeveelheid menselijk kapitaal. ${ }^{1}$ Het geringere menselijk kapitaal van deeltijders wordt in de theorie van het menselijk kapitaal verklaard door de geringere bereidheid van zowel de werknemer als de werkgever om te investeren in het menselijk kapitaal van deeltijders. Investeren in menselijk kapi-

\footnotetext{
${ }^{1}$ Een ander vaak genoemde reden is een lagere betrokkenheid met de arbeidsmarkt.
} 


\section{Summary in Dutch}

taal kan door het volgen van een training, of door het uitvoeren van taken waarvan men kan leren. Bij zowel het volgen van een training als het leren op het werk, is de werknemer op het moment van investeren minder productief omdat hij zich niet (volledig) in kan zetten voor de productie. De werkgever mist daarom een deel van zijn omzet. De werknemer kan hierdoor tijdelijk een lager loon krijgen en is vaak ook vrije tijd kwijt om te leren. Hoe meer uren per week iemand werkzaam is, hoe groter de voordelen van het investeren in iemands menselijk kapitaal. Voor de werknemer bestaan deze voordelen uit een hoger uurloon in de toekomst en misschien uit betere carriëre mogelijkheden. Voor de werkgever bestaan deze voordelen uit een hogere productiviteit. Omdat de voordelen van het investeren groter zijn naarmate een werknemer meer uren per week werkt, is de bereidheid om te investeren in het menselijk kapitaal van voltijders groter dan de bereidheid om te investeren in het menselijk kapitaal van deeltijders. Greenhalgh en Mavrotas (1996) hebben inderdaad gevonden dat deeltijders minder kans hebben op het volgen van een training dan voltijders.

In deze studie, hebben we het belang van de ontwikkeling van menselijk kapitaal centraal gesteld in de analyses naar verschillende aspecten van deeltijdwerk. We hebben niet alleen gekeken naar het perspectief van de werknemer en het bedrijfsperspectief, maar ook naar het kindperspectief.

Leergedrag van deeltijders In hoofdstuk 2 hebben we, met behulp van de ROA Leven-Lang-Leren enquête, laten zien dat ook in Nederland deeltijders minder investeren in hun menselijk kapitaal dan voltijders. Deeltijders hebben zowel een lagere trainingsparticipatie als ook een lagere mate van informeel leren dan voltijders. Dit is conform de verwachting van de theorie van het menselijk kapitaal (Becker 1964). Wel doet zich de vraag voor of het met name de deeltijders zelf zijn die minder bereid zijn om in hun menselijk kapitaal te investeren, of dat de werkgevers minder bereid zijn in deeltijders te investeren. In hoofdstuk 2 wordt deze vraag geanalyseerd en beantwoord.

Het personeelsbeleid van de werkgever blijkt de grootste drijfveer voor de investeringen in het menselijk kapitaal van de voltijds werkenden. Hoewel de leermotivatie ook een rol speelt, wordt de deelname aan trainingen en cursussen van voltijders voornamelijk beïnvloed door het personeelsbeleid van het bedrijf waar ze werken. Het informele leren van voltijders wordt zelfs alleen maar door het werkgeversbeleid gestimuleerd. Daarbij gaat het met name om het geven van zowel positieve als kritische feedback. Voor deeltijders is de situatie geheel anders. Zij worden niet door het personeelsbeleid van hun werkgever gestimuleerd tot meer formeel of in- 
formeel leren. Deeltijders kunnen dit slechts gedeeltelijk compenseren wanneer zij zeer gemotiveerd zijn om te leren en een goed beeld hebben van hun verdere loopbaan. Het achterblijven van de investeringen in het menselijk kapitaal van deeltijders betekent dat zij het risico lopen dat hun arbeidsmarktpositie op termijn verslechtert. Dit zal vooral het geval zijn als zij werkzaam zijn in een dynamische sector.

Part-time pay penalty Hoewel er veel literatuur is over het loonverschil tussen deeltijders en voltijders, is de rol die het menselijk kapitaal hierin speelt nog niet expliciet onderzocht. In hoofdstuk 3 gaan we daarom in op de vraag of verschillen in de ontwikkeling van het menselijk kapitaal van deeltijders tegenover voltijders de loonverschillen tussen deze twee groepen werknemers kan verklaren. We kijken allereerst of deeltijders op basis van de noodzaak om zich binnen bepaalde beroepen te trainen, kiezen voor bepaalde (laagbetaalde) beroepen. Daarna bekijken we of de part-time pay penalty verschillend is tussen beroepen. Verder analyseren we of deze heterogeneiteit in de part-time pay penalty verklaard kan worden door heterogeneiteit in de mate waarin deeltijders op voltijders achterlopen in de ontwikkeling van hun menselijk kapitaal.

Met behulp van Duitse data laten we zien dat de part-time pay penalty voor $30 \%$ verklaard wordt doordat deeltijders vooral bepaalde beroepen kiezen. Deze concentratie van deeltijders in bepaalde beroepen is voor een groot gedeelte te wijten aan verschillen in de gemiddelde trainingsparticipatie van werknemers met eenzelfde beroep. Deeltijders zijn vooral vertegenwoordigd in beroepen waarin over het algemeen maar weinig getraind wordt. Maar ook binnen beroepen blijken deeltijders per uur gemiddeld 5\% minder te verdienen dan voltijders. Dit verschilt echter tussen de beroepen. In beroepen waarin deeltijders ongeveer evenveel werkgerelateerde training volgen dan voltijders, wordt er geen of slechts een kleine part-time pay penalty gevonden. In beroepen waarin deeltijders veel minder trainen dan voltijders, vinden we wel een penalty voor het werken in deeltijd.

Bedrijfsproductiviteit Hoewel er veel onderzoek gedaan is naar de gevolgen van deeltijdwerk voor werknemers, is er erg weinig onderzoek gedaan naar de gevolgen van deeltijdwerk voor bedrijven. In hoofdstuk 4 zijn we ingegaan op de vraag welke invloed het werken met deeltijders heeft op de productiviteit van het bedrijf. Hoewel we op grond van de theorie van het menselijk kapitaal kunnen verwachten dat deeltijders per gewerkt uur minder productief zijn dan voltijders, hoeft dit niet automatisch te betekenen dat bedrijven met veel deeltijders minder productief zijn dan bedrijven waar minder deeltijders werken. Onder bepaalde condities kan deeltijdwerk gunstig 


\section{Summary in Dutch}

zijn voor bedrijven. Voorbeelden zijn openingstijden die de voltijds werkweek overschrijden en fluctuaties in het aantal klanten dat geholpen moet worden (Owen 1978, Mabert en Showalter 1990).

Met behulp van een dataset over de Nederlandse apotheeksector, wordt bekeken of het voor bedrijven in de dienstensector gunstig is om veel deeltijders in dienst te hebben. Hoofdstuk 4 laat zien dat apotheken met een hoog percentage deeltijders productiever zijn dan bedrijven met een hoog percentage voltijders. Dit resultaat is niet toe te schijven aan verschillen in de individuele productiviteit tussen deeltijders en voltijders, maar aan de meer efficiënte inzet van personeel in de bedrijven met veel deeltijders. Apotheken blijken gemiddeld 50 uur per week open te zijn, terwijl een voltijdse aanstelling in deze sector 36 uur per week bedraagt. Dit betekent dat het niet efficiënt is om alleen voltijders aan te stellen. Uit aanvullende data, waarin de werkschema's van apothekersassistenten van 900 bedrijven bekend zijn, blijkt ook dat deeltijders op een andere manier worden ingezet dan voltijders. Deeltijders werken niet alleen minder dagen per week, maar ook minder uren per werkdag. Ook blijkt dat deeltijders het voor hun voltijds werkende collega's mogelijk maken om een lunchpauze te hebben zonder dat de apotheek tussen de middag dicht moet.

Kinduitkomsten Er is veel literatuur die ingaat op de vraag of het slecht is voor kinduitkomsten wanneer de moeder (deeltijd) werkt voordat kinderen naar school gaan. In hoofdstuk 5 wordt de relatie tussen moeders' werkstatus en kinduitkomsten bekeken voor kinderen in groep 2 van de basisschool. Zodra kinderen naar school gaan is de potentiële tijd die werkende moeders met hun kind kunnen besteden niet veel kleiner dan de potentiële tijd die niet-werkende moeders met hun kind kunnen besteden. Tegelijkertijd is het familie-inkomen van gezinnen waarin de moeder werkt hoger. Dit kan ook ten gunste komen van het kind.

Een unieke dataset uit Zuid Limburg bevat toetsscores van kinderen uit groep 2: "taal voor kleuters" en "ordenen". In hoofdstuk 5 wordt bekeken of deze toetsscores gerelateerd zijn aan de werkstatus van de moeder. Hoewel we voor de taaltoets geen relatie vinden, blijkt de toets voor ordenen wel gerelateerd te zijn aan de werkstatus van de moeder. Meisjes scoren het beste op deze toets als de moeder een deeltijdbaan heeft, terwijl jongens het beste scoren als hun moeder voltijds werkt. Met behulp van informatie over het aantal activiteiten dat ouders ondernemen met hun kinderen, wordt bekeken of kinderen van moeders die minimaal 12 uur per week werken hoger scoren op de ordenen toets omdat ouders deze kinderen een omvangrijker pakket aan (stimulerende) activiteiten aanbieden. Dit blijkt echter niet het geval te zijn. 
De conclusie van dit proefschrift is dat de relatie tussen deeltijdwerk en de ontwikkeling van menselijk kapitaal niet zonder meer positief of negatief is. Het beroep waarin deeltijders werkzaam zijn is bepalend voor de gevolgen van deeltijdwerk voor werkenden. Werknemers in beroepen waarvoor een hoge opleiding vereist is, ondervinden geen hinder van het werken in deeltijd, terwijl deeltijders in de lagere beroepen minder trainingskansen hebben en ook een lager uurloon verdienen dan voltijders in hetzelfde beroep. Voor bedrijven hangt het succes van deeltijd af van de sector waarin het bedrijf werkzaam is. Voor bedrijven in de dienstensector is deeltijdwerk gunstig, maar dit is mogelijk niet het geval voor bedrijven in de industrie. Of deeltijdwerk goed is voor de ontwikkeling van kinderen, hangt ervan of het kind de schoolgaande leeftijd al heeft bereikt. Terwijl bestaand onderzoek vaak aantoont dat het voor de ontwikkeling van jonge kinderen die nog niet naar school gaan slecht is wanneer de moeder (veel) werkt, laat dit proefschrift zien dat kleuters betere toetsscores halen wanneer de moeder minimaal 12 uur per week werkt. 



\section{Biography}

Annemarie Cornelia Nelen was born in Breda, the Netherlands, on June 14, 1983. In 2003, she started her Bachelor in International Economic Studies at Maastricht University. During her semester abroad, she visited the Humboldt Universität in Berlin. She got her Master in Social Economics in 2007 at Maastricht University.

Between September 2007 and September 2011, she worked as a researcher and PhD student at the Research Centre of Education and the Labour Market (ROA) at Maastricht University. She presented her PhD papers at several national and international conferences like the EEA, SOLE, EALE and ESPE. She participated in several research projects on human capital development varying from a literature study on the returns to education and training on behalf of NWO-PROO to the further development of ROA's Life-Long-Learning Survey.

As from September 2011, Annemarie is employed as postdoctoral researcher at the Schumpeter School of Business and Economics at the University of Wuppertal. She is affiliated with ROA, NSI and IZA. 



\section{ROA Dissertation Series}

1. Lex Borghans (1993), Educational Choice and Labour Market Information, Maastricht, Research Centre for Education and the Labour Market

2. Frank Cörvers (1999), The Impact of Human Capital on International Competitiveness and Trade Performance of Manufacturing Sectors, Maastricht, Research Centre for Education and the Labour Market

3. Ben Kriechel (2003), Heterogeneity Among Displaced Workers, Maastricht, Research Centre for Education and the Labour Market

4. Arnaud Dupuy (2004), Assignment and Substitution in the Labour Market, Maastricht, Research Centre for Education and the Labour Market

5. Wendy Smits (2005), The Quality of Apprenticeship Training, Conflicting Interests of Firms and Apprentices, Maastricht, Research Centre for Education and the Labour Market

6. Judith Semeijn (2005), Academic Competences and Labour Market Entry: Studies Among Dutch Graduates, Maastricht, Research Centre for Education and the Labour Market

7. Jasper van Loo (2005), Training, Labor Market Outcomes and Self-Management, Maastricht, Research Centre for Education and the Labour Market

8. Christoph Meng (2005), Discipline-Specific or Academic? Acquisition, Role and Value of Higher Education Competencies, Maastricht, Research Centre for Education and the Labour Market 
ROA Dissertation Series

9. Andreas Ammermüller (2007), Institutional Effects in the Production of Education: Evidence from European Schooling Systems, Maastricht, Research Centre for Education and the Labour Market

10. Bart Golsteyn (2007), The Ability to Invest in Human Capital, Maastricht, Research Centre for Education and the Labour Market

11. Raymond Montizaan (2010), Pension Rights, Human Capital Development and Well-being, Maastricht, Research Centre for Education and the Labour Market 